\title{
Mercury Thermal Hydraulic Loop (MTHL) Summary Report
}

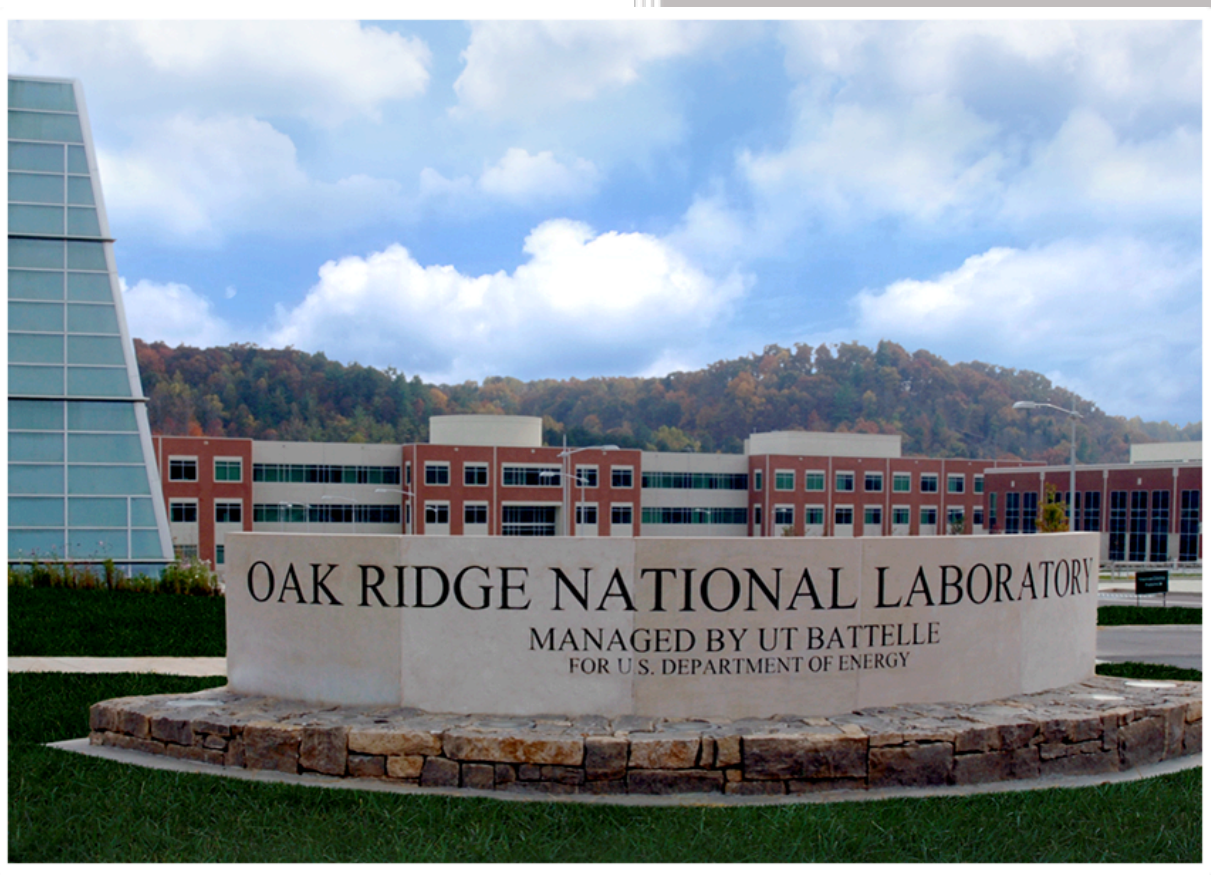

Approved for public release. Distribution is unlimited.
D. K. Felde

J. M. Crye

M. W. Wendel

G. L. Yoder, Jr

J. J. Carbajo

G. Farquharson

P. A. Jallouk

M. T. McFee

W. D. Pointer

A. E. Ruggles

March 2017 


\title{
DOCUMENT AVAILABILITY
}

Reports produced after January 1, 1996, are generally available free via US Department of Energy (DOE) SciTech Connect.

Website http://www.osti.gov/scitech/

Reports produced before January 1, 1996, may be purchased by members of the public from the following source:

\author{
National Technical Information Service \\ 5285 Port Royal Road \\ Springfield, VA 22161 \\ Telephone 703-605-6000 (1-800-553-6847) \\ TDD 703-487-4639 \\ Fax 703-605-6900 \\ E-mail info@ntis.gov \\ Website http://www.ntis.gov/help/ordermethods.aspx
}

Reports are available to DOE employees, DOE contractors, Energy Technology Data Exchange representatives, and International Nuclear Information System representatives from the following source:

Office of Scientific and Technical Information

PO Box 62

Oak Ridge, TN 37831

Telephone 865-576-8401

Fax 865-576-5728

E-mail reports@osti.gov

Website http://www.osti.gov/contact.html

This report was prepared as an account of work sponsored by an agency of the United States Government. Neither the United States Government nor any agency thereof, nor any of their employees, makes any warranty, express or implied, or assumes any legal liability or responsibility for the accuracy, completeness, or usefulness of any information, apparatus, product, or process disclosed, or represents that its use would not infringe privately owned rights. Reference herein to any specific commercial product, process, or service by trade name, trademark, manufacturer, or otherwise, does not necessarily constitute or imply its endorsement, recommendation, or favoring by the United States Government or any agency thereof. The views and opinions of authors expressed herein do not necessarily state or reflect those of the United States Government or any agency thereof. 
Reactor and Nuclear Systems Division

\section{MERCURY THERMAL HYDRAULIC LOOP (MTHL) SUMMARY REPORT}

D. K. Felde, Oak Ridge National Laboratory

J. M. Crye, Oak Ridge National Laboratory

M. W. Wendel, Oak Ridge National Laboratory

G. L. Yoder, Jr., Oak Ridge National Laboratory

J. Carbajo, Oak Ridge National Laboratory

G. Farquharson, Oak Ridge National Laboratory

P. A. Jallouk, Oak Ridge National Laboratory

M. T. McFee, Oak Ridge National Laboratory

W. D. Pointer, Oak Ridge National Laboratory

A. E. Ruggles, University of Tennessee

Date Published March 2017

Prepared by

OAK RIDGE NATIONAL LABORATORY

P.O. Box 2008

Oak Ridge, TN 37831-6285

managed by

UT-Battelle, LLC

for the

U.S. DEPARTMENT OF ENERGY

under contract DE-AC05-00OR22725 



\section{CONTENTS}

LIST OF FIGURES $\mathrm{V}$

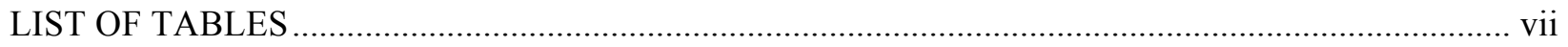

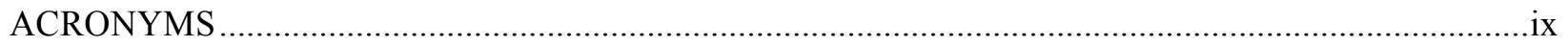

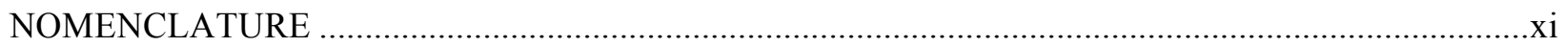

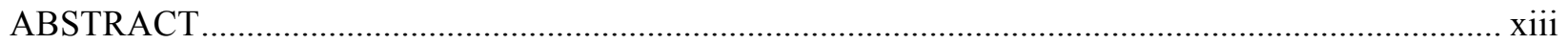

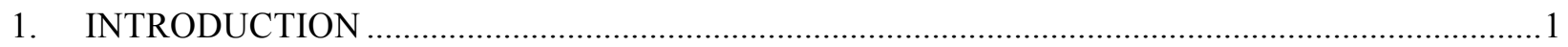

1.1 DESCRIPTION OF EXPERIMENTAL FACILITY .................................................

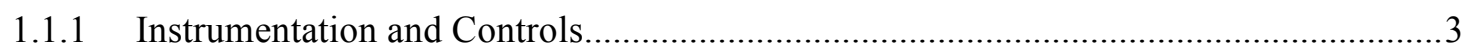

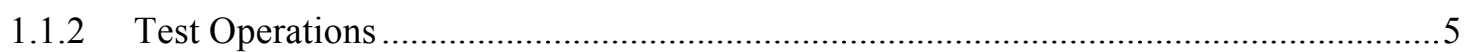

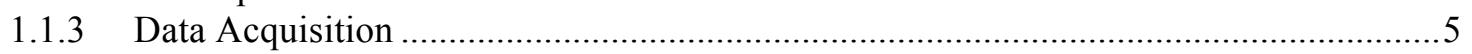

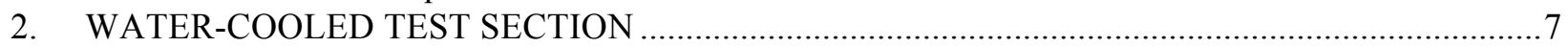

2.1 DATA ANALYSIS METHODS FOR THE WATER-COOLED TEST SECTION...............11

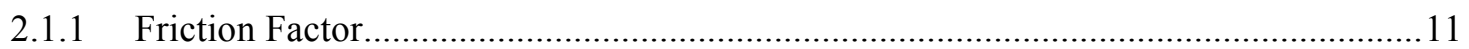

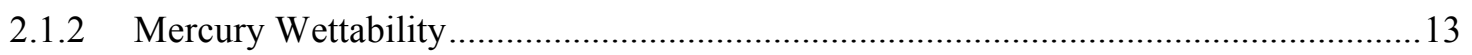

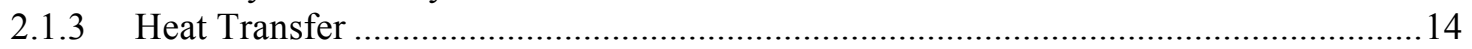

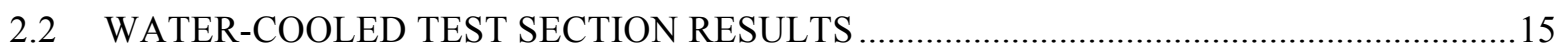

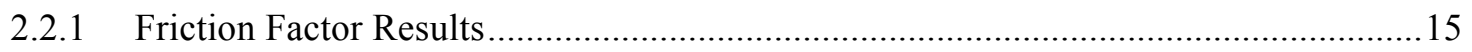

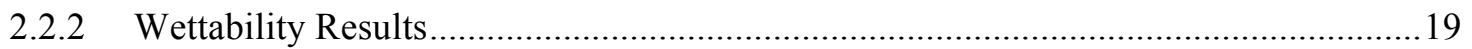

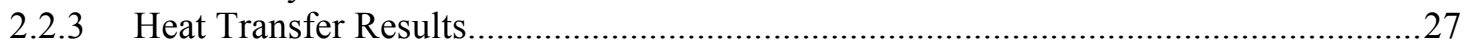

3. ELECTRICALLY HEATED (STRAIGHT) TEST SECTION ................................................... 31

3.1 DATA ANALYSIS METHODS AND RESULTS FOR STRAIGHT HEATED TEST

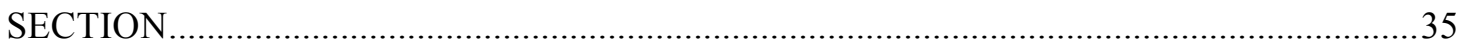

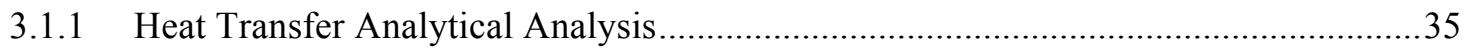

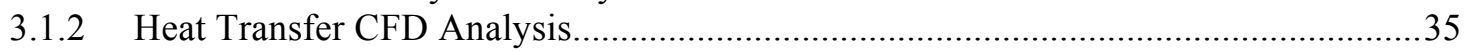

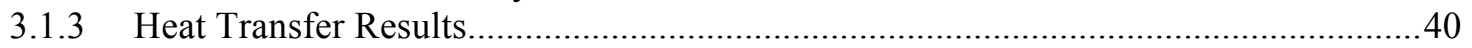

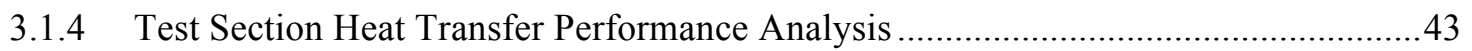

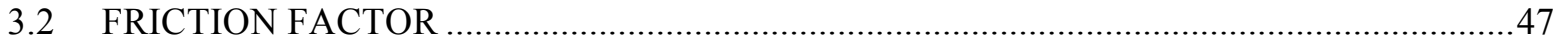

4. CURVED ELECTRICALLY HEATED TEST SECTION ............................................................49

4.1 FABRICATION AND POST-TEST EVALUATION OF THE CURVED TEST

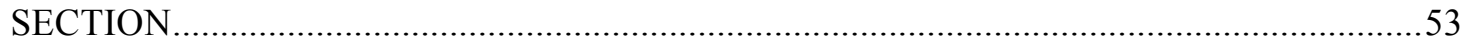

4.2 DATA ANALYSIS METHODS AND RESULTS FOR THE CURVED TEST

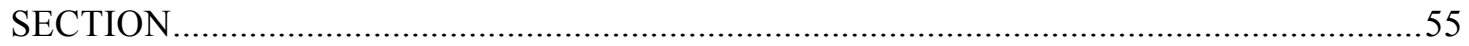

4.2.1 Test Section Heat Transfer Performance Analysis ...................................................60

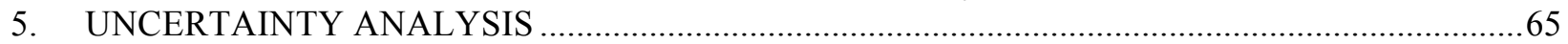

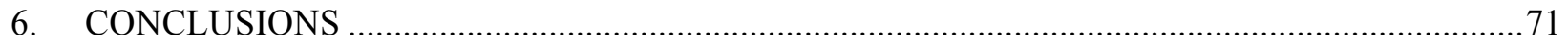

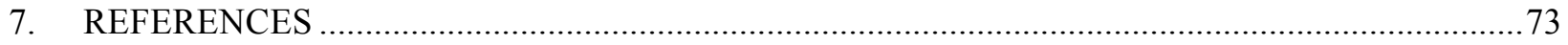





\section{LIST OF FIGURES}

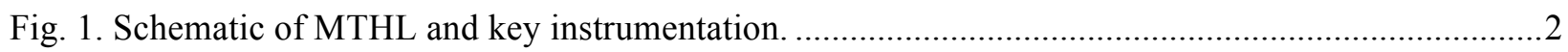

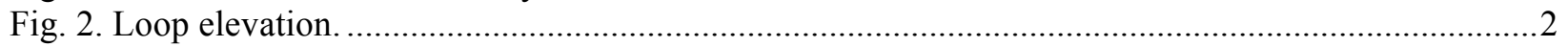

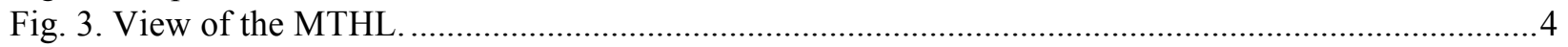

Fig. 4. Close-up of EM flowmeter installed upstream of test section....................................................

Fig. 5. MTHL water-cooled test section design............................................................................... 7

Fig. 6. Water-cooled test section channel plates shown following application of TLCs (black

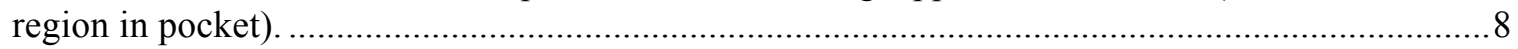

Fig. 7. Components used in water-cooled test section, including shim plate in foreground, window plate in background, Lexan window and backing plate at the right. ...............................

Fig. 8. Components used in water-cooled test section, including assembly of window plate, channel plate, and shim in background with Lexan window and backing plate in foreground.

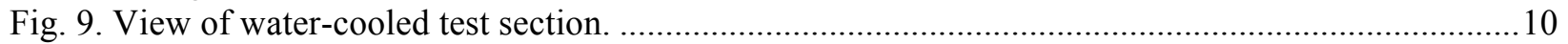

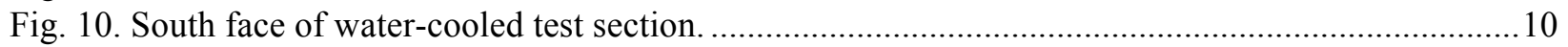

Fig. 11. Detailed drawing of flow channel dimensions in water-cooled test section. ...............................12

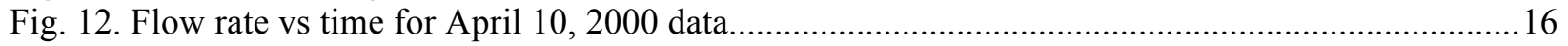

Fig. 13. Test section pressure drop vs flow rate for all test dates.........................................................16

Fig. 14. Comparison of experimental friction factor results with Moody Curve for all test dates;

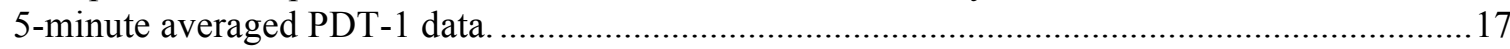

Fig. 15. Comparison of experimental friction factor results with Moody Curve for June 8 and

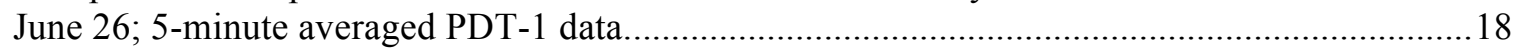

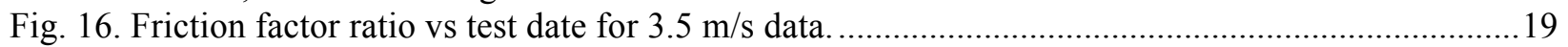

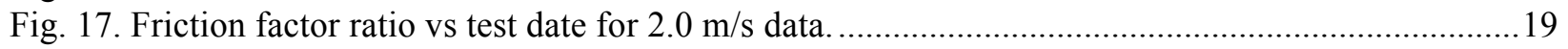

Fig. 18. Multiple layers associated with thermochromic crystal measurement technique. .......................20

Fig. 19. Steady state radial temperature variation for a $7.5 \mathrm{~mm}$ diameter nonwetted spot......................21

Fig. 20. Time histories of crystal and SS temperatures after a $7.5 \mathrm{~mm}$ diameter nonwetted spot

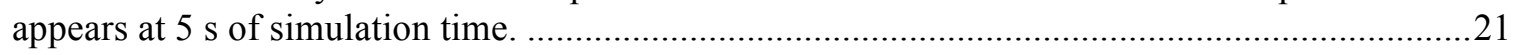

Fig. 21. Ideal temperature differences represented by a $10 \mathrm{~mm}$ diameter circular nonwetting

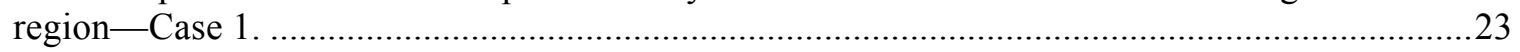

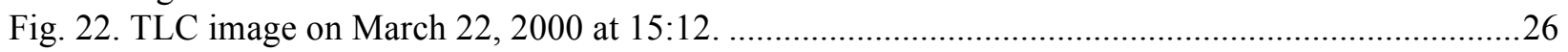

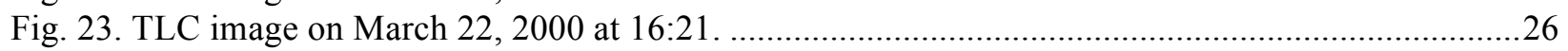

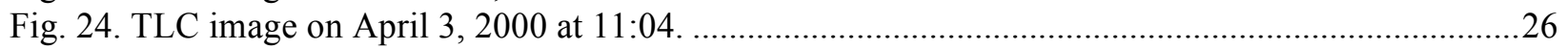

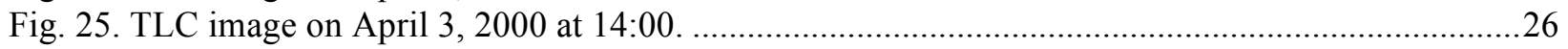

Fig. 26. Comparison of phosphor temperature measurements with CFD model results for 2 and

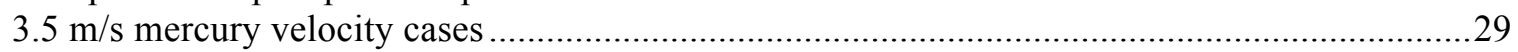

Fig. 27. Experimental Nusselt numbers obtained using phosphor temperature measurement

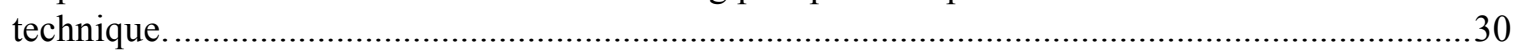

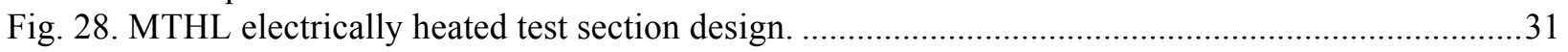

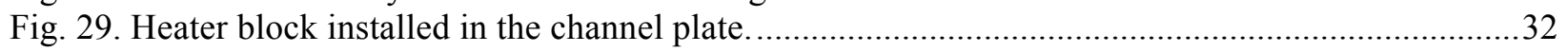

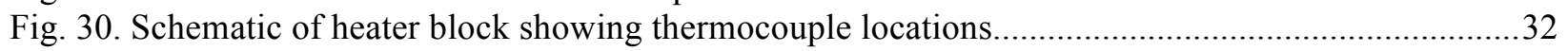

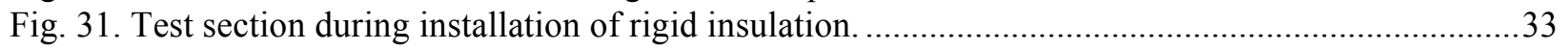

Fig. 32. Heater leads being fed through rigid insulation during test section assembly...........................33

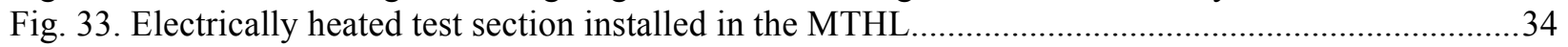

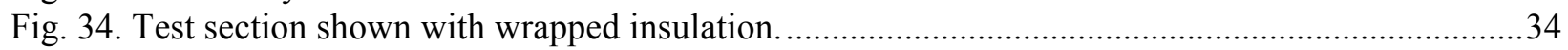

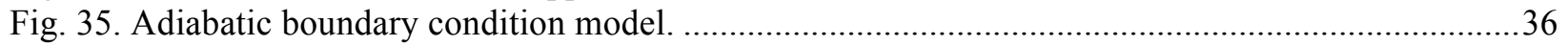

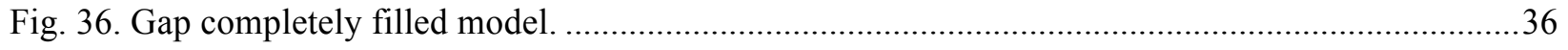

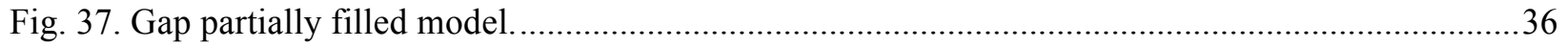

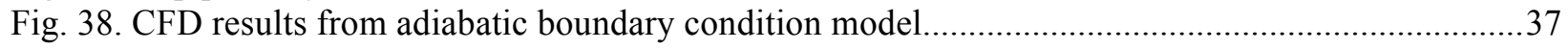




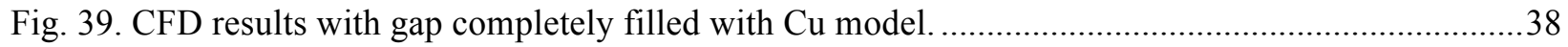

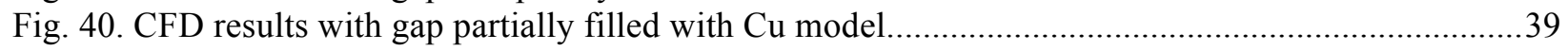

Fig. 41. Comparison of CFD predictions for a rectangular channel to experimental data. .......................40

Fig. 42. Experimental heat transfer coefficient vs bulk temperature...................................................41

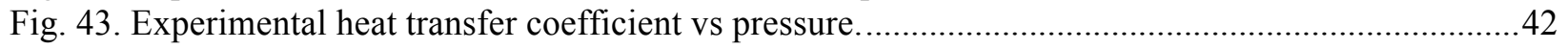

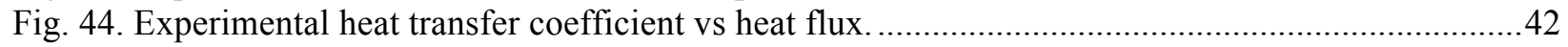

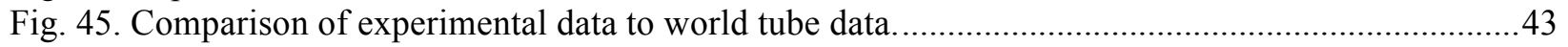

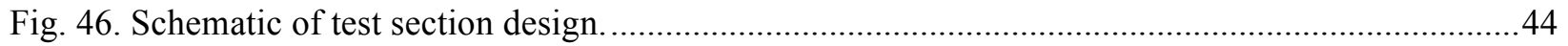

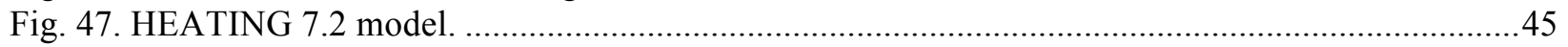

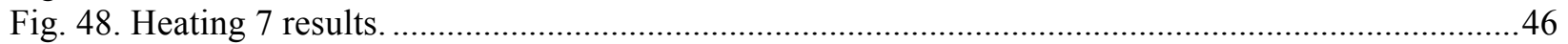

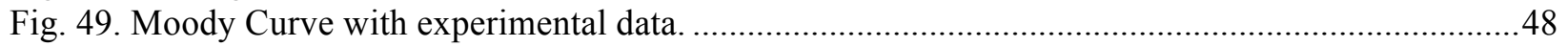

Fig. 50. Ratio of enthalpy rise in $\mathrm{Hg}$ to heater power input vs velocity................................................48

Fig. 51. Schematic drawing of the curved test section. ......................................................................... 49

Fig. 52. Test section base and cover plate for MTHL curved test section................................................49

Fig. 53. Thermocouple locations for the outer heater plate ...............................................................50

Fig. 54. Close-up view of the inside heater brazed on the test channel..................................................51

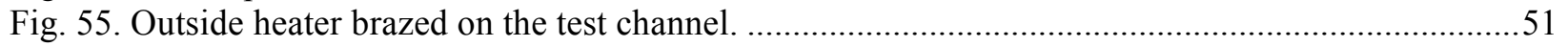

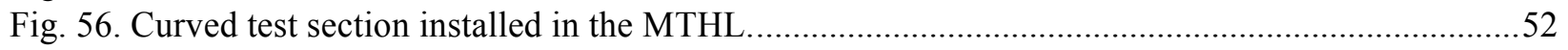

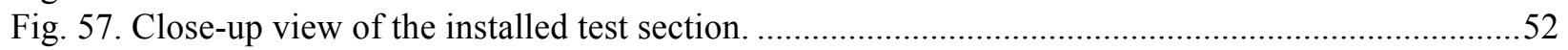

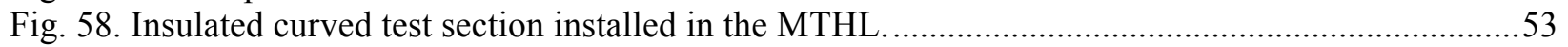

Fig. 59. Post-run section showing flow channel geometry and thermocouples at span-wise

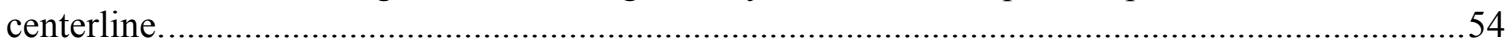

Fig. 60. Detail view of thermocouple and wall geometry $\left(+10^{\circ}\right.$ on outside wall $)$....................................5

Fig. 61. Detail of thermocouple and wall geometry $\left(+10^{\circ}\right.$ inside wall) .................................................55

Fig. 62. Results of CFD analysis of curved test section (centerline velocity of $3.5 \mathrm{~m} / \mathrm{s}$, inlet temperature of $62{ }^{\circ} \mathrm{C}$, inside heater power of $2860 \mathrm{~W}$, and outside heater power of 2910

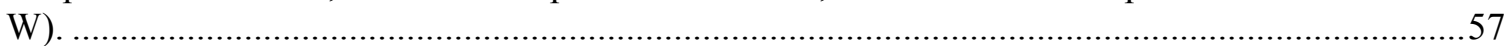

Fig. 63. Effect of time on heat transfer at inside thermocouple locations. ...............................................58

Fig. 64. Effect of time on heat transfer at outside thermocouple locations. .............................................59

Fig. 65. Effect of exit pressure on inside thermocouple locations.......................................................59

Fig. 66. Effect of exit pressure on outside thermocouple locations........................................................60

Fig. 67. HEATING 7.3 model of the thermocouple including a gap in the braze material.......................60

Fig. 68. Temperature profile for case with gap in braze material beneath thermocouple (Case 2 in

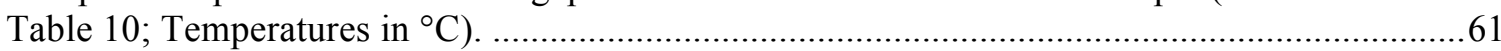

Fig. 69. HEATING 7.3 model of peened thermocouple groove...........................................................62

Fig. 70. Temperature profile for case with peened thermocouple groove (Case 1 in Table 2, temperatures in ${ }^{\circ} \mathrm{C}$ ).

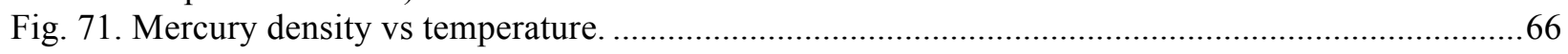

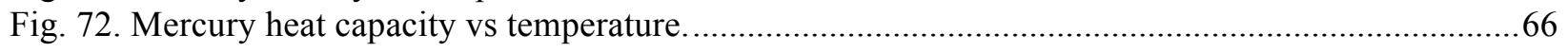

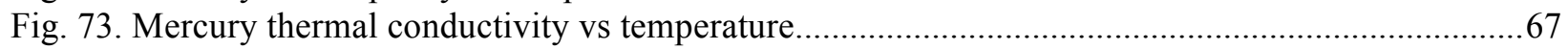

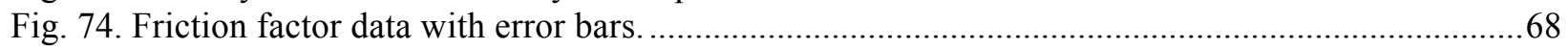

Fig. 75. $\mathrm{Nu}$ number vs $\mathrm{Pe}$ number showing all data with error bars....................................................69 


\section{LIST OF TABLES}

Table 1. Typical thermal/fluid conditions at the peak wall temperature point in the SNS window cooling channel at the target nose.......

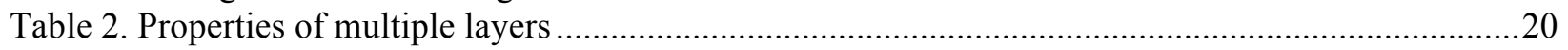

Table 3. Comparison of temperatures calculated for both wetting and nonwetting conditions scoping studies

Table 4. Operating parameters for TLC cases

Table 5. Comparison of temperatures under both wetting and nonwetting conditions $(10 \mathrm{~mm}$ diameter nonwetting region), actual TLC cases ....

Table 6. Comparison of temperatures under both wetting and nonwetting conditions $(2.5 \mathrm{~mm}$ diameter nonwetting region), actual TLC cases

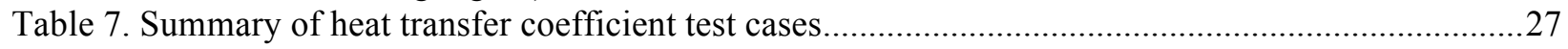

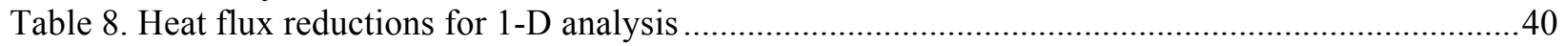

Table 9. Conditions used in calculations and calculational results......................................................45

Table 10. Parametric calculations performed with gap geometry shown in Fig. 69 ...............................62

Table 11. Parametric calculations performed with peened geometry shown in Fig. 71 ...........................63

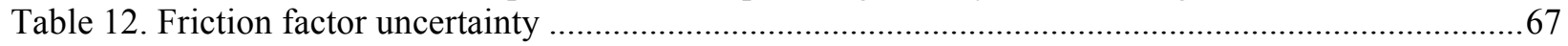

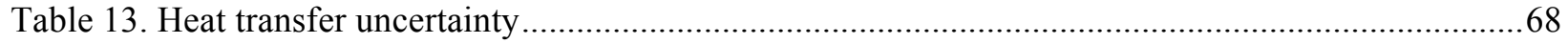





\section{ACRONYMS}

CCD charged coupled device

CFD computational fluid dynamics

DOE US Department of Energy

EDM electron discharge machining

EM electromagnetic

MTHL Mercury Thermal Hydraulic Loop

OD

outer diameter

ORNL Oak Ridge National Laboratory

PC

personal computer

RGB

RNG

red-green-blue format

RTD

SNS

Runge-Kutta

SS

resistance temperature detector

Spallation Neutron Source

TC

stainless steel

TLC thermochromic liquid crystal

UV ultraviolet

1-D one-dimensional

3-D three-dimensional 



\section{NOMENCLATURE}

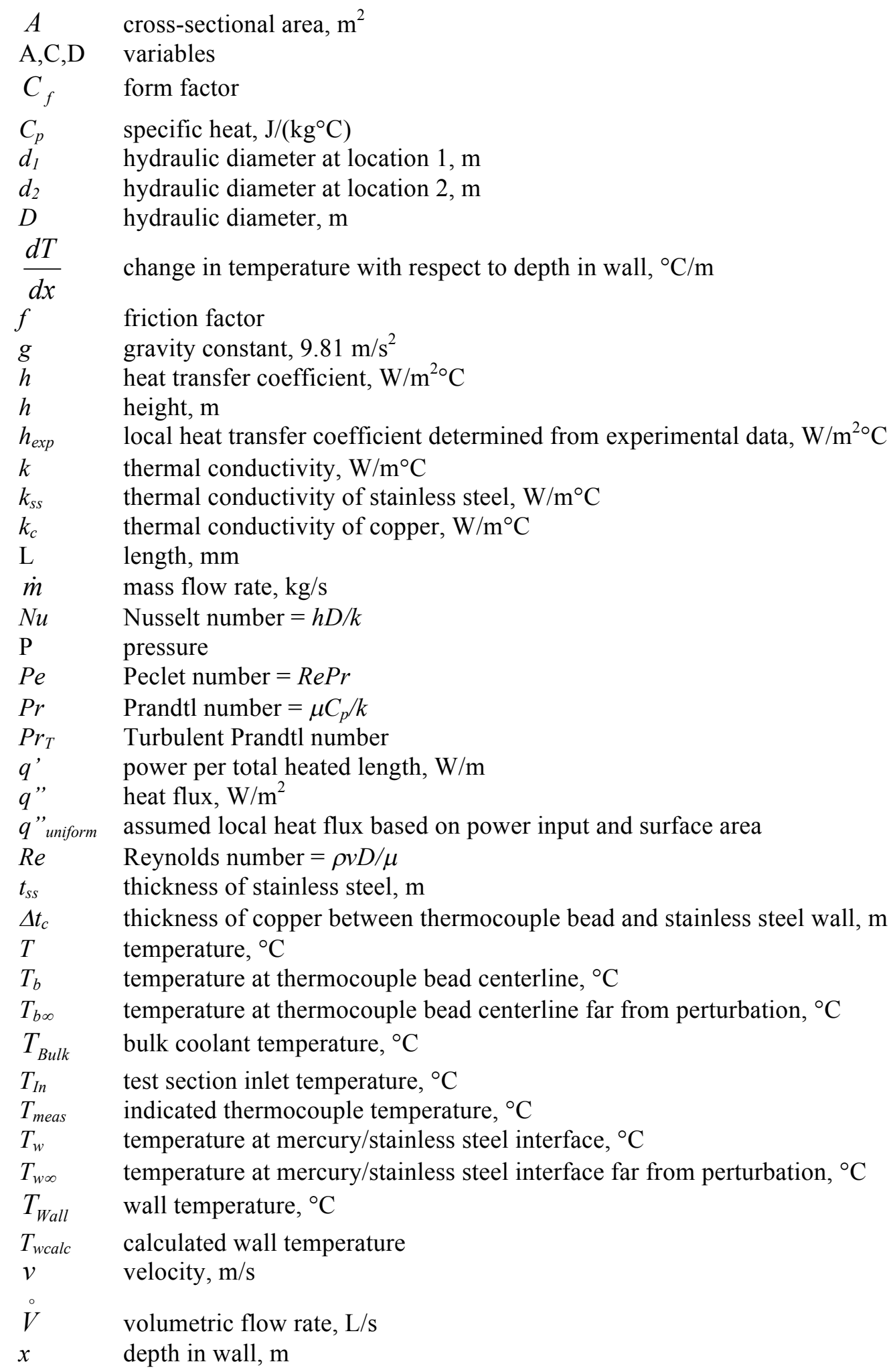




\title{
NOMENCLATURE (CONT'D)
}

\author{
Greek \\ $\delta \quad$ heated length to specified location, $\mathrm{m}$ \\ $\mu \quad$ viscosity, $\mathrm{kg} /(\mathrm{m}-\mathrm{s})$ \\ $\rho$ density, $\mathrm{kg} / \mathrm{m}^{3}$ \\ $\sigma$
$\theta$$\quad$ angle of gradual expansion or contraction, degrees
}




\begin{abstract}
The Spallation Neutron Source (SNS) is a high-power linear accelerator built at Oak Ridge National Laboratory (ORNL) which incorporates the use of a flowing liquid mercury target. The Mercury Thermal Hydraulic Loop (MTHL) was constructed to investigate and verify the heat transfer characteristics of liquid mercury in a rectangular channel. This report provides a compilation of previously reported results from the water-cooled and electrically heated straight and curved test sections that simulate the geometry of the window cooling channel in the target nose region.
\end{abstract}

The water-cooled test section was designed to allow localized and/or transient nonwetting behavior to be investigated. Thermochromic liquid crystals (TLCs) capable of resolving temperature differences of less than $0.5{ }^{\circ} \mathrm{C}$ were used to study the temperature distribution on the stainless steel (SS) wall surface. This distribution could be studied over a wide range of temperatures and flow rates. The resolution of the crystals was sufficient to detect nonwettable regions on the order of $2.5 \mathrm{~mm}$ in diameter. No areas of nonwettability were detected during testing.

Tests conducted in the electrically heated (straight) test sections provided measurements of heat transfer coefficients under SNS conditions in a rectangular geometry. The results expressed using appropriate nondimensional parameters were consistent with world data. When compared to computational fluid dynamics (CFD) predictions of heat transfer in the same rectangular channel, the predictions are a bit higher, especially at low flow rates. However, data at the current SNS design velocity of $3.2 \mathrm{~m} / \mathrm{s}$ do agree well with the CFD predictions. A parametric study of the data showed that the heat transfer coefficient is independent of variations in bulk temperature, pressure, and heat flux.

The experimental results for friction factor in the rectangular channel showed that at higher flow rates, including the SNS design velocity, there was good agreement between the results and the Moody curve. At the lower flows, the experimental results were lower than those predicted by the Moody curve, with the greatest deviation occurring at the lowest flow rates. Results from later tests in the sequence showed improved agreement with the Moody curve at the low flow rates, although the reasons for this improvement have not been identified. Pressure drop data were obtained with the test section surface continuously exposed to mercury from less than an hour to over 450 hours. No effect of time on friction factor values was discerned.

An electrically heated curved test section was fabricated which simulated the semicircular converging/diverging flow channel geometry of the SNS target window cooling channel. Tests were conducted to investigate the effects of this geometry on the heat transfer characteristics under prototypic SNS conditions. From a quantitative standpoint, the results were largely inconclusive due to apparent fabrication problems with the test section. Calculated heat transfer coefficients that were taken early in the sequence showed results lower than those measured with the electrically heated (straight) test section. A consistent degradation in measured heat transfer coefficients was observed over a relatively short time (hours); this degradation appears to be related to shutdown cycles, as well. A repeatable variation with static pressure was also measured. The results that showed a time and pressure dependence on heat transfer are believed to be the result of an effect of deficiencies in the test section fabrication rather than a result of the curved flow geometry. These problems have led to uncertainties and variability of the data, which effectively prevents any clear separation of effects caused by the curved flow geometry.

These data were taken in 2000-2002, and the MTHL was subsequently dismantled. A draft of this report was written at that time, but it was never published because work on the MTHL ceased. The information presented in this report will be helpful to those who will build mercury systems in the future. Because 
several staff members who participated in the experiment are nearing the end of their careers, the publication is being completed at this time. 


\section{INTRODUCTION}

The Spallation Neutron Source (SNS) is designed to achieve very high fluxes of neutrons for scientific experiments. The dynamics of the flow in the SNS target-both in the bulk region of the flow and in the window cooling channel-were experimentally evaluated. To evaluate mercury flow in the window cooling channel, the friction factor and heat transfer coefficient must be verified. It is widely known that mercury does not completely wet a stainless steel (SS) surface, so it is necessary to determine whether such regions of nonwettability can occur, and if they do, under what operating conditions do they occur and what changes can be made in the operating mode or in the addition of additives to the mercury to overcome the nonwettability. Finally, since the window cooling channel flow travels through a semicircular channel, it would be useful to experimentally determine the effect of this curvature on the heat transfer coefficient.

This is the final report in a series ${ }^{1,2,3}$ aimed at investigating mercury heat transfer through the wall under typical SNS window cooling channel flow conditions (see Table 1). This report provides a compilation of results from tests conducted with the water-cooled and electrically heated (straight) test sections, and it also describes the results from tests with a curved test section.

Table 1. Typical thermal/fluid conditions at the peak wall temperature point in the SNS window cooling channel at the target nose

\begin{tabular}{cc}
\hline Heat Flux & $712 \mathrm{~kW} / \mathrm{m}^{2}$ \\
$\mathrm{~T}_{\text {Wall/Hg Interface }}$ & $101{ }^{\circ} \mathrm{C}$ \\
$\mathrm{T}_{\text {Bulk }}$ & $80{ }^{\circ} \mathrm{C}$ \\
Velocity & $3.2 \mathrm{~m} / \mathrm{s}$ \\
$\mathrm{T}_{\text {Stainless Steel }}$ & $132{ }^{\circ} \mathrm{C}$ \\
\hline
\end{tabular}

\subsection{DESCRIPTION OF EXPERIMENTAL FACILITY}

A flowing liquid mercury loop has been designed and constructed to study the heat transfer characteristics of mercury flowing through a rectangular channel with a small gap similar to that in the mercury window cooling channel. A schematic of the loop is shown in Fig. 1. The loop uses an electromagnetic (EM) circulating pump capable of providing $6 \mathrm{~kg} / \mathrm{s}$ of mercury flow at a pump head of $0.25 \mathrm{MPa}$. The annular flow linear induction pump was fabricated by the University of Latvia's Institute of Physics, and can be controlled to provide a wide range of mercury flow rates through the loop. The loop uses $316 \mathrm{SS}$ tubing that is $31.8 \mathrm{~mm}$ in diameter with a wall thickness of $2.77 \mathrm{~mm}$, and it has a design pressure of $1 \mathrm{MPa}$ at $150{ }^{\circ} \mathrm{C}$. All of the loop piping is angled to allow mercury to drain into a storage tank. The loop design includes a bypass around the test section that allows calibration of an EM flowmeter and an additional means of providing lower flows to the test section. Two $38.1 \mathrm{~mm}$ Eagle EG\&G bellows seal hand control valves, one located downstream of the test section and the other in the bypass leg, are used to control the flow split. A $152 \mathrm{~mm} 316$ SS API KETEMA heat exchanger with mercury flowing on the shell side and water flowing on the tube side is used to remove frictional losses, heat from EM pump inefficiencies, and heat added by the test section. A $50 \mathrm{~L}$ storage tank located at the bottom of the facility holds the loop mercury. Mercury used for these experiments is triple distilled and was sampled following its addition to the loop to ensure that contaminants were not present. The loop is filled by applying helium overpressure to the mercury in the storage tank. A dip tube inside the tank allows mercury to fill the loop from bottom to top. Pressure in the loop is maintained by modulating the helium overpressure. If the loop must be shut down quickly, this design allows all mercury to drain from the loop into the storage tank. A second smaller tank ( $203 \mathrm{~mm}$ in diameter by $305 \mathrm{~mm}$ long) is attached at the highest loop elevation, the top of the heat exchanger. The vent tank is designed to provide a mercury/helium interface that allows vapor trapped in the loop to escape. 


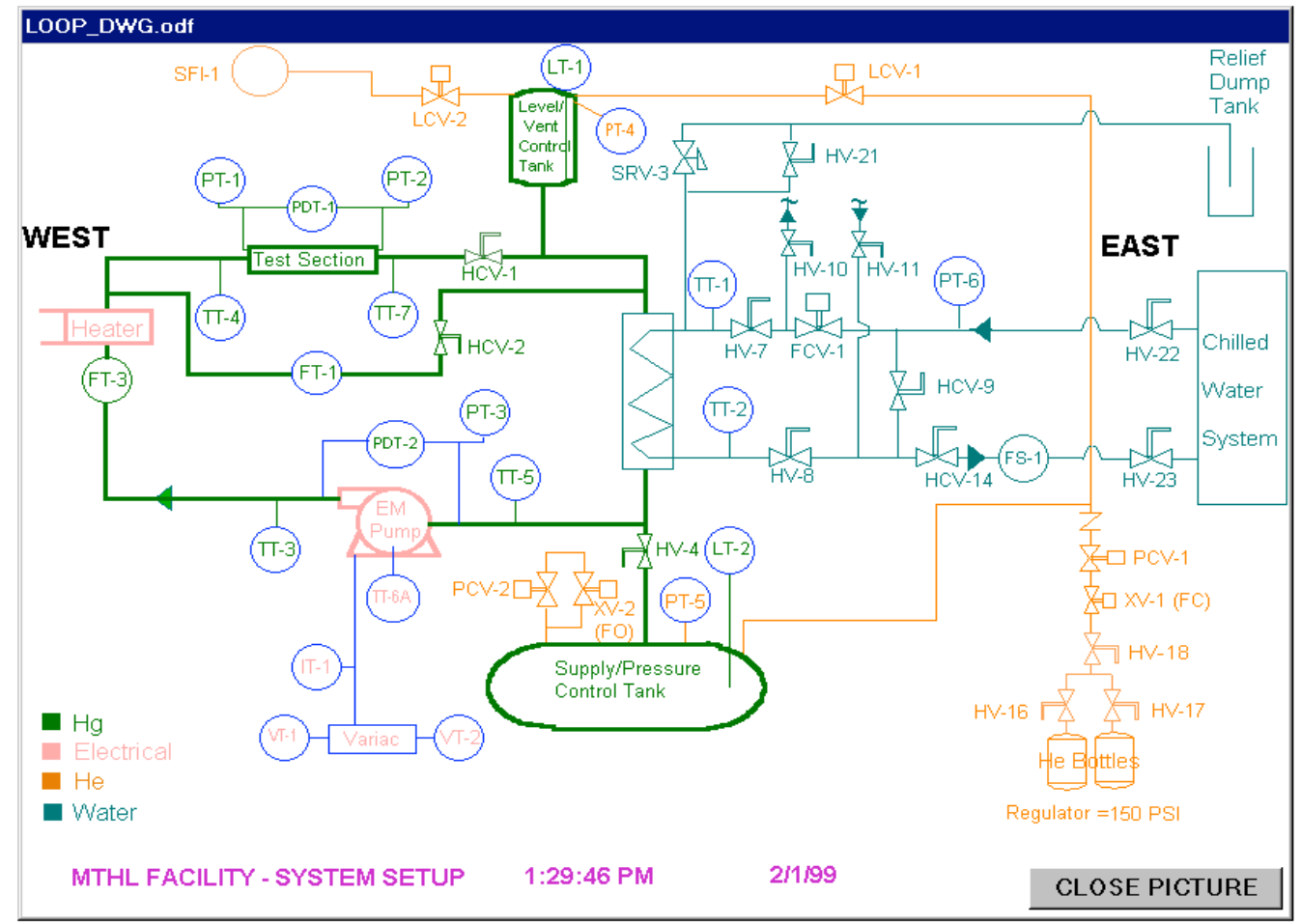

Fig. 1. Schematic of MTHL and key instrumentation.

The mercury level is controlled in this tank by manipulating a set of valves which either vents the tank to raise the mercury level or provides backpressure to reduce the mercury level. (In conjunction with control of the storage tank overpressure, the set of vents is also used for elevating the total system pressure.) The loop is enclosed by acrylic panels which are attached to the loop framework. The acrylic panels serves as a splashguard in case of a mercury leak. A SS catch pan is located beneath the loop to capture any mercury leaks. The pan is sloped to allow for drainage into another $50 \mathrm{~L}$ waste tank. In practice, there were no significant mercury leaks experienced during test operations. An elevation drawing of the loop is shown in Fig. 2, and a photograph of the loop is shown in Fig. 3.

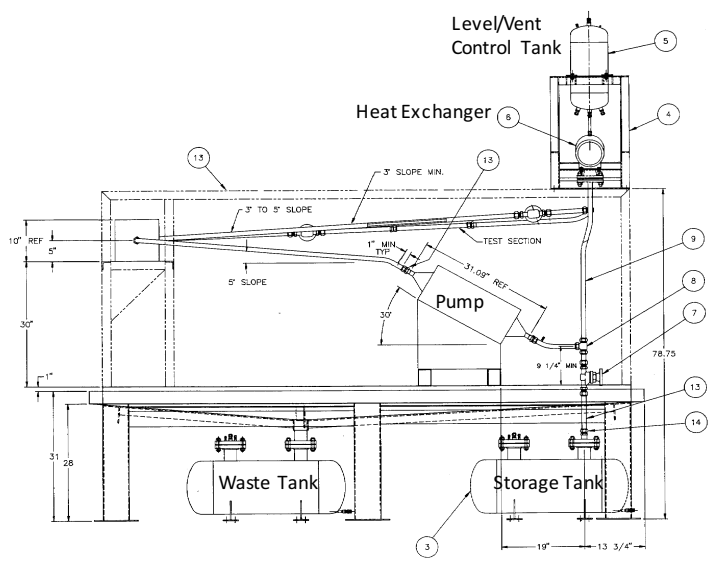

Fig. 2. Loop elevation. 


\subsubsection{Instrumentation and Controls}

Two flow measurement devices are used in the loop. A Venturi meter is located in the bypass leg of the loop, and an EM flowmeter is placed before the flow split (both instruments were built at the University of Latvia, Institute of Physics). A photograph of the EM flowmeter is shown in Fig. 4. This configuration allows the EM flowmeter to be calibrated with the Venturi meter by shutting off test section flow, and it also allows flow to be measured in the test section if the bypass is used (difference between EM and Venturi meter readings). The range of the EM flowmeter is approximately $0.06-0.5 \mathrm{~L} / \mathrm{s}$ of mercury flow, while the Venturi meter presently installed has a range of $0.0-0.5 \mathrm{~L} / \mathrm{s}$.

Eight pressures (or differential pressures) are monitored on the mercury side of the loop: pump suction pressure, pump differential pressure, test section inlet pressure, test section outlet pressure, test section differential pressure, Venturi differential pressure, storage tank pressure, and vent tank pressure. Pressure control of the loop is accomplished using bottled helium in combination with control valves on the storage and vent tanks designed to vent the system or add helium, based on measured pressure and the desired operating pressure. Measurement of the heat exchanger outlet pressure is made on the water-side of the loop.

Both the storage tank and the vent tank have Magnetrol level probes (capacitance based) to detect liquid level. The level signal from the vent tank is used to control the location of the mercury/helium interface within the tank as described above. The level signal in the storage tank is used as a check for trapped vapor in the loop, as well as an indirect or secondary means of determining the liquid level in the loop.

Liquid mercury temperatures are measured at the pump outlet and at the test section inlet and outlet using resistance temperature detectors (RTDs). Pump inlet temperature is measured using a type $\mathrm{K}$ thermocouple. Six temperature measurements internal to the pump (the pump operational temperature limit is $150^{\circ} \mathrm{C}$ ) are monitored in order to prevent damage to the pump coils during operation.

Temperatures are also monitored on the secondary or water side of the heat exchanger. Secondary side cooling is provided by a closed loop $75 \mathrm{~kW}$ Pioneer air-cooled chiller system to eliminate the possibility of mercury release to the environment in the event of a heat exchanger leak. Hand-operated control valves are located on the water inlet and outlet of the heat exchanger and in a bypass leg around the heat exchanger to control secondary side water flow and pressure. 


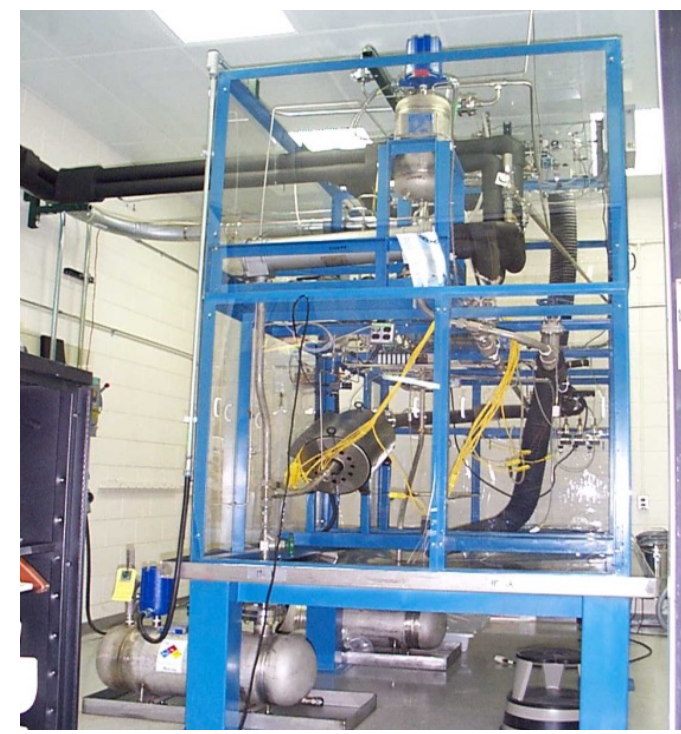

Fig. 3. View of the MTHL.

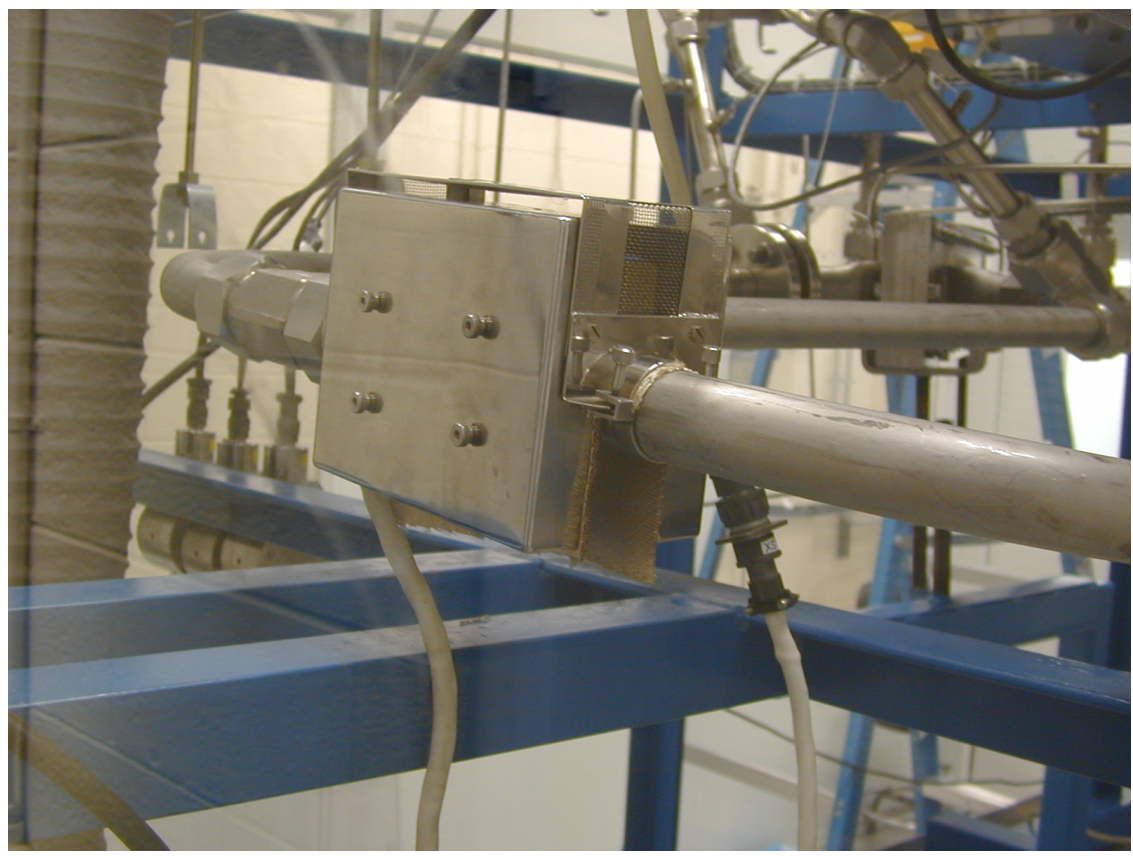

Fig. 4. Close-up of EM flowmeter installed upstream of test section.

Automatic controls are used to maintain mercury level and pressure during loop operation. Loop pressure is controlled by monitoring the storage tank pressure, while loop mercury/helium interface level is controlled using the level indicator in the vent tank. Test section inlet temperature is controlled by altering the secondary side water flow rate. Mercury flow control is performed manually by adjusting EM pump voltage. The personal computer (PC)-based data acquisition and control system uses an Azonix $\mu$ DCS Plus interface device, along with Intellution FIX software, to store and reduce the data and to provide loop control. 


\subsubsection{Test Operations}

Test operations are initiated by pressurizing the storage tank with the upper level tank vented. The system is filled to bring the mercury level to $\sim 125 \mathrm{~mm}$ above the bottom of the upper tank. This requires a storage tank pressure of $\sim 417 \mathrm{kPa}$. Pressure and level control systems are placed in automatic control mode once the mercury reaches the desired levels. The EM pump is soft-started and brought up to the desired pumping rate using the Variac controls over a span of a few minutes. Prior to taking test data, the test section flow line is isolated and the bypass line opened so that the EM flowmeter and Venturi flowmeter operate in series. A calibration check of the EM flowmeter is made, and the scale factor is adjusted if necessary. (The EM flowmeter actually proved to be very stable, and good agreement was obtained between the two flowmeters, especially for flow rates above $\sim 0.1 \mathrm{~L} / \mathrm{s}$. Flow rates below this level are actually on the low end of the differential pressure range for the Venturi meter and subject to significantly higher uncertainties.) Following this operation, the isolation valve on the test section line is opened, and the bypass line is isolated. From this point, system parameters are adjusted to obtain desired flow rates, temperatures, and pressures at the test section inlet as specified in the test plan.

\subsubsection{Data Acquisition}

The data acquisition was performed on a PC using Intellution FIX Software. This system served two purposes: (1) system monitoring and control in real time and (2) data archival for post-processing. The Intellution system was used to control the loop operation and display system pressures, temperatures, liquid level, and other major loop operational parameters. Also, parameters such as velocity, Reynolds number, friction factor, and heat transfer coefficient were calculated and displayed on screens in order to provide real-time feedback on the hydrodynamic and thermal operating conditions of the system and test section. 



\section{WATER-COOLED TEST SECTION}

The water-cooled test section is designed to investigate wetting and heat transfer at the SS wall/mercury interface under typical SNS window cooling channel conditions. In this test section, heat is transferred from hot flowing mercury to cooler water through a SS wall as opposed to the heat flow in the opposite direction that would occur in the actual target. The test section was designed in this way to allow for evaluation of localized and/or transient nonwetting behavior. Heat fluxes up to $0.8 \mathrm{MW} / \mathrm{m}^{2}$ are possible with this design.

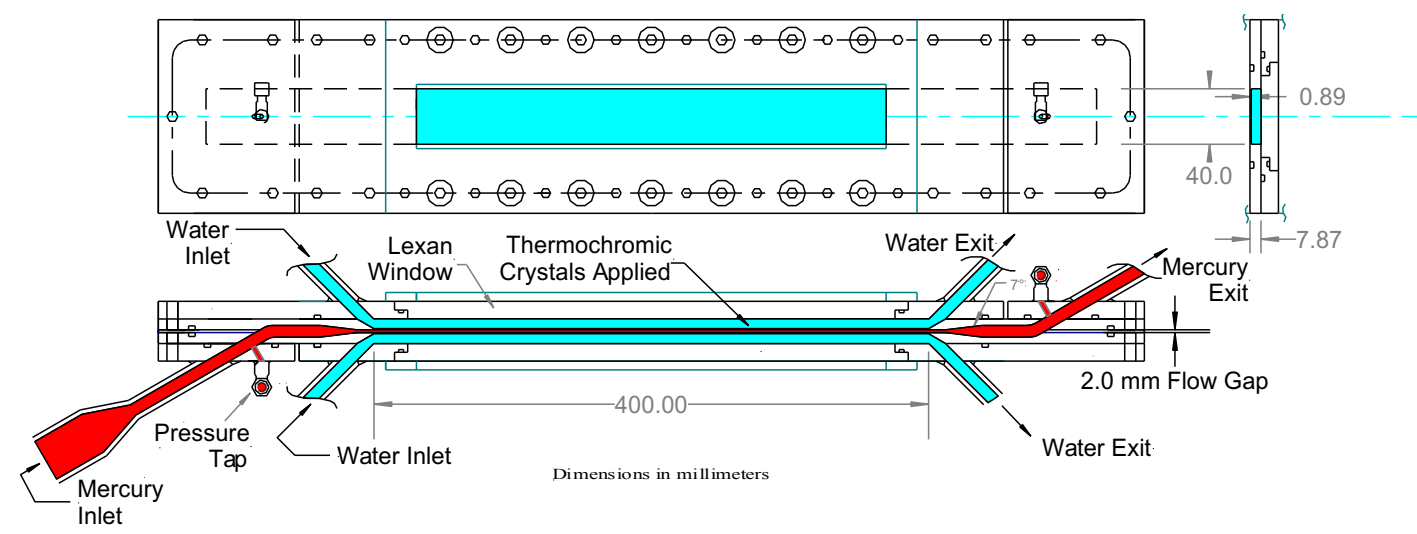

Fig. 5. MTHL water-cooled test section design.

The water-cooled test section shown in Fig. 5 is machined from 316 SS stock and has a rectangular mercury flow cross section of $2 \mathrm{~mm}$ gap by $40 \mathrm{~mm}$ wide and is $\sim 400 \mathrm{~mm}$ long. The mercury flow channel is formed by a cutout in a $2 \mathrm{~mm}$ thick shim plate sandwiched between two SS channel plates and is sealed using O-rings. Mercury inlet and exits are located on opposite sides of the test section. At the inlet, the mercury is supplied to the test section through a $38.1 \mathrm{~mm}$ outer diameter (OD) tube with a $3.4 \mathrm{~mm}$ wall thickness. At the test section, the flow channel changes to an $8.4 \mathrm{~mm}$ by $40 \mathrm{~mm}$ rectangular cross section channel. Here, the mercury flow makes a $30^{\circ}$ change in direction and travels a distance of about $45 \mathrm{~mm}$ before narrowing to $2 \mathrm{~mm}$ by $40 \mathrm{~mm}$ for a length of about $418 \mathrm{~mm}$. It then opens $8.4 \mathrm{~mm}$ by $40 \mathrm{~mm}$ prior to exiting the test section through a $38.1 \mathrm{~mm}$ OD tube. The transition from a round to rectangular mercury channel geometry is accomplished by flattening a section of $38.1 \mathrm{~mm}$ OD tube and welding the nearly rectangular end to the flow adapter plates, which are shown at both ends of the test section in Fig. 5 . The pressure tap lines are also located in the flow adapter plates.

This test section is operated with the mercury heated above ambient via frictional heating and EM pump inefficiencies with additional heat supplied by the loop heater when necessary. Water channels machined into the back side of the SS channel plates (which form the mercury channel) are used to cool the mercury. The water flow channels have a cross section of $7 \mathrm{~mm}$ by $40 \mathrm{~mm}$ for a length of $400 \mathrm{~mm}$. A thin wall of 316-SS, $0.89 \mathrm{~mm}$ thick, separates the mercury and water channels. These fluids flow co-currently, and the main region of heat transfer is $40 \mathrm{~mm}$ wide and $400 \mathrm{~mm}$ long on each face. The window base plates that provide the water connections are on the outside surface of the channel plates. The outer water channel wall is formed using clear polycarbonate plates supported by SS backing plates. The windows permit the water side of the channel plates to be viewed, allowing the use of thermochromic crystals and laser phosphor techniques for temperature measurement. The channel plates shown in Fig. 6 have just been painted with the TLCs on the water side of the channel wall. The shim plate, window plate, window, and backing plate are shown in Fig. 7. An assembly of the shim plate, channel, and window plates is shown in Fig. 8. 
The O-rings used in the assembly that are wetted by mercury are made of Parker Parafluor material, while those wetted by water are Viton. The Parker Parafluor material was tested offline for compatibility with mercury at temperatures to $250^{\circ} \mathrm{C}$ and showed little effect.

Test section cooling water is provided by the chiller unit described above. Water flow rates for each side of the test section are monitored by $12.7 \mathrm{~mm}$ diameter turbine flow meters (Hoffer Flow Controls, Inc.), while water inlet and outlet temperature measurements are from RTDs immersed in the liquid stream. Inlet and exit water pressure are also measured.

A photograph of the installed test section is shown in Fig. 9. The inlet cooling water line connections to the north face can be seen on either side of the window, and the mercury inlet line is visible to the far right of the test section. The fitting for the inlet pressure tap is visible on the flat part of the test section and is located between the inlet water line and inlet mercury line. A view of the south face of the installed test section is shown in Fig. 10 with the EM pump in the left foreground.

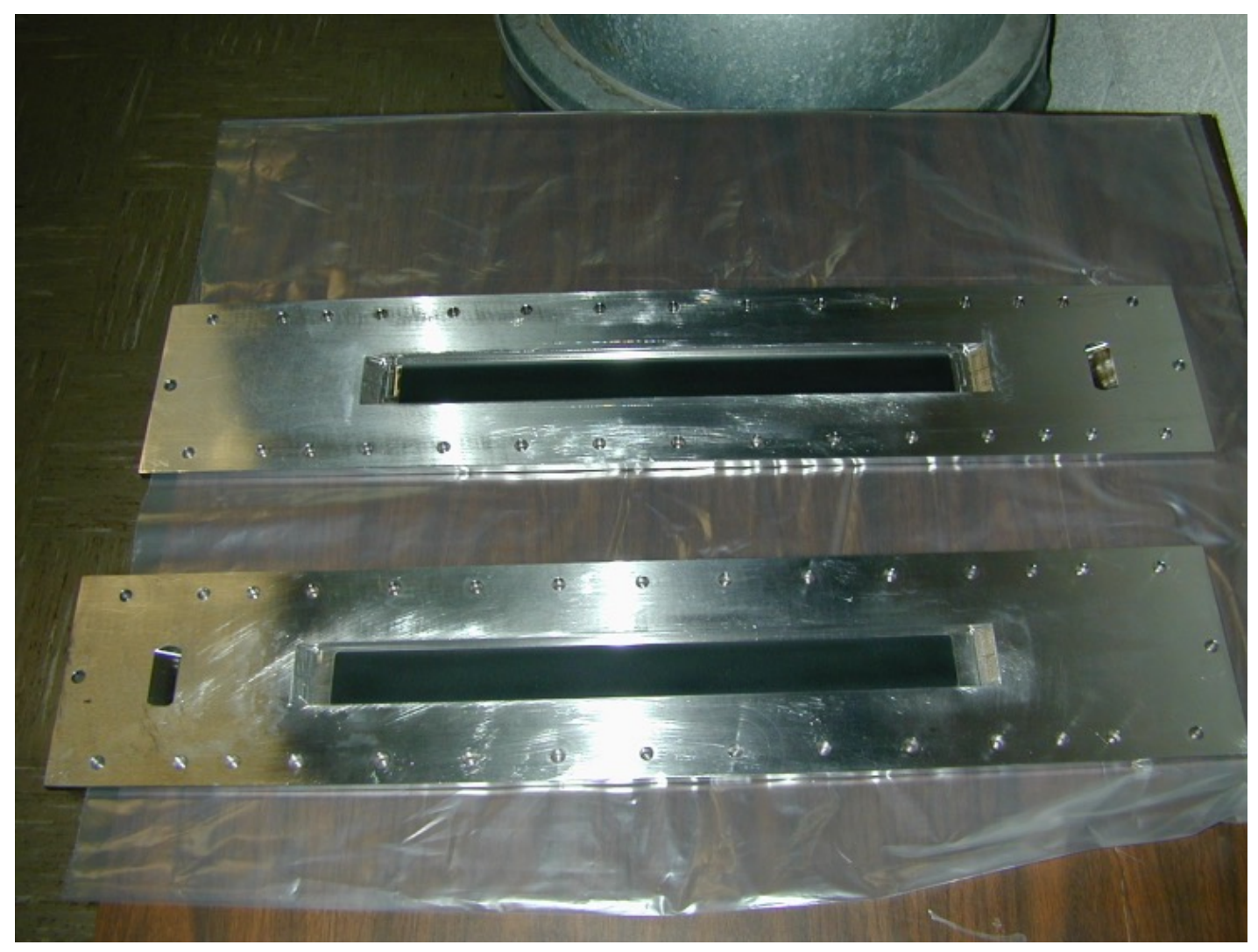

Fig. 6. Water-cooled test section channel plates shown following application of TLCs (black region in pocket). 


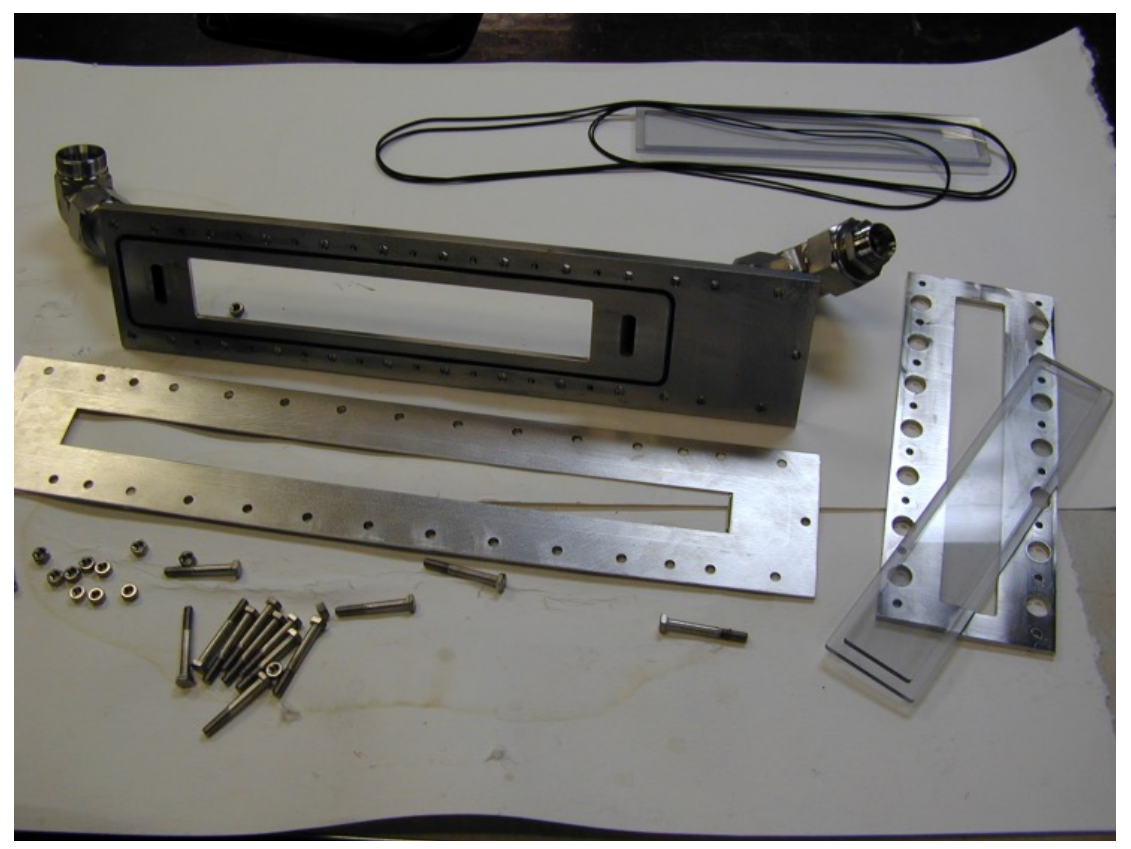

Fig. 7. Components used in water-cooled test section, including shim plate in foreground, window plate in background, Lexan window and backing plate at the right.

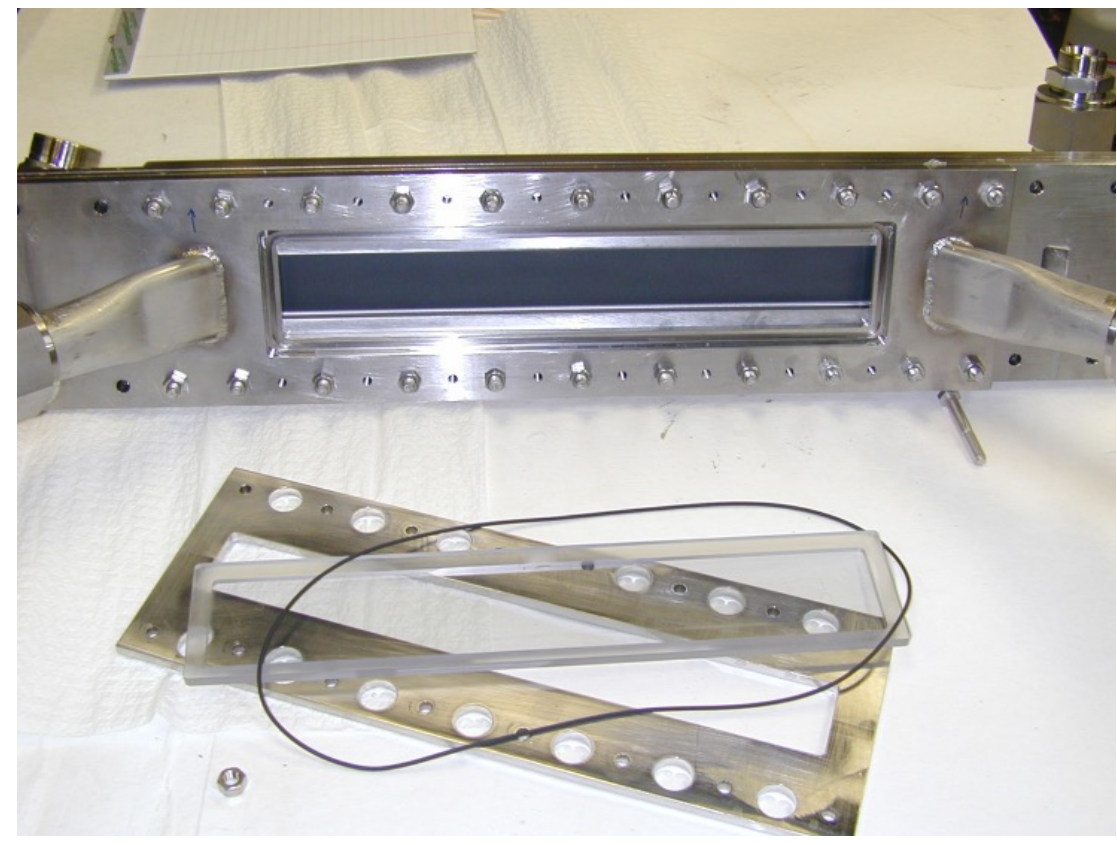

Fig. 8. Components used in water-cooled test section, including assembly of window plate, channel plate, and shim in background with Lexan window and backing plate in foreground. 


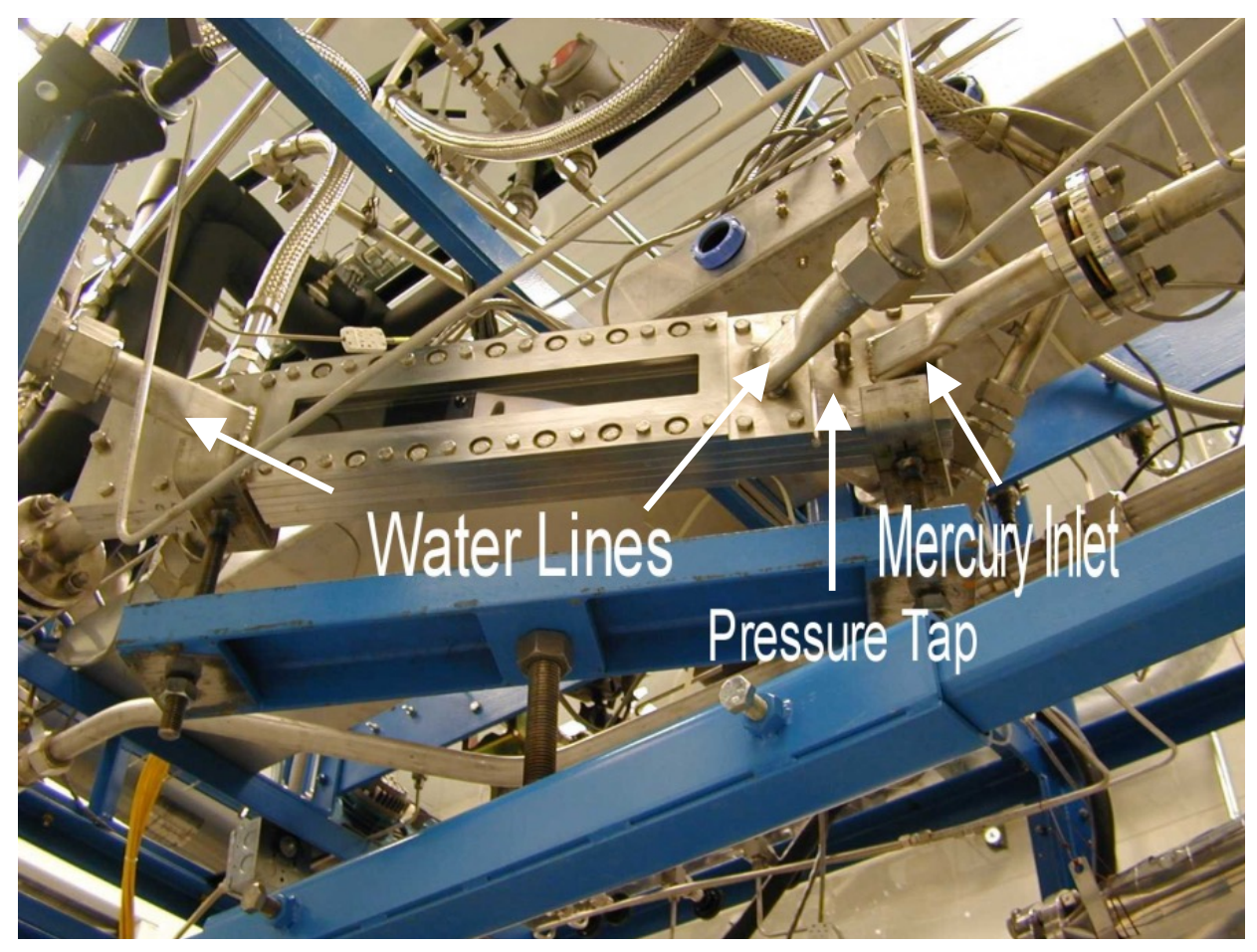

Fig. 9. View of water-cooled test section.

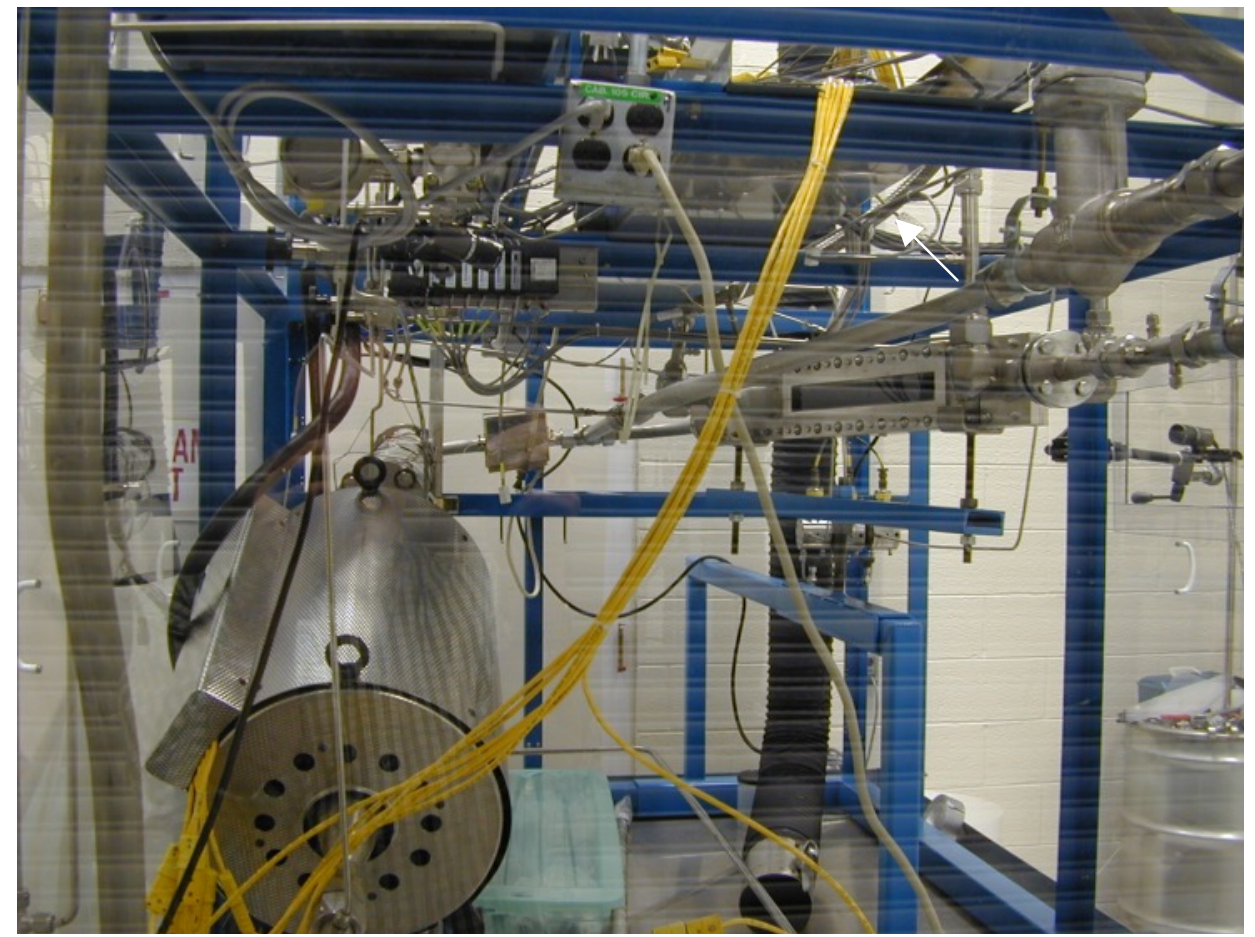

Fig. 10. South face of water-cooled test section.

To detect variations in localized heat transfer over potential areas of nonwetting, the two $40 \mathrm{~mm}$ by $400 \mathrm{~mm}$ thin-walled regions of the test section were coated with TLCs on the water side. TLCs are 
organic chemicals which respond to changes in temperature by changing their color. These color changes result from the liquid crystals' selective reflectance of the incident light. A more detailed description of this technique is presented in a publication by Crabtree. ${ }^{4}$ To visualize any localized areas of nonwetting through the water layer, the test section had two polycarbonate windows, each with a viewable region of $40 \mathrm{~mm}$ by $339 \mathrm{~mm}$. Color images of the viewable region were captured using a COHU red-green-blue (RGB) format charged coupled device (CCD) camera. Image processing techniques are employed to convert the color reflected by the TLC color display to values of hue, saturation, and intensity, and the relationship between hue and temperature is developed from a pretest calibration.

This technique required the application of several layers of material. On the bare 316-SS surface for this test section, a nominal $0.04 \mathrm{~mm}$ layer of black paint was air-brushed on to provide a background for the liquid crystal color changes. Then a $0.04 \mathrm{~mm}$ layer of crystals was air-brushed on. This layer consisted of crystals capable of responding to temperatures in the nominal range of 55 to $75^{\circ} \mathrm{C}$. An additional 0.04 $\mathrm{mm}$ layer of crystals was added with a nominal range of 85 to $105^{\circ} \mathrm{C}$. Finally, two more coatings were applied: an air-brushed clear coat layer $\sim 0.04 \mathrm{~mm}$ thick, and an outer coat of $0.022 \mathrm{~mm}$ thick Parylene to seal the crystals from the water was applied. The Parylene was vapor deposited in a vacuum chamber. Because of the limited range of each crystal layer, the application of two TLC layers effectively doubled the temperature span over which meaningful data could be obtained. As the surface temperature of the test section was brought up to $55^{\circ} \mathrm{C}$, the low temperature TLCs used here first changed from colorless (viewed as black due to the background paint) to red. As the temperature of the surface was further increased, the TLCs progressed through the remainder of the visible spectrum of light before becoming colorless again as the temperature of the surface exceeded $75^{\circ} \mathrm{C}$. With a further increase in temperature, the second higher temperature TLCs became visible at about $85^{\circ} \mathrm{C}$ and continued to exhibit color changes up to about $105^{\circ} \mathrm{C}$, when they became colorless again.

In addition to the thermochromic crystal measurements, whose primary purpose was to detect localized regions of nonwetting, there was also interest in obtaining actual heat transfer coefficient results. As will be discussed later, the TLC technique was not suitable for this purpose since the multiple layers of lowconductivity materials resulted in large uncertainties for the calculated values of the heat transfer coefficient. As an alternative, a technique extensively researched at Oak Ridge National Laboratory (ORNL) by D. Beshears, S. W. Allison, and M. Cates was used. ${ }^{5}$ In this technique, an appropriate phosphor is combined with a binder and air-brushed onto the SS surface. When excited by an ultraviolet (UV) light source such as a nitrogen laser, the phosphors exhibit a fluorescence spectra with well-defined peaks. One wavelength from the spectrum of the emitted light is observed. Since the decay time of the fluorescence is temperature dependent, a correlation between decay rate and temperature is used to obtain the surface temperature. Measurements using this technique are made at discrete points. The sensors actually consist of optical fibers that transmit the laser beam used to excite the phosphor and also receive the signal light produced from the phosphor decay. Since the wavelength of the laser will not transmit through the polycarbonate window, the sealed fiber penetrates the window via a bored-through compression fitting. The end of the fiber is withdrawn slightly from a flush position on the inner surface of the window to prevent any flow disturbance. The laser transmits through the flowing water to excite the phosphor coated on the surface.

\subsection{DATA ANALYSIS METHODS FOR THE WATER-COOLED TEST SECTION}

\subsubsection{Friction Factor}

For purposes of analyzing the pressure drop data, the mercury flow channel was divided into seven regions for which the diameters and lengths were measured and cross sectional areas calculated. The key dimensions are shown in Fig. 11. 
The flow rate through the test section was measured by the EM flowmeter upstream of the test section. The velocity of the fluid in each of the 7 regions of the test section is calculated by

$$
v=\frac{\stackrel{\circ}{A}}{A},
$$

where $v$ is the velocity, $\stackrel{\circ}{V}$ is the volumetric flow rate, and $A$ is the cross sectional area.

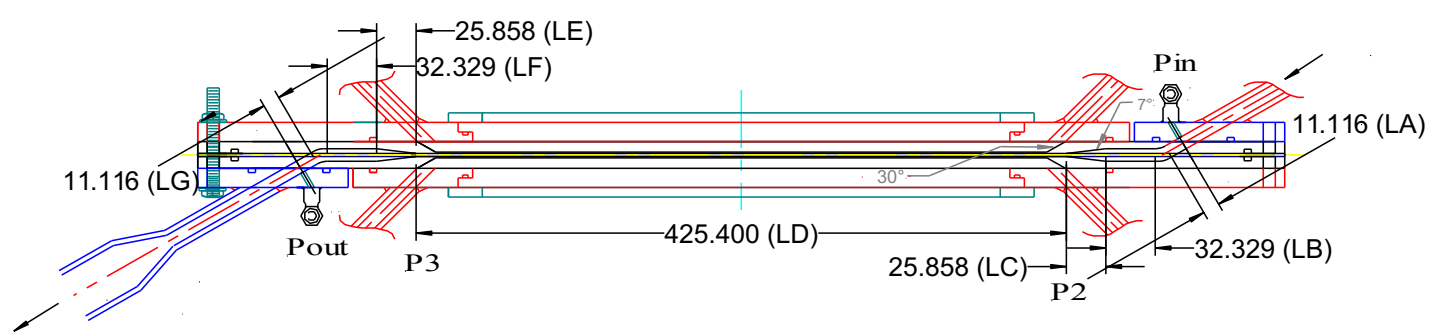

Fig. 11. Detailed drawing of flow channel dimensions in water-cooled test section.

The friction factor in that portion of the test section is represented by $L D$ (i.e., the region of the $2 \mathrm{~mm}$ gap shown in Fig. 11). The pressure taps, however, are located at $\mathrm{P}_{\mathrm{IN}}$ and $\mathrm{P}_{\text {OUT. }}$. Thus it is necessary to calculate the change in pressure in lengths $L A, L B, L C, L E, L F$, and $L G$ and subtract that from the total pressure drop to obtain the pressure drop across $L D$. This was done by applying the modified Bernoulli equation to each of the six lengths listed above. This was relatively straightforward except for three loss coefficients. In lengths $L C$ and $L E$, the gradual enlargement and contraction loss coefficients are calculated by

$$
\begin{gathered}
C_{f \text { Gradual Contraction }}=0.8 \cdot\left(1-\frac{d_{1}^{2}}{d_{2}^{2}}\right) \cdot \sin \left(\frac{\theta}{2}\right) \text { for } \theta \leq 45^{\circ} \text { and } \\
C_{f \text { Gradual Expansion }}=2.6 \cdot\left(1-\frac{d_{1}^{2}}{d_{2}^{2}}\right)^{2} \cdot \sin \left(\frac{\theta}{2}\right) \text { for } \theta \leq 45^{\circ},
\end{gathered}
$$

where $d_{1}$ is the smaller diameter, $d_{2}$ is the larger diameter, and $\theta$ is the angle of the gradual expansion or contraction. ${ }^{6}$ A loss coefficient is also required for the two $30^{\circ}$ bends located after $L A$ and $L F$ and is calculated by

where $f$ is the friction factor. ${ }^{6}$

$$
C_{f \text { Bend }}=8 \cdot f
$$

The modified Bernoulli equation

$$
P_{1}+\rho g h_{1}+\frac{1}{2} \rho v_{1}^{2}=P_{2}+\rho g h_{2}+\frac{1}{2} \rho v_{2}^{2}+\text { Losses }
$$

where $\rho$ is the density, $h$ is the height, and $g$ is the gravity constant, is applied between

- $\mathrm{P}_{\mathrm{IN}}$ and $\mathrm{P}_{2}$,

- $\mathrm{P}_{2}$ and $\mathrm{P}_{3}$, and

- $\mathrm{P}_{3}$ and $\mathrm{P}_{\text {OUT, }}$

as shown in Fig. 11. In the modified Bernoulli equation, frictional losses are determined by 


$$
\frac{1}{2} \rho v^{2} \cdot f \frac{L}{D}
$$

The form losses are determined by

$$
\frac{1}{2} \rho v^{2} \cdot C_{f}
$$

Since $\mathrm{P}_{\mathrm{IN}}$ and $\mathrm{P}_{\text {OUT }}$ are known from the data, there are three unknowns $\left(\mathrm{P}_{2}, \mathrm{P}_{3}\right.$, and $\left.f\right)$ and three equations. Thus, the pressures at the inlet and outlet of the flat region and the friction factor can be backed out from the experimentally measured total test section pressure drop. This calculation was performed on each measured data point and each time block in an Excel spreadsheet.

This experimentally determined friction factor was compared to the friction factor given by the correlation

$$
f=(1.82 \cdot \log R e-1.64)^{-2},
$$

which represents the value from the Moody curve for flow in a smooth tube ${ }^{7}$.

To determine the density used in the modified Bernoulli equation as well as the specific heat, thermal conductivity, and viscosity, the following temperature-dependent correlations ${ }^{8}$ were programmed into the Excel spreadsheet:

$$
\begin{gathered}
\rho=13602.68 \cdot\left(1+0.00018182 \cdot T+0.0000000078 * T^{2}\right)^{-1} \\
C_{p}=\left(30.5-0.012 \cdot T+0.0000102 \cdot T^{2}+1.93667 \cdot 10^{-9} \cdot T^{3}-1.9411 \cdot 10^{-12} \cdot T^{4}\right) / 2.0059 \cdot 10^{5} \\
k=-1.38+0.0506 \cdot T-0.000075 \cdot T^{2}+0.0000000456 \cdot T^{3} \\
\mu=\exp \left(-7.1622-\frac{117.913}{124.04-T}\right)
\end{gathered}
$$

where $\rho$ is the density in $\mathrm{kg} / \mathrm{m}^{3}, T$ is the temperature in Kelvin, $C_{p}$ is the specific heat in $\mathrm{J} / \mathrm{kg}{ }^{\circ} \mathrm{C}, k$ is the thermal conductivity in $\mathrm{W} / \mathrm{m}^{\circ} \mathrm{C}$, and $\mu$ is the viscosity in $\mathrm{kg} / \mathrm{m}$-s. The temperature used for the fluid properties is the average between the inlet and the outlet mercury temperatures (TT-4 and TT-7) in the test section.

\subsubsection{Mercury Wettability}

In addition to determining the friction factor, a knowledge of the wettability of the surface and the magnitude of the heat transfer coefficient between the inside wall of the test section and the mercury are of interest. For the wettability analysis, an image of the TLCs discussed in the previous section was captured by the RGB camera. The camera captured a region $313 \mathrm{~mm}$ wide and $41 \mathrm{~mm}$ high (slightly wider than the channel). This represented a $518 \times 62$ pixel array. The RGB values were used to determine hue (for a description of this technique, see Ref. 2). Since each pixel provided a temperature measurement, this technique was capable of a spatial resolution as small as $0.6 \mathrm{~mm}$.

To properly convert the hues to temperatures, it was necessary to calibrate the TLCs. In the calibration, a small constant temperature water bath was attached to the water lines connected to both faces of the test section. The water bath was capable of producing a maximum flow of five liters per minute and temperatures in the range of room temperature to about $100^{\circ} \mathrm{C}$. Two and a half liters per minute of water, initially at about $53^{\circ} \mathrm{C}$, were injected into the inlet channel on each face. The water flowed over the TLC layer on the SS surface, exited out of the outlet channel, and returned to the bath. Since there was no mercury inside the test section, the SS wall temperature was very close to the water temperature. 
However, some heat did conduct through the SS to adjacent cooler parts of the test section, producing a small difference between the inlet and outlet water temperature. This difference was about $0.5{ }^{\circ} \mathrm{C}$ at $53{ }^{\circ} \mathrm{C}$ and increased to about $2{ }^{\circ} \mathrm{C}$ at a water inlet temperature of $95^{\circ} \mathrm{C}$. For the mercury wettability studies using the TLCs, the primary interest is the relative temperature difference between one local spot and the next. Therefore, the sensitivity of the TLCs to small temperature differences is important whereas the magnitude of the absolute temperature is not.

Starting at a water inlet temperature of $53{ }^{\circ} \mathrm{C}$, the temperatures of the water at the inlet and the outlet were recorded, along with the hue value for a $10 \mathrm{~mm} \times 10 \mathrm{~mm}$ portion of the test section wall. This portion of the test section wall was located roughly halfway between the inlet and outlet thermocouples. The hue value then represented a wall temperature that was the average of the inlet and outlet water temperatures. The water temperature was then raised slightly, and this procedure was repeated. For the lower temperature crystals, twenty data points were taken in the temperature range of $53{ }^{\circ} \mathrm{C}$ to $76{ }^{\circ} \mathrm{C}$. This procedure was repeated for the higher temperature crystals in the wall temperature range of $82^{\circ} \mathrm{C}$ to $95.4^{\circ} \mathrm{C}$. Only the lower half of the high temperature crystal range was calibrated to avoid boiling the water. Subsequent wettability tests all occurred with the TLC readings in the calibrated temperature range. The image at each water temperature level was then converted to a hue value and analyzed for the average hue. With the temperature corresponding to each of these hue values known, a curve of hue as a function of temperature was obtained and fitted with a polynomial. This calibration then served as the basis for converting the test section image acquired from hue to temperature. This was performed on a pixel-by-pixel basis.

\subsubsection{Heat Transfer}

The total heat transferred from the mercury to the water was determined by performing an energy balance on the mercury flowing through the test section. Since the inlet and outlet mercury temperatures and the flow rate were known, the heat leaving the mercury was calculated and converted to a heat flux at the inside wall. During all experiments, the water conditions on the north and south faces were kept as close to each other as possible. Since the wall conditions on both faces were nearly identical, the heat transfer characteristics on the north and south faces were also assumed to be the same. The mercury heat transfer coefficient on each face of the test section can be calculated by:

$$
q^{\prime \prime}=h \cdot\left(T_{\text {Bulk }}-T_{\text {Wall }}\right)
$$

where $q^{\prime \prime}$ is the heat flux, $h$ is the heat transfer coefficient, $T_{B u l k}$ is the bulk temperature, and $T_{\text {Wall }}$ is the inside wall temperature. The proper determination of the magnitude of the heat flux, bulk temperature, and the inside wall temperature is critical for correct heat transfer coefficient determination. In addition, the expected heat transfer coefficients are high, resulting in small differences between the inside wall and bulk temperatures.

Since some fraction of the heat is convected and conducted from the mercury to the water via alternate paths other than through the $0.89 \mathrm{~mm}$ thick wall portion of the test channel, obtaining the heat flux, $q^{\prime \prime}$, from an energy balance based on the mercury temperature rise between the RTD measurement locations is not a sufficiently accurate representation of the heat flux through the wall. For this reason, a detailed model of the test section was made using the CFD commercial code CFX 4.3 (AEA Technology).

Both the local bulk fluid temperature and the local heat flux at the axial locations corresponding to where the wall temperature measurement is made must also be determined. Because this test section acts as a cocurrent heat exchanger, and because of the complex 3-dimensional (3-D) nature of the heat transfer 
between the mercury and the water, it would not necessarily be accurate to assume a linear change in the bulk mercury temperature and the average heat flux between the inlet and the outlet. Here again, the results of the CFX code are used to determine the shape of the temperature and heat flux profiles in order to calculate $T_{B u l k}$ and $q$ " at the appropriate axial locations.

Finally, the inside wall temperature at the mercury/SS interface, $T_{\text {Wall }}$, needs to be determined. While the TLC method is useful for local wettability detection, it was not suitable for heat transfer coefficient determination. The multiple layers added to the wall increased the thermal resistance between the mercury and water sides. Coupled with the lack of an accurate knowledge of the thermal conductivity of the various layers, the calculation of the inside wall temperature $(\mathrm{Hg} / \mathrm{SS}$ interface) from the outside wall temperature $\left(\mathrm{H}_{2} \mathrm{O} /\right.$ crystal interface $)$ results in a large uncertainty in the calculated heat transfer coefficient. As a result, for the heat transfer coefficient measurement, the TLC layers were removed and replaced with a much thinner single layer of phosphor in a binder. In this analysis, it is assumed that the temperature recorded by the phosphor is the actual wall temperature. Thus, the inside wall temperature is calculated from Fourier's law of heat conduction using the local heat flux through the $0.89 \mathrm{~mm}$ wall, the outside wall temperature obtained from the phosphor, and the thickness of the SS wall.

To provide a comparative basis, the heat transfer coefficient is also calculated from the correlation

$$
N u=0.685 \cdot(P e)^{0.3726}
$$

where $N u$ is the Nusselt Number, and $P e$ is the Peclet Number. ${ }^{9}$ This represents a correlation chosen during the conceptual design stage of the SNS to reflect nominal wetted heat transfer conditions. More recently, comparison of results from the CFD design code being used for SNS shows good agreement with a correlation based on Lyons data with a turbulent Prantl number dependence ${ }^{10}$. This equation is

$$
N u=7+0.025\left(\frac{P e}{P r_{T}}\right)^{0.8}
$$

As will be shown in a later figure, these two correlations are very similar in the range of the window channel fluid conditions.

\subsection{WATER-COOLED TEST SECTION RESULTS}

\subsubsection{Friction Factor Results}

Data are available for the calculation of friction factors from all of the experiments conducted with the water-cooled test section. In general, the loop is operated by setting the mercury and water flow rates and then adjusting the loop heater to obtain the desired inlet mercury temperature. Figure 12 is an example of the flow rate through the test section vs. time for the April 10, 2000 tests showing only the steady state portions of the data. The four flow rate levels shown correspond to test section velocities of 1, 2, 3 and 3.5 $\mathrm{m} / \mathrm{s}$. Earlier test series did include data at velocities up to $4 \mathrm{~m} / \mathrm{s}$. Figure 13 displays the total test section pressure drop between $\mathrm{P}_{\mathrm{IN}}$ and $\mathrm{P}_{\mathrm{OUT}}$ as a function of flow rate for all the tests and has a parabolic shape as expected.

The data were recorded at 10-second intervals, and each data point represents an instantaneous snapshot of values at that time. When analyzing the 10 -second data, wide scatter is observed in calculations of the friction factor. A significant part of the scatter in these results is due to the fact that the friction factor must be calculated using both flow and pressure drop data. The response time of these two instruments varies greatly. The pressure transducers, for example, are fast responding instruments limited by the $0.1 \mathrm{~s}$ 
data acquisition rate, while the EM flow meter is a slower responding instrument, on the order of $2 \mathrm{~s}$ measurement cycles. As a result of natural fluctuations in the system flow rate, the pressure transducers tended to respond to these fluctuations in a more timely manner than the EM flow meter. To reduce the scatter due to the instrument response time, the friction factor data are averaged over 5-minute intervals.

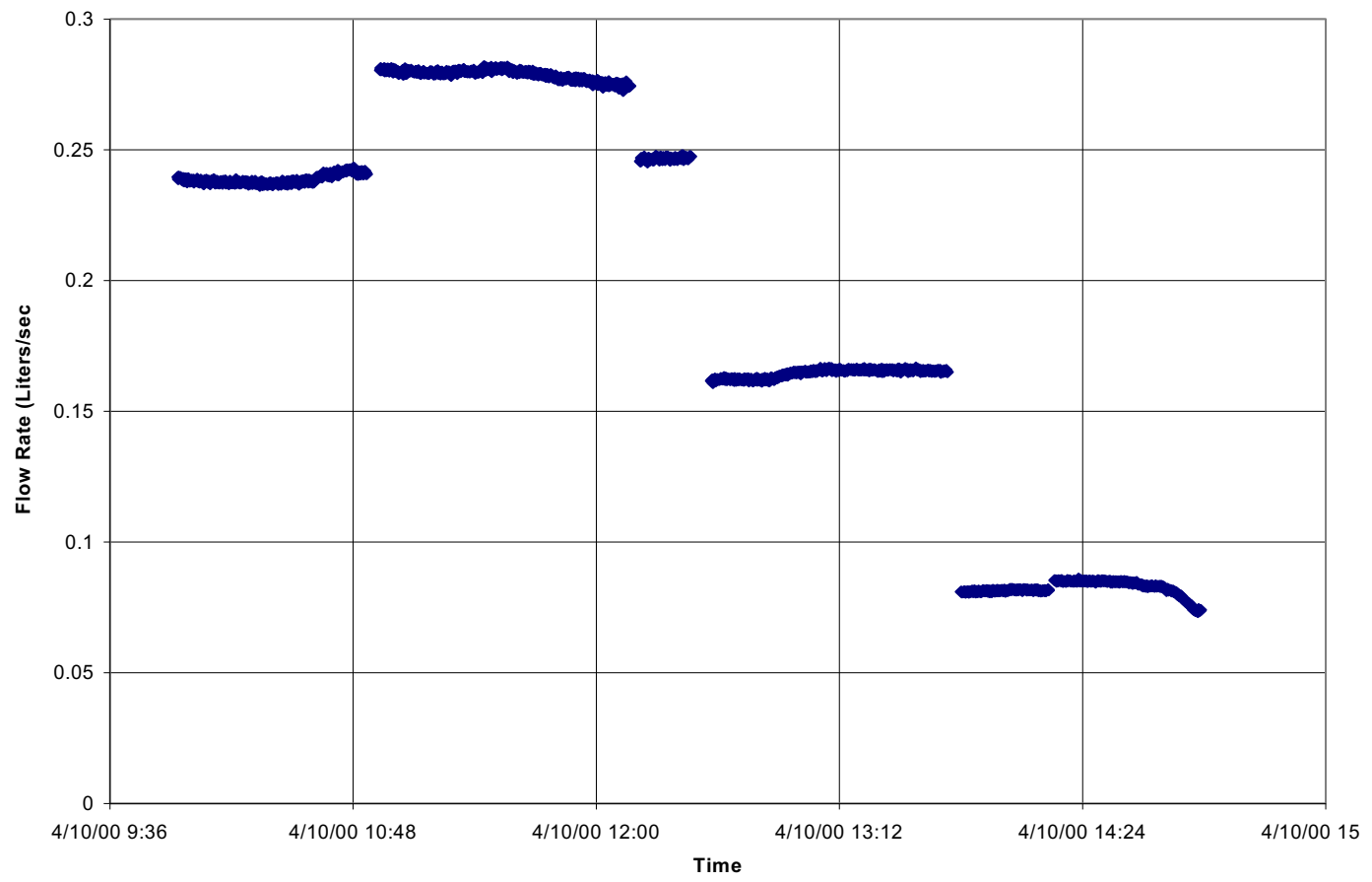

Fig. 12. Flow rate vs time for April 10, 2000 data.

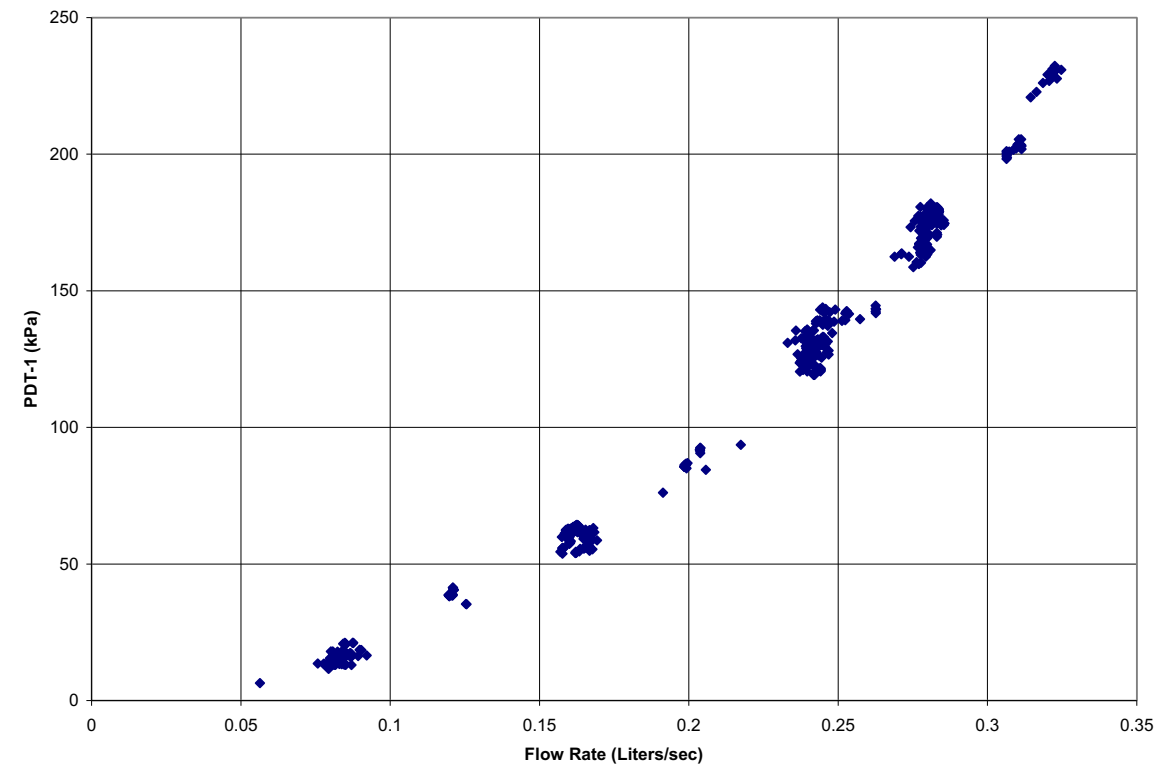

Fig. 13. Test section pressure drop vs flow rate for all test dates. 
Figure 14 shows friction factors with 5-minute averages for all of the test dates. At low Reynolds numbers, the data lie slightly below the Moody Curve for a smooth pipe. Wide scatter is observed, especially at the lower flow rates, even with the 5-minute averaging.

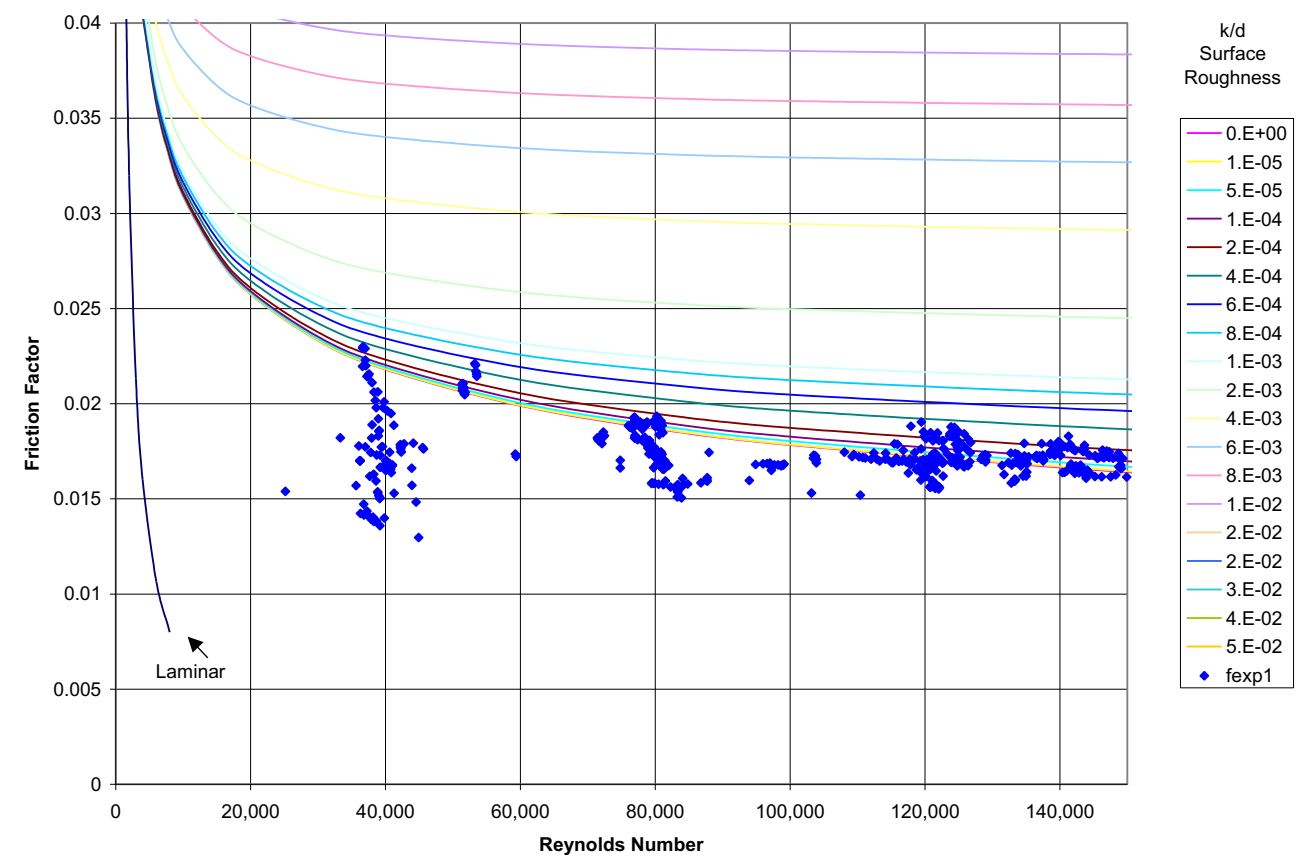

Fig. 14. Comparison of experimental friction factor results with Moody Curve for all test dates; 5-minute averaged PDT-1 data.

The reason for the increased scatter at lower flow rates has not been determined. The flow rate measurement at low flows (e.g., $1 \mathrm{~m} / \mathrm{s}$ ) may have a higher uncertainty from a calibration standpoint since the Venturi flowmeter used to calibrate the EM flowmeter is at the bottom of its range in this case. It should be noted, however, that the EM flowmeter manufacturer's data indicate good agreement at this lower end of the range based on calibration using a lower range Venturi meter. Another potential source for scatter in the data is the effect of changing differential pressure across the relatively thin flow channel walls. Water pressure is used to balance the mercury pressure on the other side of the wall to minimize the imposed stress. Since pressure drop along the water channel is relatively low, the pressure drop along the axial length of the mercury channel at high velocities results in differential pressures across the wall up to $100 \mathrm{kPa}$ in some cases, which could cause changes of a few percent in the flow gap. This effect would be more pronounced at the higher velocities, but this is where the least scatter and best agreement with the Moody Curve are seen. At low velocities, the differential pressure across the wall is much lower and would not be expected to affect the flow gap. In addition, the data do not show any systematic behavior when plotted against the differential pressure across the wall.

Data from later tests show significantly less scatter and a much better match with the Moody Curve at lower velocities. A comparison plot for the tests performed on June 8 and June 26, 2000 is shown in Fig. 15. The reason for this improvement is not clear. A portion of the data for the low velocity cases on June 26 was obtained by running the loop with the bypass line containing the Venturi open. Flow rate to the test section then becomes the difference between the flow measured by the Venturi and the EM flowmeter. Using this method, it was possible to use the Venturi meter in a higher flow range, where the higher uncertainty range at low flows is avoided. This differential flow measurement did result in slightly 
higher calculated friction factors at the lower velocities. However, the friction factor from tests based solely on the EM flowmeter, which are included in the plot, were also higher at the lower velocities than in the previous tests.

The possibility that the improved agreement with the Moody Curve results in later tests could be a function of the SS wall's aging in contact with the mercury has also been considered. In Fig. 16, the friction factor ratio as a function of time is presented for data at the nominal SNS velocity of $3.5 \mathrm{~m} / \mathrm{s}$. The friction factor ratio is determined by dividing the friction factor from the experimental results by the friction factor obtained from the Moody curve for a smooth pipe. The results for this case cover hundreds of hours of continuous exposure time to mercury. These results indicate that the friction factor remains fairly constant with time. A similar comparison is shown for the $2 \mathrm{~m} / \mathrm{s}$ case in Fig. 17, which also shows a limited variation over time.

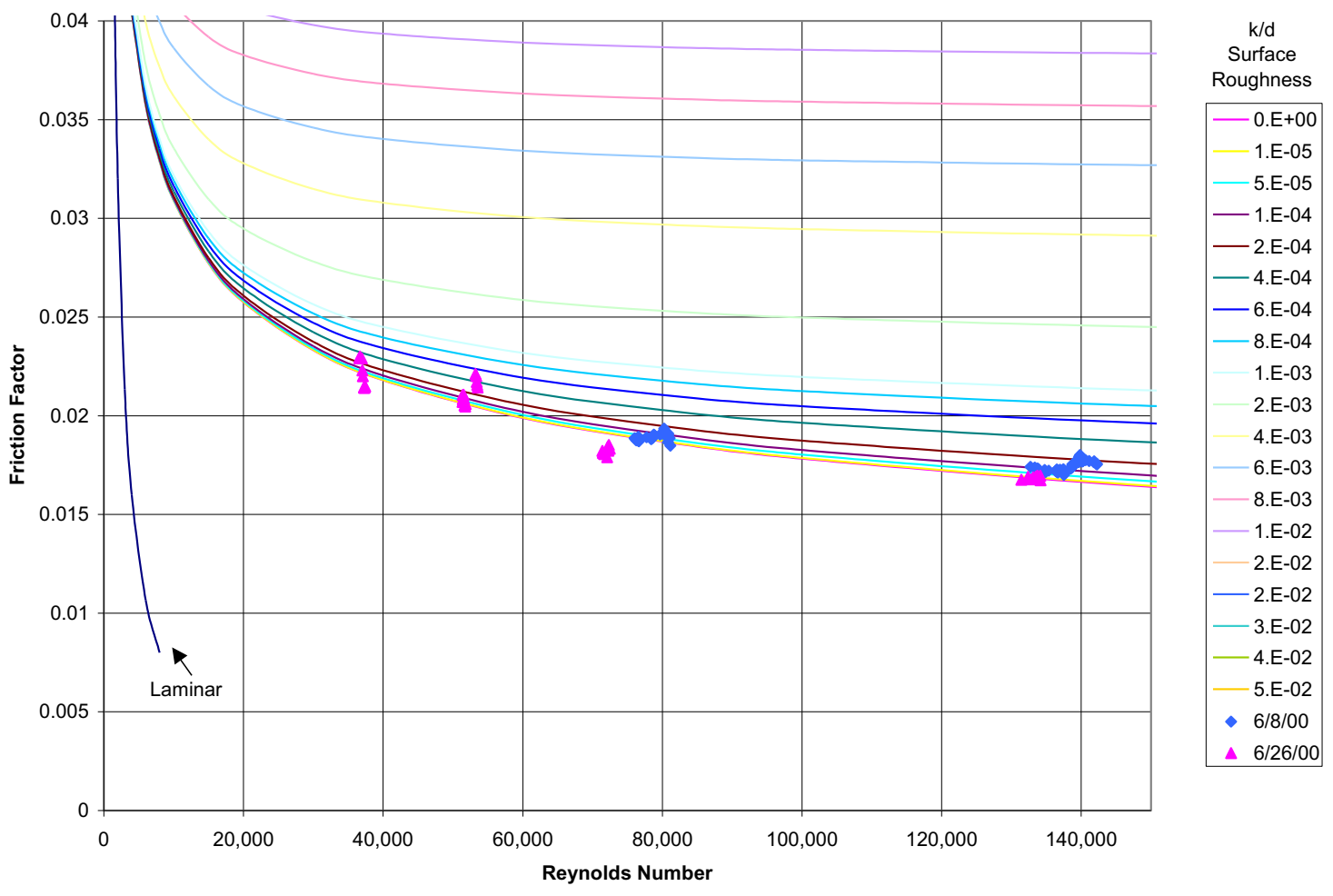

Fig. 15. Comparison of experimental friction factor results with Moody Curve for June 8 and June 26; 5-minute averaged PDT-1 data. 


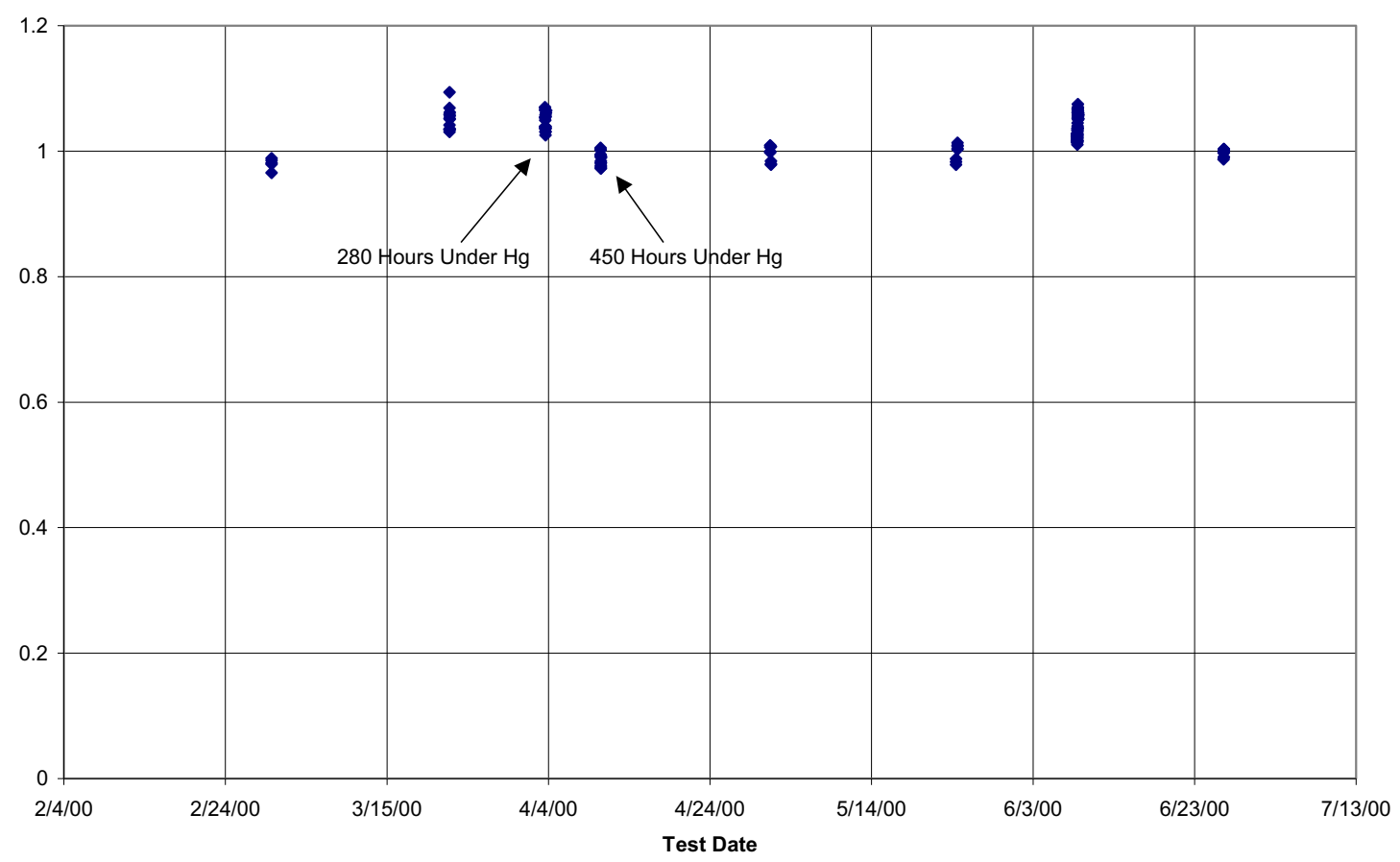

Fig. 16. Friction factor ratio vs test date for $3.5 \mathrm{~m} / \mathrm{s}$ data.

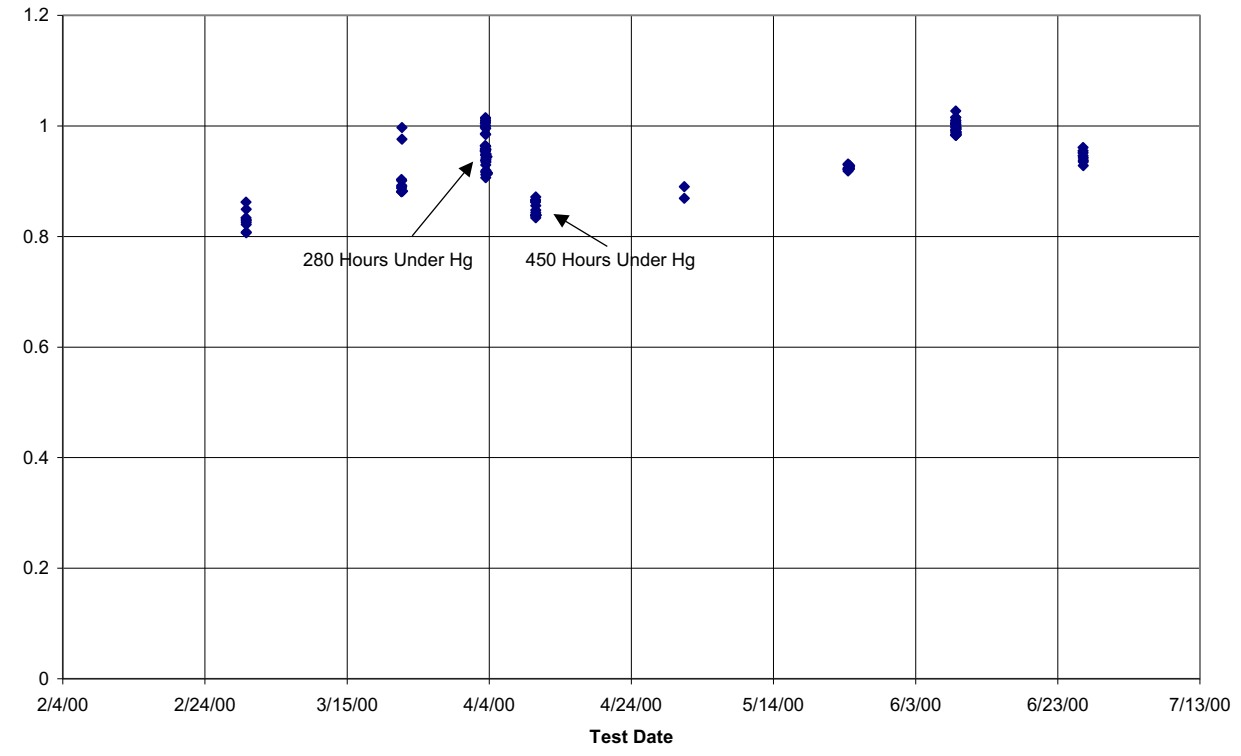

Fig. 17. Friction factor ratio vs test date for $2.0 \mathrm{~m} / \mathrm{s}$ data.

\subsubsection{Wettability Results}

A schematic of the multiple layers used with the TLCs is shown in Fig. 18. A series of calculations was performed to determine the influence of the TLC layers on measurement uncertainty. The thermal conductivity and thickness associated with each layer are shown in Table 2. While the conductivity for the SS is known with relative confidence, the values for the other materials are known with far less certainty. For example, the manufacturer quoted values of $0.16-0.25 \mathrm{~W} / \mathrm{m}-{ }^{\circ} \mathrm{C}$ for the crystals themselves 
and an approximate value of $0.21 \mathrm{~W} / \mathrm{m}-{ }^{\circ} \mathrm{C}$ for the clear coating. For the calculations performed here, the Parylene is assumed to have a thermal conductivity of $0.082 \mathrm{~W} / \mathrm{m}-{ }^{\circ} \mathrm{C}$. The black paint, which contains a significant component of carbon-black, should have a higher conductivity, and an estimated value of 1.5 $\mathrm{W} / \mathrm{m}-{ }^{\circ} \mathrm{C}$ is chosen. This is about one-quarter of the value for carbon-black. The multiple layers contribute significantly to increasing the wall resistance, so the results from these tests are not suitable for heat transfer coefficient calculation given the uncertainty associated with the various thermal conductivities.

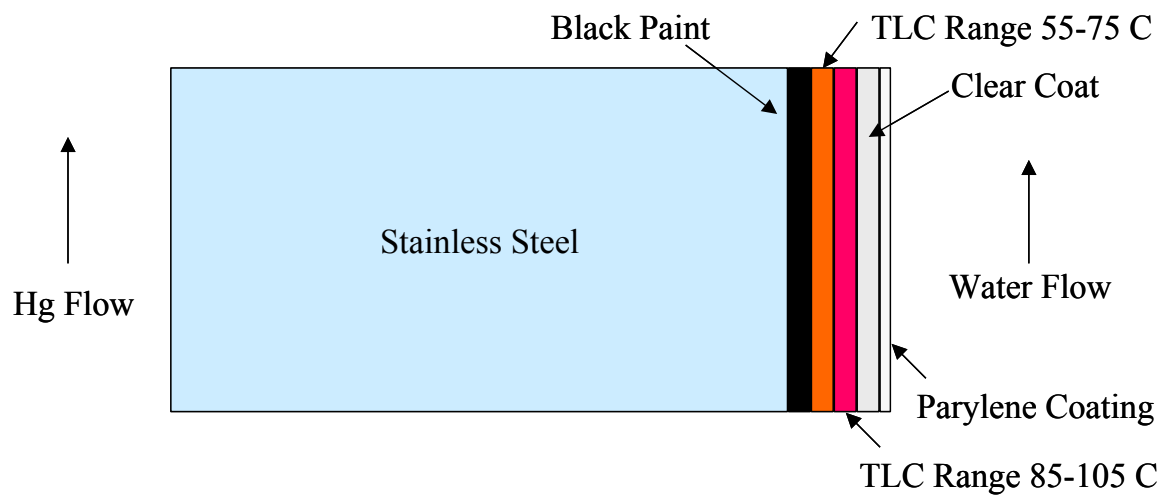

Fig. 18. Multiple layers associated with thermochromic crystal measurement technique.

Table 2. Properties of multiple layers

\begin{tabular}{lcc}
\hline \multicolumn{1}{c}{ Layer } & $\begin{array}{c}\text { Thickness } \\
(\mathbf{m m})\end{array}$ & $\begin{array}{c}\text { Estimated } \\
\text { thermal conductivity } \\
(\text { Watts/(m·K)) }\end{array}$ \\
\hline Parylene & 0.02 & 0.082 \\
Clear coat & 0.04 & 0.21 \\
High-temperature crystals & 0.04 & 0.21 \\
Low-temperature crystals & 0.04 & 0.21 \\
Black paint & 0.04 & 1.5 \\
SS 304 & 0.89 & 14.6 \\
\hline
\end{tabular}

The primary purpose for using the TLCs is to determine the wettability of the SS surface. Here the objective is to determine if local nonwetting regions occur. If they do, the heat transfer coefficient on the mercury side can be expected to decrease significantly and cause a localized decrease in wall temperature. Since heat is driven from the bulk mercury flow to the wall in the test section, a nonwetting region appears as a localized cold spot on the test section wall instead of a localized hot spot as expected in the actual SNS target. An analysis performed by Siman-Tov based on thermal stress considerations indicates that a nonwetting spot in the window cooling channel of the SNS target "cannot be tolerated if it is greater than $7.5 \mathrm{~mm}$ in diameter residing for anything longer than 0.6 seconds." ${ }^{9}$ Considering the relative sensitivity of the liquid crystals to detection of small temperature differences $\left(0.5^{\circ} \mathrm{C}\right)$, the key question is whether a localized cold spot on the inside surface of the SS wall would still be detectable in the low- or high-temperature liquid crystal layer. In this case the relative differences between the localized cold spot and the wetted surroundings is more important than the temperature level. 
Both steady state and transient calculations were performed using the HEATING7 code to evaluate the ability of the TLCs to detect a nonwetting spot $7.5 \mathrm{~mm}$ in diameter. A steady state calculation of a $7.5 \mathrm{~mm}$ diameter nonwetting spot was performed using conductivity values from Table 2 and the operational parameters of Table 5. Results are presented in Fig. 19, which shows radial temperature profiles at different locations within the wall separating the mercury flow channel from the water cooling channel (Fig. 18). Four positions are shown: (1) temperatures in the SS next to the mercury, (2) temperatures at the center of the low temperature crystal layer, (3) temperatures at the center of the high temperature crystal layer, and

(4) temperatures in the Parylene next to the water. This figure also shows the location of the assumed nonwetted spot in the model. The model is extended radially

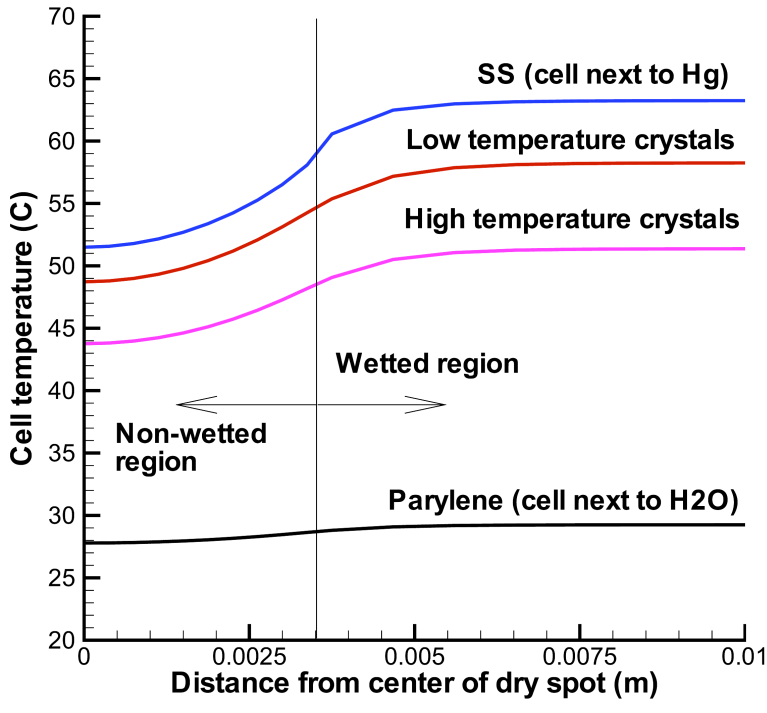

Fig. 19. Steady state radial temperature variation for a $7.5 \mathrm{~mm}$ diameter nonwetted spot. $0.1 \mathrm{~m}$ to ensure that the radial edge of the model (assumed to be insulated) did not impact the temperature calculations in the region of interest. However, only regions of significant radial temperature change are shown in Fig. 19. Results indicate that a $7.5 \mathrm{~mm}$ spot could be easily detected at these conditions, since the temperature difference between the centerline of the nonwetted spot and the wetted portion of the test section would be approximately 8 degrees $\mathrm{C}$. The wetted regions and a portion of the nonwetted spot would be within the active color band of the crystals and the edge of the nonwetted region would therefore be easily discernible.

Transient calculations were also performed to evaluate the time response of the crystals to a transient nonwetted spot. Reference 9 notes that stress limits in the target would be exceeded if a $7.5 \mathrm{~mm}$ spot would exist for 0.6 seconds at the mercury/target surface. The transient calculations were designed to determine if the geometry of the test section would allow detection of this condition. Results of these calculations shown in Fig. 20 are presented as temperature vs. time histories at two locations within the wall that separates the mercury from the water (Fig. 18). The lower curve is at the center of the low temperature crystal layer, and the upper curve is at the SS/mercury interface (radially, both temperatures are located at points on the centerline of the nonwetted spot). In this simulation, the $7.5 \mathrm{~mm}$ nonwetted region was assumed to instantaneously appear at the

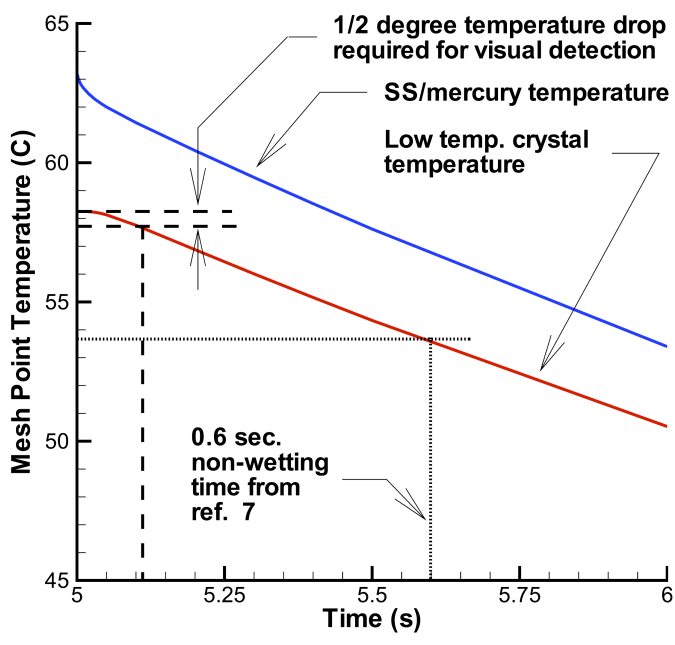

Fig. 20. Time histories of crystal and SS temperatures after a $7.5 \mathrm{~mm}$ diameter nonwetted spot appears at $5 \mathrm{~s}$ of simulation time.

$\mathrm{SS} /$ mercury surface at a simulation time of 5 seconds. Six tenths of a second after the appearance of the nonwetted spot, the temperature at the crystal location decreased approximately $4.5^{\circ} \mathrm{C}$. It is estimated 
that a temperature variation of less than $0.5^{\circ} \mathrm{C}$ can be visually detected in the crystals. Figure 20 indicates that the crystal temperature at the spot centerline would decrease by $0.5{ }^{\circ} \mathrm{C}$ within about 0.1 second after the transient, allowing detection of the nonwetted spot at that time. The test section design is therefore capable of detecting nonwetting regions of the scale and time duration that would cause stress limits to be exceeded in the actual SNS target.

Scoping studies on TLC sensitivity were also performed for an expected experimental range of parameters. For this analysis, it is assumed that the typical nonwetting spot would be $10 \mathrm{~mm}$ in diameter. This configuration represents an area of about 213 pixels. Assuming azimuthal symmetry, a HEATING-7 model was made of the SS wall and the various layers associated with the liquid crystals. A representative heat transfer coefficient of $7,200 \mathrm{~W} / \mathrm{m}^{2}{ }^{\circ} \mathrm{C}$ and a temperature of $24{ }^{\circ} \mathrm{C}$ are used for the water side, as they represent reasonable values for the cases run. For the mercury side, several heat transfer coefficients and temperature levels are explored under steady-state conditions to generate a matrix of cases. This determines the sensitivity of the temperature variation in the thermochromic crystal layers relative to those occurring on the inside of the SS. In these cases, the temperatures and heat transfer coefficients of the mercury and water are assumed, thus avoiding the assumption of constant heat flux. The cases run for scoping studies are shown in Table 3.

Table 3. Comparison of temperatures calculated for both wetting and nonwetting conditions - scoping studies

\begin{tabular}{lcccccc}
\hline Case & $\begin{array}{c}\text { Avg. Hg } \\
\text { Temp. }\left({ }^{\circ} \mathbf{C}\right)\end{array}$ & $\begin{array}{c}\text { Assumed Hg heat } \\
\text { transfer } \\
\text { coefficient in } \\
\text { wetted region** } \\
\left(\mathbf{W} / \mathbf{m}^{2}{ }^{\circ} \mathbf{C}\right)\end{array}$ & $\begin{array}{c}\text { SS temp. in } \\
\text { wetted region } \\
\left({ }^{\circ} \mathbf{C}\right)\end{array}$ & $\begin{array}{c}\text { SS temp. in } \\
\text { nonwetted } \\
\text { region }\left({ }^{\circ} \mathbf{C}\right)\end{array}$ & $\begin{array}{c}\text { Crystal temp. } \\
\text { in wetted } \\
\text { region }\left({ }^{\circ} \mathbf{C}\right)\end{array}$ & $\begin{array}{c}\text { Crystal temp. } \\
\text { in nonwetted } \\
\text { region }\left({ }^{\circ} \mathbf{C}\right)\end{array}$ \\
\hline 1 & 70 & 19,300 & 67.4 & 49.1 & 56.7 & 43.4 \\
2 & 81 & 29,500 & 78.9 & 55.9 & 65.0 & 48.7 \\
$3^{*}$ & 150 & 34,600 & 146.0 & 95.0 & 89.8 & 63.7 \\
4 & 70 & 34,600 & 68.5 & 49.9 & 57.2 & 44.1 \\
$5^{*}$ & 150 & 19,300 & 143.0 & 92.8 & 88.2 & 62.4 \\
6 & 70 & 19,300 & 67.9 & 52.2 & 56.9 & 45.8 \\
7 & 70 & 19,300 & 68.5 & 56.3 & 57.5 & 48.8 \\
\hline
\end{tabular}

Note: Water temperature $24{ }^{\circ} \mathrm{C}$ and water heat transfer coefficient $=7,200 \mathrm{~W} / \mathrm{m}^{2}{ }^{\circ} \mathrm{C}$

* Cases 3 and 5 used the higher temperature crystals where the corresponding crystal layer was further away from the SS wall.

**Heat transfer coefficient in nonwetted region assumed to be zero.

In Table 3, Cases 1 and 3 represent the approximate maximum and minimum ranges in temperature and mercury flow rate (represented by the mercury side heat transfer coefficient) encountered in all the TLC runs. Case 2 is representative of a case at an intermediate flow rate. Cases 4 and 5 represent conditions opposite to Cases 1 and 3. In Cases 1 and 3, the low flow rates correspond to the low mercury temperatures, and the high flow rates correspond to the high mercury temperatures. These cases represent the possible steady state operating conditions attainable with the loop. High flow rates indicate high pump heat values, and it is not possible to experimentally attain steady state cases at low fluid temperatures. Therefore, Cases 4 and 5 represent cases that are not attainable in this loop but are of interest regarding wettability.

The results from Cases 1 to 5 indicate that while the temperature differences (nonwetted to wetted) in the crystal layers would be smaller than the differences at the inside of the SS wall, they are still large enough to be discernible by the thermochromic crystals. For example, for Case 1, a temperature difference of $18.3{ }^{\circ} \mathrm{C}\left(67.4^{\circ} \mathrm{C}-49.1^{\circ} \mathrm{C}\right)$ would have existed between the center of a $10 \mathrm{~mm}$ diameter nonwetting spot 
and the surrounding totally wetted SS. In the lower crystal temperature layer, the same corresponding locations would have yielded a temperature difference of $13.0^{\circ} \mathrm{C}\left(56.4{ }^{\circ} \mathrm{C}-43.4^{\circ} \mathrm{C}\right)$. For Case 5 , representing the same heat transfer coefficient but a higher mercury temperature, the higher temperature range crystals would have been applicable. Here, the SS temperature difference on the inside wall would have been $50.2{ }^{\circ} \mathrm{C}$. The high-temperature range crystals would have registered a temperature difference of $25.8^{\circ} \mathrm{C}$. Indeed, for that case, the wetted region would have been at $88.2^{\circ} \mathrm{C}$, while the nonwetted region, if it had occurred, would have been $62.4^{\circ} \mathrm{C}$. This would have been below the range of applicability of the high-temperature range crystals but within the low-temperature crystal range.

Case 1 results were repeated due to the uncertainty of the thermal conductivities used. In this case, the smallest crystal temperature differences between the wetted and nonwetted regions are calculated. Case 6, therefore, represents a repeat of Case 1, except the thermal conductivities for all materials except the SS were reduced by $25 \%$. In Case 7, they are reduced by $50 \%$ from the values in Case 1 . Cases 6 and 7 indicate temperature differences in the crystals of $11.1^{\circ} \mathrm{C}$ and $8.7^{\circ} \mathrm{C}$, respectively. This shows that while an accurate knowledge of the thermal conductivities is important for correct temperature measurement, it is not necessary for determining the occurrence of wettability. While large decreases in conductivity values result in smaller temperature differences between wetted and nonwetted regions, in all cases, the temperature differences are more than an order of magnitude greater than the resolution of the crystals, which is about $0.5^{\circ} \mathrm{C}$.

A plot of the idealized temperature differences represented by Case 1 is shown in Fig. 21 .

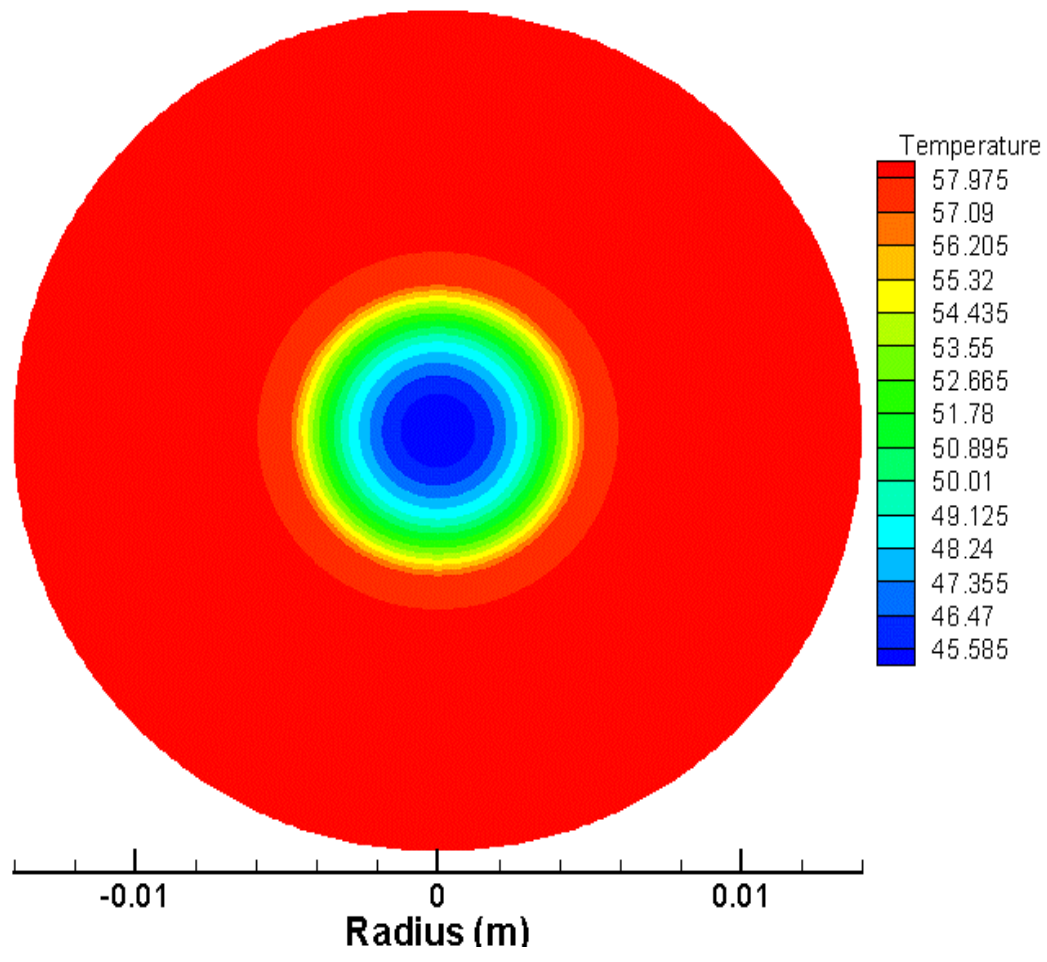

Fig. 21. Ideal temperature differences represented by a $10 \mathrm{~mm}$ diameter circular nonwetting region-Case 1.

The experimental runs conducted where useful TLC results were obtained are summarized in Table 4. During these runs, the TLC colors were continuously observed during both heating up and cooling down phases. In no case were situations encountered in which the lower and higher temperature crystals in 
immediately adjacent areas were visible. However, in the hotter, upstream end of the test section, the high-temperature crystals were sometimes active, while at the cooler downstream end, a dark blue color representing the tail end of the low-temperature range of the lower temperature crystals was still visible.

Figures 22 through 25, show examples of the TLC temperature distributions obtained. The colors in the figures result from the conversion process from TLC hue values to the temperatures used in the contour plots. Nonwetting spot calculations similar to the parametric studies discussed above were also performed for these 4 specific experimental conditions. The operating mercury and water fluid temperatures corresponding to these four pictures are tabulated in Table 5, along with results of the calculations. 
Table 4. Operating parameters for TLC cases

\begin{tabular}{lccc}
\hline Date & $\begin{array}{c}\text { Flow rate } \\
\text { range(L/s) }\end{array}$ & $\begin{array}{c}\text { Average mercury } \\
\text { temperature range }\left({ }^{\circ} \mathbf{C}\right)\end{array}$ & $\begin{array}{c}\text { Number of TLC } \\
\text { images recorded }\end{array}$ \\
\hline $3-22-00$ & $0.081-0.326$ & $80-149$ & 23 \\
$4-3-00$ & $0.070-0.325$ & $70-96$ & 43 \\
$4-10-00$ & $0.081-0.279$ & $70-152$ & 12 \\
\hline
\end{tabular}

Table 5. Comparison of temperatures under both wetting and nonwetting conditions (10 mm diameter nonwetting region), actual TLC cases

\begin{tabular}{|c|c|c|c|c|c|c|c|}
\hline $\begin{array}{l}\text { Date/ } \\
\text { time }\end{array}$ & $\begin{array}{c}\text { Mercury } \\
\text { velocity } \\
(\mathbf{m} / \mathbf{s})\end{array}$ & $\begin{array}{c}\text { Average } \\
\mathrm{Hg} / \mathrm{H}_{2} \mathrm{O} \\
\text { temp. } \\
\left({ }^{\circ} \mathrm{C}\right)\end{array}$ & $\begin{array}{c}\text { Assumed } \\
\mathrm{Hg}^{a} / \mathrm{H}_{2} \mathrm{O} \\
\text { heat transfer } \\
\text { coefficient } \\
\left(\mathrm{W} / \mathrm{m}^{2} \circ \mathrm{C}\right)\end{array}$ & $\begin{array}{l}\text { SS temp. in } \\
\text { wetted region } \\
\left({ }^{\circ} \mathrm{C}\right)\end{array}$ & $\begin{array}{l}\text { SS temp. in } \\
\text { nonwetted } \\
\text { region }\left({ }^{\circ} \mathrm{C}\right)\end{array}$ & $\begin{array}{l}\text { Crystal temp. } \\
\text { in wetted } \\
\text { region }\left({ }^{\circ} \mathrm{C}\right)\end{array}$ & $\begin{array}{l}\text { Crystal temp. } \\
\text { in nonwetted } \\
\text { region }\left({ }^{\circ} \mathrm{C}\right)\end{array}$ \\
\hline $\begin{array}{l}3-22-00 / \\
15: 12\end{array}$ & 1.01 & $65.2 / 24.0$ & $\begin{array}{c}19,356 . / \\
7,225 .\end{array}$ & 62.9 & 46.5 & 55.1 & 42.6 \\
\hline $\begin{array}{l}3-22-00 / \\
16: 21\end{array}$ & 2.06 & $74.0 / 14.7$ & $\begin{array}{c}25,460 . / \\
8320 .\end{array}$ & 71.4 & 47.3 & 56.7 & 39.7 \\
\hline $\begin{array}{l}4-3-00 / \\
11: 04\end{array}$ & 1.98 & $72.7 / 21.0$ & $\begin{array}{c}25,081 . / \\
9,116 .\end{array}$ & 70.4 & 49.2 & 57.4 & 42.6 \\
\hline $\begin{array}{l}4-3-00 / \\
14: 00\end{array}$ & 3.5 & $98.0 / 21.0$ & $\begin{array}{c}31,705 . / \\
8,350 .\end{array}$ & 95.3 & 63.8 & 72.1 & 51.5 \\
\hline
\end{tabular}

${ }^{a}$ Heat transfer coefficient for mercury in nonwetted region is assumed to be zero.

Note: Darkened areas indicate calculated or assumed values.

As the tables illustrate, in all these cases, a difference of greater than $10{ }^{\circ} \mathrm{C}$ is predicted to occur in the TLC layer between the wetted and nonwetted regions. In all cases, no such marked difference was noted during the experiments. In order to examine how small a nonwetting spot could be detected, the calculations were repeated, assuming a nonwetting spot size of $2.5 \mathrm{~mm}$ in diameter. This encompasses an area of about 13 pixels. The results indicate that the temperature differences are still large enough to be discernible by the crystals. These results are presented in Table 6 . In this case, the differences that would have existed in the crystal temperatures between the wetted and nonwetted region range from 1.2 to $2.6^{\circ} \mathrm{C}$, which is still large enough to be detected. 
Table 6. Comparison of temperatures under both wetting and nonwetting conditions (2.5 mm diameter nonwetting region), actual TLC cases

\begin{tabular}{|c|c|c|c|c|c|c|c|}
\hline $\begin{array}{c}\text { Date/ } \\
\text { time }\end{array}$ & $\begin{array}{c}\text { Mercury } \\
\text { velocity } \\
(\mathrm{m} / \mathbf{s})\end{array}$ & $\begin{array}{c}\text { Average } \\
\mathrm{Hg} / \mathrm{H}_{2} \mathrm{O} \\
\text { Temp. } \\
\left({ }^{\circ} \mathrm{C}\right)\end{array}$ & $\begin{array}{c}\text { Assumed } \\
\mathrm{Hg}^{a} / \mathrm{H}_{2} \mathrm{O} \text { Heat } \\
\text { transfer } \\
\text { coefficient } \\
\left(\mathrm{W} / \mathrm{m}^{2}{ }^{\circ} \mathrm{C}\right) \\
\end{array}$ & $\begin{array}{l}\text { SS temperature - } \\
\text { in Wetted } \\
\text { Region }\left({ }^{\circ} \mathrm{C}\right)\end{array}$ & $\begin{array}{l}\text { SS temperature } \\
\text { in nonwetted } \\
\text { region }\left({ }^{\circ} \mathrm{C}\right)\end{array}$ & $\begin{array}{c}\text { Crystal } \\
\text { temperature }- \text { In } \\
\text { wetted region } \\
\left({ }^{\circ} \mathbf{C}\right)\end{array}$ & $\begin{array}{c}\text { Crystal } \\
\text { temperature in } \\
\text { nonwetted } \\
\text { region }\left({ }^{\circ} \mathrm{C}\right)\end{array}$ \\
\hline $\begin{array}{c}3-22-00 / \\
15: 12\end{array}$ & 1.01 & $65.2 / 24.0$ & 19,356. / 7,225. & 62.9 & 60.1 & 55.0 & 53.8 \\
\hline $\begin{array}{c}3-22-00 / \\
16: 21\end{array}$ & 2.06 & $74.0 / 14.7$ & $25,460 . / 8320$ & 71.4 & 67.3 & 56.7 & 55.0 \\
\hline $\begin{array}{c}4-3-00 / \\
11: 04\end{array}$ & 1.98 & $72.7 / 21.0$ & $25,081 . / 9,116$ & 70.4 & 66.8 & 57.4 & 56.0 \\
\hline $\begin{array}{c}4-3-00 / \\
14: 00\end{array}$ & 3.5 & $98.0 / 21.0$ & $31,705 . / 8,350$ & 95.3 & 90.1 & 72.1 & 70.1 \\
\hline
\end{tabular}

${ }^{a}$ Heat transfer coefficient for mercury in nonwetted region is assumed to be zero.

Note: Darkened areas indicate calculated or assumed values.

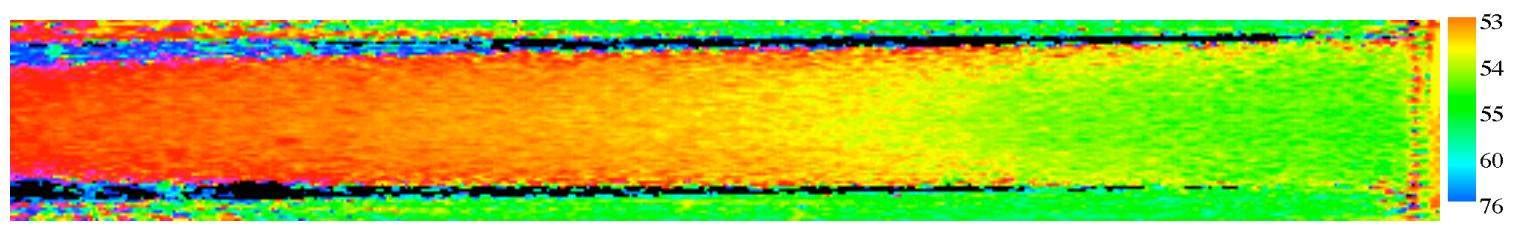

Fig. 22. TLC image on March 22, 2000 at 15:12.

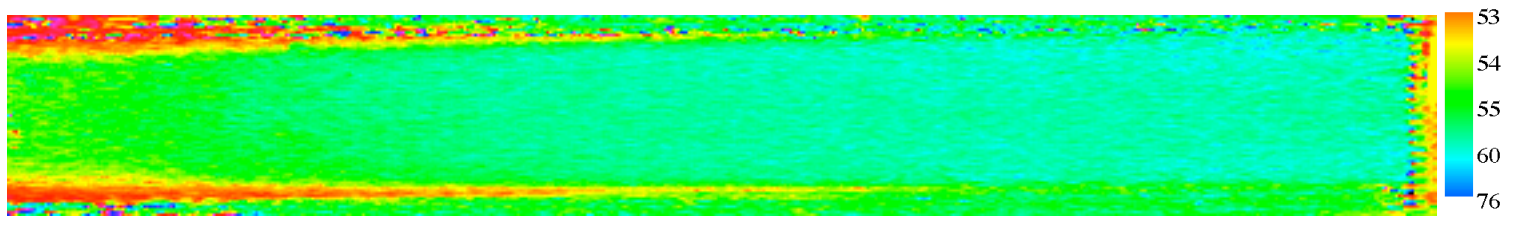

Fig. 23. TLC image on March 22, 2000 at 16:21.

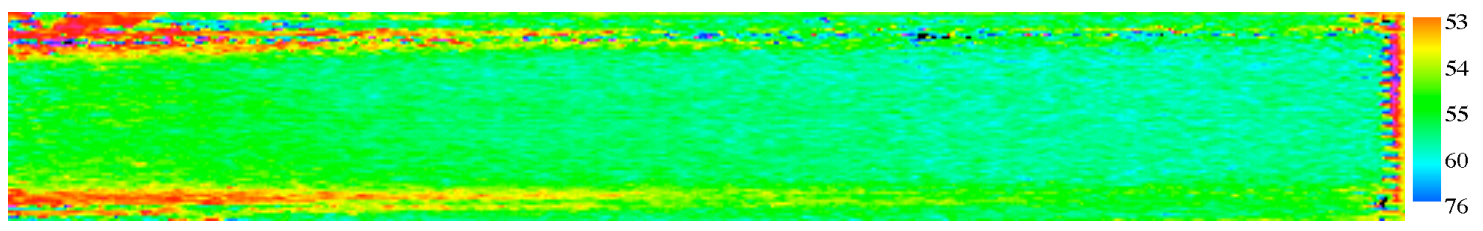

Fig. 24. TLC image on April 3, 2000 at 11:04.

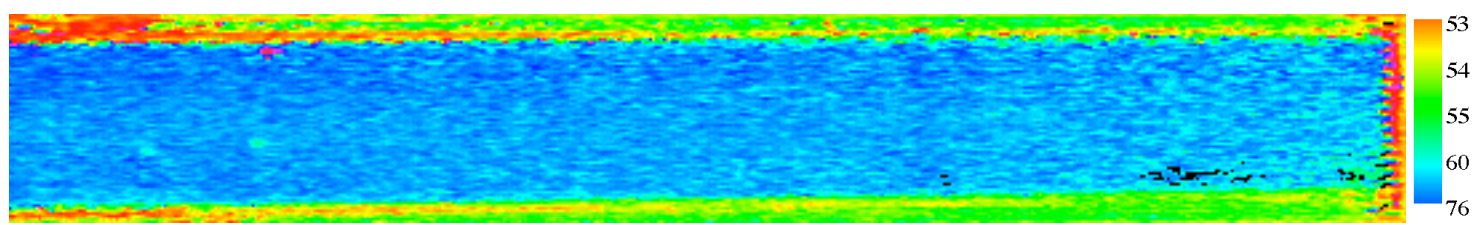

Fig. 25. TLC image on April 3, 2000 at 14:00.

The examples shown represent a relatively large number of images captured during the tests described above. None of the visual images observed showed distinctive regions indicating differences sufficient to 
imply nonwetting regions. The best image data were observed in the lower temperature range of the crystals: the red, yellow, and early green colors as viewed directly from the crystal surface. The images shown above were converted from RGB to hue and then were converted to temperature maps on a pixelby-pixel basis. Some noise (pixel-to-pixel variation) was noticed in these converted images that was not observed visually; this became more pronounced as the crystal colors transitioned to the darker greens and into the blue color range. This was thought to be partially due to effects of reflections in the lighting. Some noise effect can also be seen in the images captured during the in-place calibration where there were spatial temperature variations.

\subsubsection{Heat Transfer Results}

The main goal for the water-cooled test section was to visually observe the SS surface to attempt to detect regions of nonwettability using TLCs. To further enhance the usefulness of this test section, experiments using a phosphor coating on the water side were initiated on May 1, 2000. The date of these runs, flow rate, temperature range, and the number of phosphor readings recorded are given in Table 7.

Table 7. Summary of heat transfer coefficient test cases

\begin{tabular}{lccc}
\hline Date & $\begin{array}{c}\text { Flow rate } \\
\text { range(L/s) }\end{array}$ & $\begin{array}{c}\text { Avg. mercury } \\
\text { temperature range }\left({ }^{\circ} \mathbf{C}\right)\end{array}$ & $\begin{array}{c}\text { Number of phosphor } \\
\text { temperature readings } \\
\text { recorded }\end{array}$ \\
\hline $5-1-00$ & $0.087-0.278$ & $45-109$ & 32 \\
$5-24-00$ & $0.087-0.312$ & $75-115$ & 48 \\
$6-8-00$ & $0.159-0.284$ & $60-99$ & 78 \\
\hline
\end{tabular}

As mentioned earlier, phosphor temperature readings were taken using sensors located at two axial locations along the north face of the test section. For the runs on May 1 and 24, the two sensors were located $140 \mathrm{~mm}$ upstream from the axial center of the test section and $140 \mathrm{~mm}$ downstream from the axial center. For the test on June 8, one sensor was located at the axial center, and one was located $140 \mathrm{~mm}$ downstream from the axial center. During these runs, improvements were made in the binder used to apply the phosphor and in the calibration technique used for the phosphor measurement. For the calibration, the sensor and a test coupon with the same phosphor and binder that was sprayed on the test section wall were immersed in the water of a controlled temperature bath. The sensor was located to reproduce the distance through the water that the actual test conditions impose. Phosphor fluorescence decay data were taken at bath temperature intervals throughout the expected wall temperature range, and a curve fit was obtained for reducing the phosphor fluorescence decay rate to temperature.

Results of the tests conducted on June 8 reflect the continuous improvement in the phosphor temperature technique, and the analysis is focused on these data. The phosphor coating was approximately half the thickness of the previous coating layers $(0.013 \mathrm{~mm})$, and the new phosphor has better resolution over the range of operating conditions. A CFD model is used as the basis for analysis of the results. To obtain reasonable estimates of heat transfer coefficients, the bulk fluid temperatures and local heat fluxes at the phosphor temperature locations must be determined. This requires modeling of heat losses and other parameters affecting the heat distribution along the test section.

A steady-state 3-D CFD model of the MTHL's test section region was created and analyzed for two cases corresponding to loop conditions when phosphor data were recorded: one at $3.5 \mathrm{~m} / \mathrm{s}$, and one at $2.0 \mathrm{~m} / \mathrm{s}$ test section velocity. The water, the SS structure, and the mercury are all modeled. The commercial code CFX4.3, developed by AEA Technology, was employed in the analysis using an eddy viscosity turbulence model. Symmetry was assumed in the model. The model includes the mercury, SS, and water 
regions, and it accounts for the heat flow that does not pass through the $0.89 \mathrm{~mm}$ thick channel wall region.

Calculations were performed on the DEC 4100 Personal Workstation. The RNG k-epsilon turbulence model is invoked with standard wall functions. The assumed turbulent Prandtl number is 3.1 for the mercury and 0.9 for the water. The model contains 498,198 control volumes, and it required approximately 2 days of computational effort for convergence.

Using the measured water and mercury flow rates and the water and mercury inlet temperatures, a steadystate converged solution was obtained. The results could then be compared with other measured quantities, such as total heat exchange between the mercury and water, phosphor temperatures, and pressure drop. Heat transfer through the thin wall portion of the channel is approximately $80 \%$ for both cases.

A comparison of the bulk mercury temperature, mercury-side wall temperature, and phosphor layer wall temperature as a function of the axial position along the channel is shown in Fig. 26. The measured phosphor layer temperatures are shown overlaid on the CFD model results. The measured temperatures show reasonable agreement with the predicted value and good agreement with the slope of the axial profile. The results are conservative from a heat transfer standpoint in that the heat transfer across the mercury/SS interface would need to be increased to raise the predicted water-side wall temperature to match the measured temperatures. 


\section{$3.5 \mathrm{~m} / \mathrm{s}$ Mercury Flow}

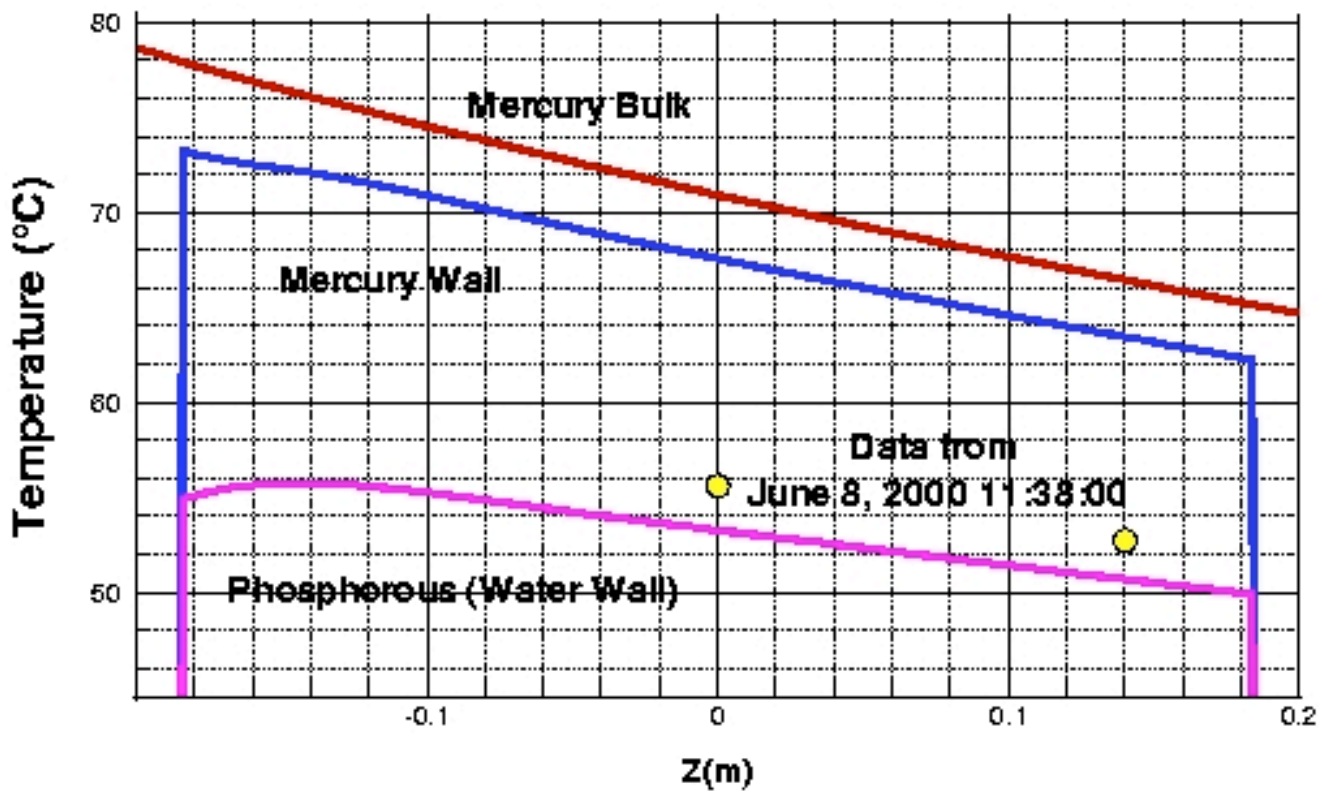

$2.0 \mathrm{~m} / \mathrm{s}$ Mercury Flow

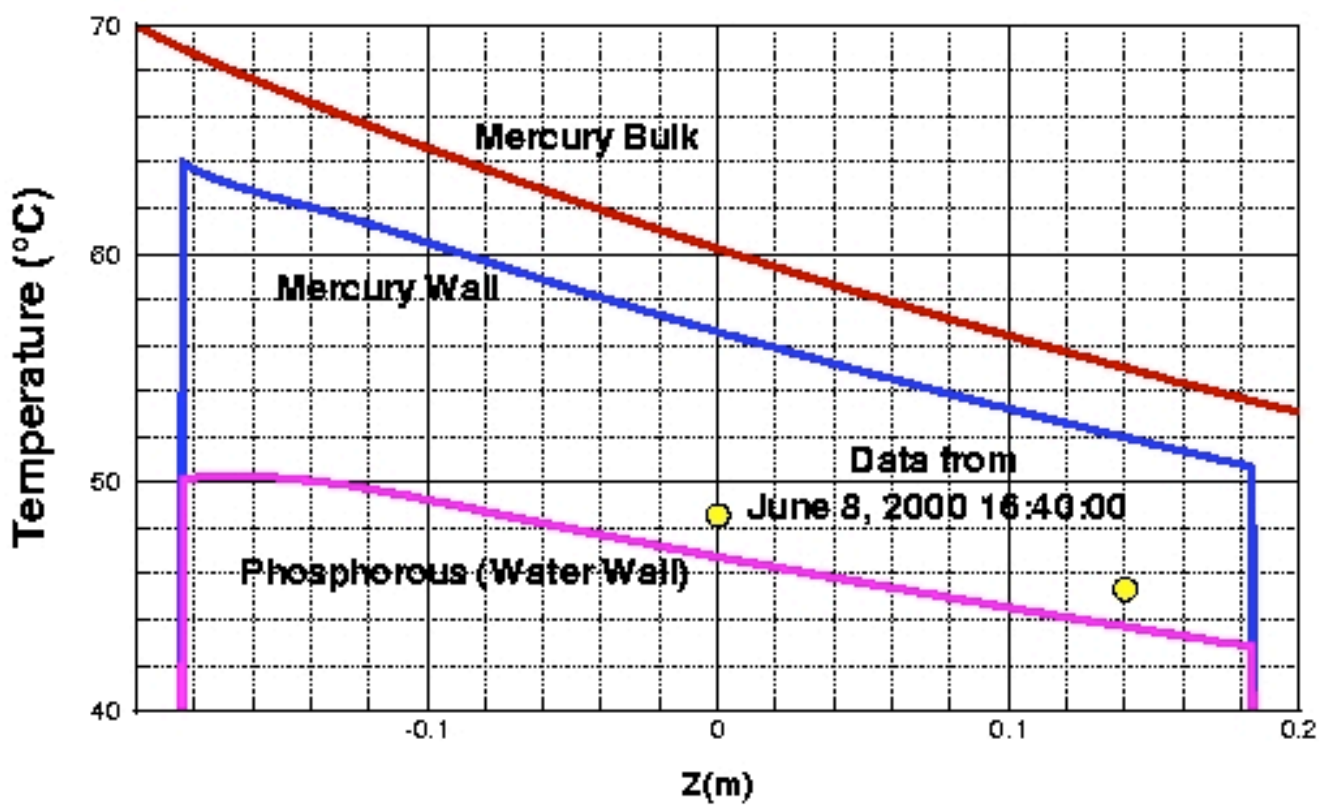

Fig. 26. Comparison of phosphor temperature measurements with CFD model results for 2 and $3.5 \mathrm{~m} / \mathrm{s}$ mercury velocity cases.

Analysis of the heat transfer coefficients for the phosphor measurements indicates $N u$ numbers above the wetted design correlation values. This analysis uses results from the CFD model to provide estimates of the bulk fluid temperature and heat flux profiles along the axial length of the test section. Results obtained at the axial centerline sensor are shown in Fig. 27. This plot shows the calculated $N u$ values for the phosphor temperature data of June 8 compared with liquid metal data from the literature. Axial profile shapes from the CFD cases are used for calculating bulk fluid temperatures and heat flux at the phosphor 
sensor location to calculate the $N u$ numbers. Uncertainties in the calculated heat transfer coefficients are dominated by the small film temperature drop on the mercury side in comparison to the temperature drops through the SS wall and phosphor layer. These values are not considered as reliable as those presented in the next section from the electrically heated test section due to the complexities associated with the watercooled test section design.

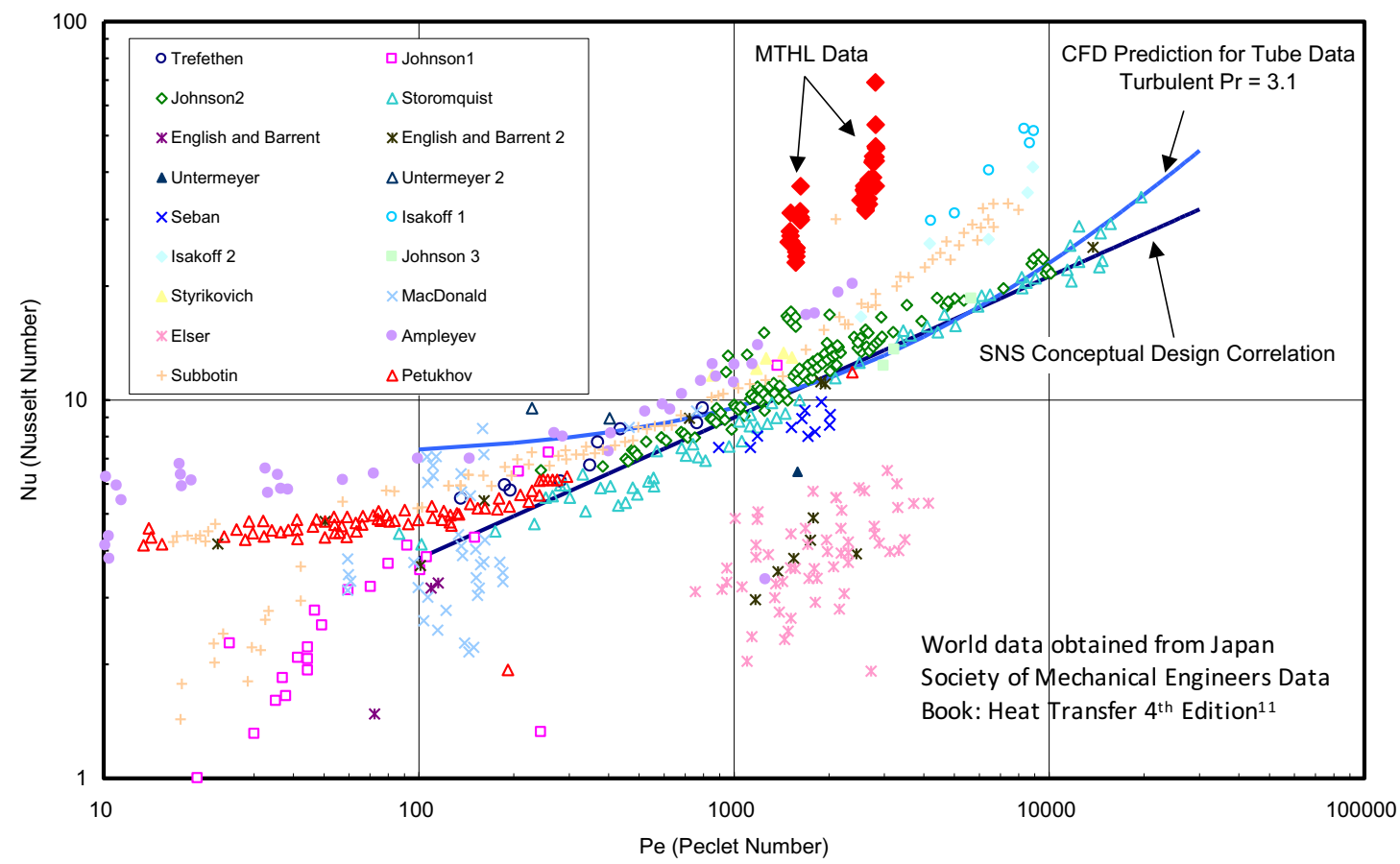

Fig. 27. Experimental Nusselt numbers obtained using phosphor temperature measurement technique. 


\section{ELECTRICALLY HEATED (STRAIGHT) TEST SECTION}

The electrically heated test section provides a more straightforward design for determining heat transfer coefficients. A copper heater block is brazed to the back of the flat SS channel wall to provide a known heat flux into the flowing mercury. The heater is designed to produce up to $1.2 \mathrm{MW} / \mathrm{m}^{2}$ at the mercury/SS interface. A schematic drawing of the test section is shown in Fig. 28.
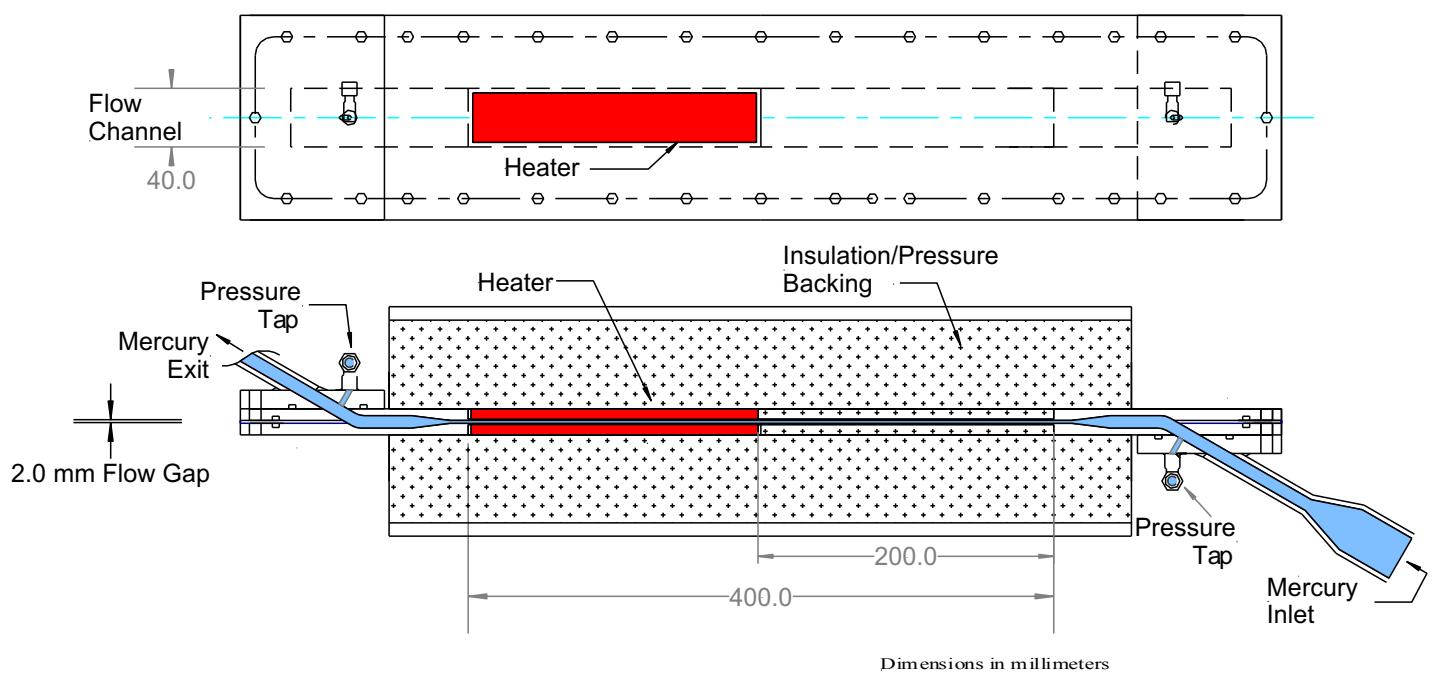

Fig. 28. MTHL electrically heated test section design.

The test section is machined from $316 \mathrm{SS}$ stock and has a rectangular mercury flow cross section of $2 \mathrm{~mm}$ gap by $40 \mathrm{~mm}$ wide and is $\sim 400 \mathrm{~mm}$ long. The mercury flow channel portion of the test section is identical to that of the water-cooled test section described previously and is created using the same shim plate and transition components.

To produce a heated region along the flow channel, a $400 \mathrm{~mm}$ long by $40 \mathrm{~mm}$ wide pocket is machined in the back of the channel plates in order to reduce the thickness of the channel wall to $1.27 \mathrm{~mm}$. A heater comprised of a copper block with miniature heater cables is brazed into a $1.8 \mathrm{~mm}$ deep pocket on the top of a copper block that is $200 \mathrm{~mm}$ long $\times 36 \mathrm{~mm}$ wide $\times 5 \mathrm{~mm}$ thick. The heater blocks were fabricated by the Delta M Corporation and are designed to produce a heat flux of $1.2 \mathrm{MW} / \mathrm{m}^{2}(8.7 \mathrm{~kW}$ each $)$. The $3.2 \mathrm{~mm}$ of copper between the heater cables and the SS acts as a high conductivity thermal diffuser to produce a uniform heat flux at the copper/SS interface. Thermocouples are installed in $0.89 \mathrm{~mm}$ grooves machined in the bottom of the copper plate. The copper heater block with thermocouples installed is then brazed as a unit onto the downstream $200 \mathrm{~mm}$ of the SS channel plate. The thermocouple leads can be observed running along the far edge of the heater block in Fig. 29. The larger heater power leads can be seen at the two ends of the heater. A diagram of the heater dimensions and the locations of the thermocouples is shown in Fig. 30. The junctions of the Inconel-sheathed $0.8 \mathrm{~mm}$ diameter type $\mathrm{K}$ thermocouples are located along the span-wise centerline. 


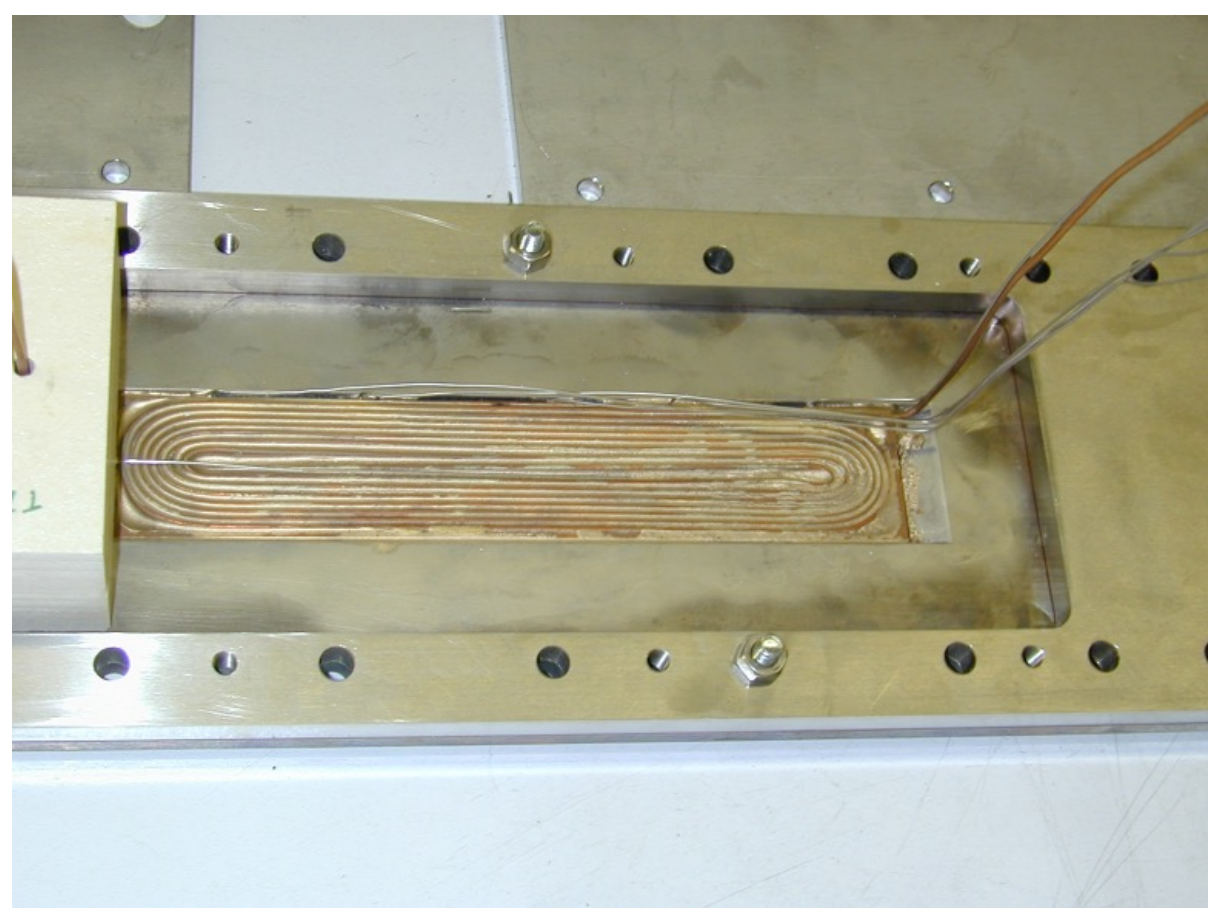

Fig. 29. Heater block installed in the channel plate.

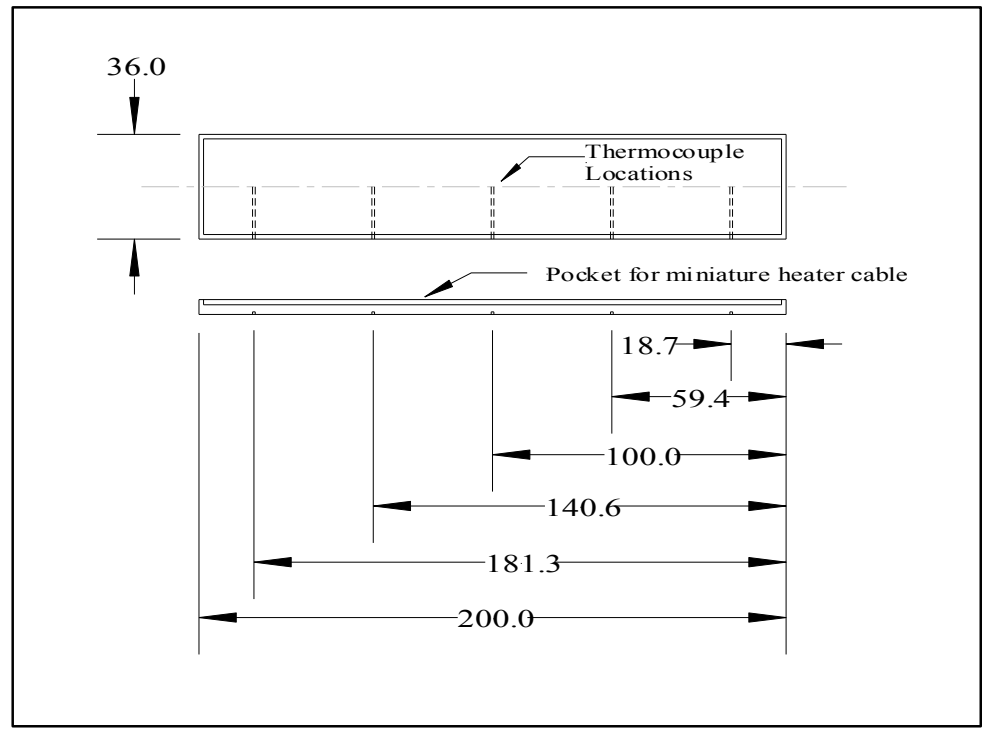

Fig. 30. Schematic of heater block showing thermocouple locations.

Rigid ceramic plates are installed over the thin-walled region of the channel plates, along with a supporting SS backing plate. Along with the thermal insulating properties, the plates provide pressure backing support for the relatively thin wall regions of the channel. These components are shown in Figs. 31 and 32 during test section assembly. A photograph of the test section assembly installed in the loop is shown in Fig. 33. In addition to the rigid insulation, the entire test section region from the inlet mercury temperature measurement location to the outlet temperature location was insulated as shown in Fig. 34. 


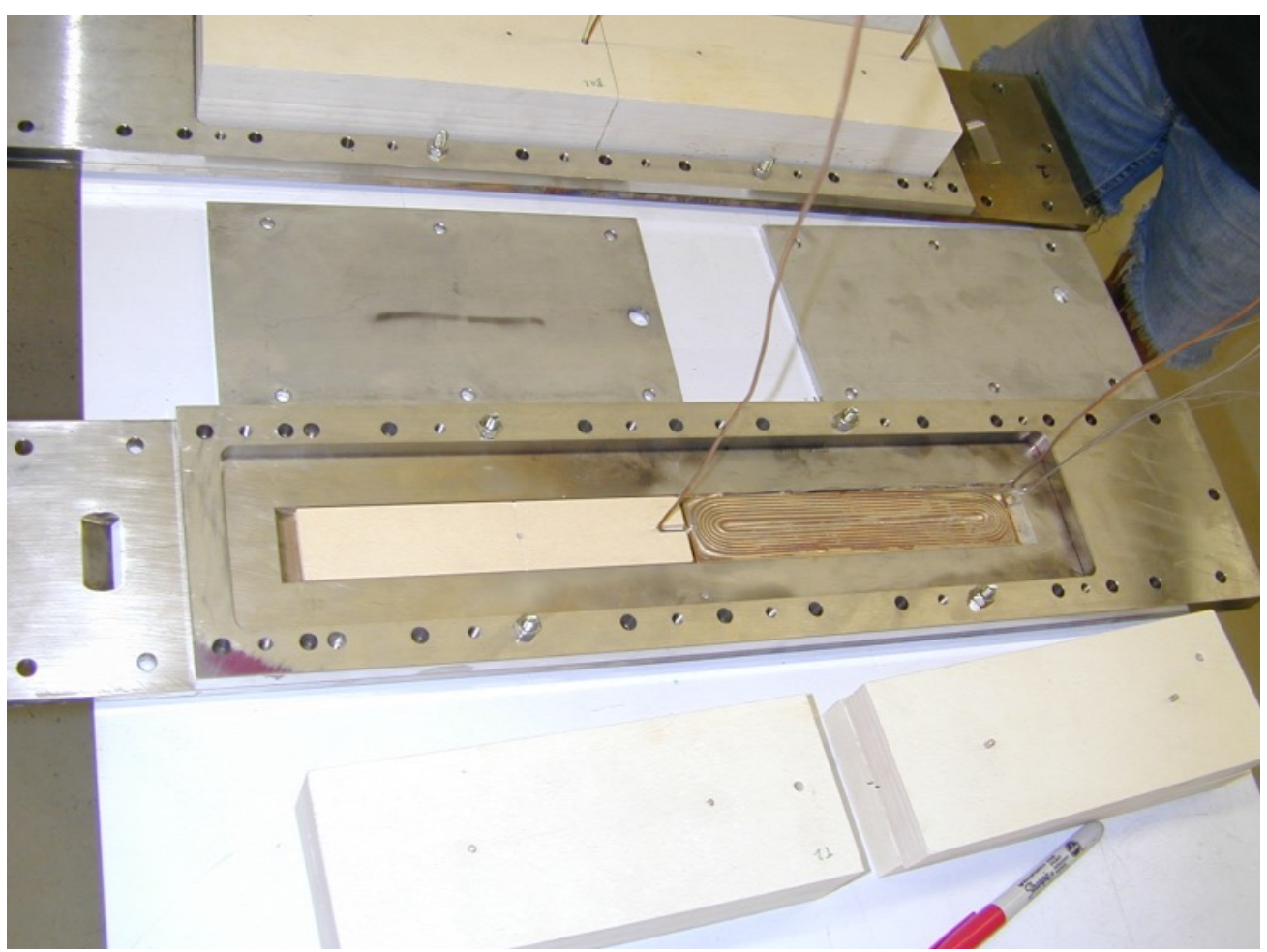

Fig. 31. Test section during installation of rigid insulation.

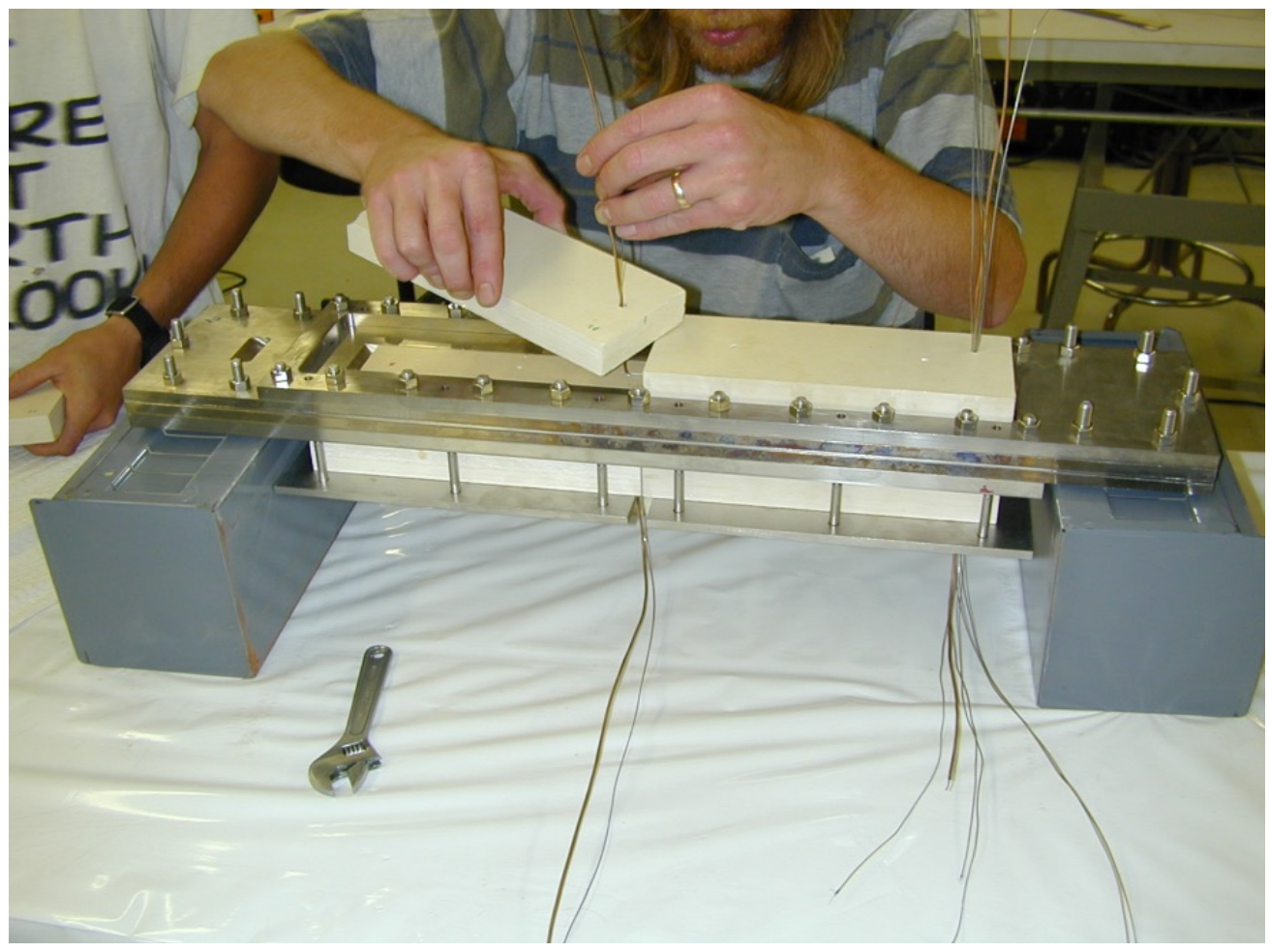

Fig. 32. Heater leads being fed through rigid insulation during test section assembly. 


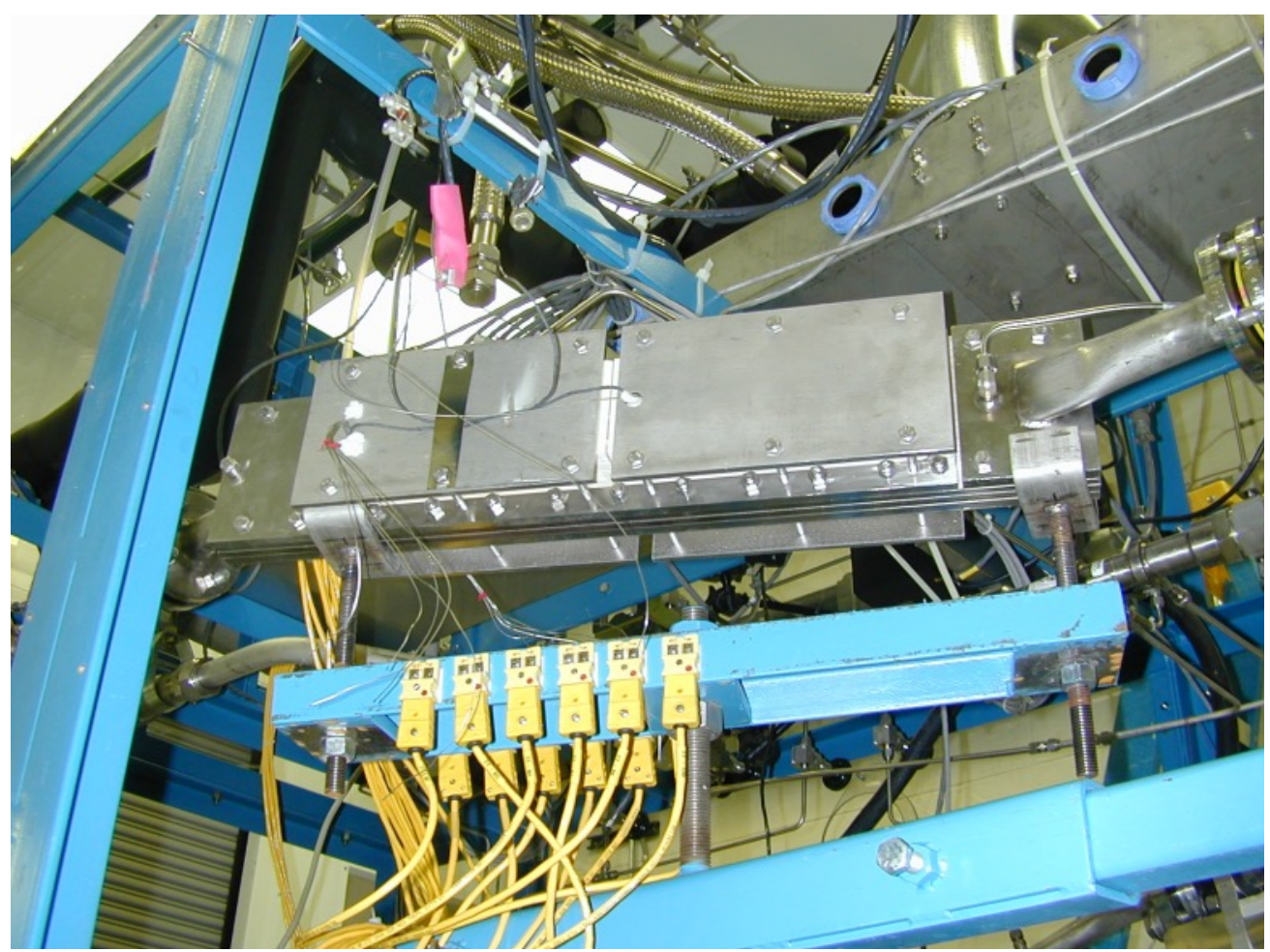

Fig. 33. Electrically heated test section installed in the MTHL.

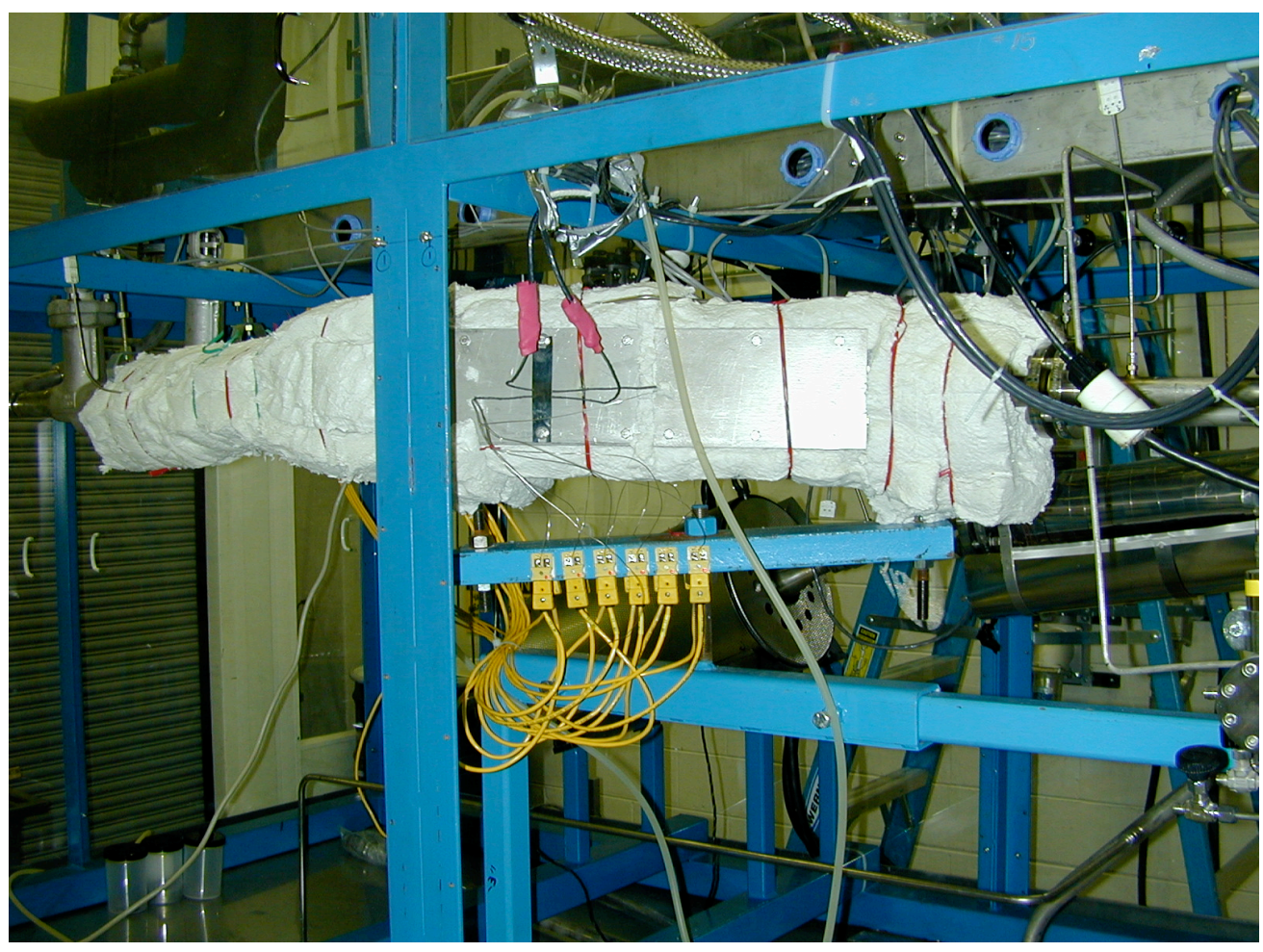

Fig. 34. Test section shown with wrapped insulation. 


\subsection{DATA ANALYSIS METHODS AND RESULTS FOR STRAIGHT HEATED TEST SECTION}

\subsubsection{Heat Transfer Analytical Analysis}

The bulk temperature of the mercury is established at each of the five thermocouple locations in the test section via an energy balance on the portion of the test section exposed to the heaters. In establishing the bulk temperature, all heat produced by the heaters is assumed to enter the fluid. With the bulk temperature known, the temperature at the mercury/SS interface is determined from the temperature reading of the thermocouple and Fourier's law of heat conduction. In one dimension, Fourier's law of heat conduction is expressed as

$$
q^{\prime \prime}=-k \frac{d T}{d x}
$$

where $q^{\prime \prime}$ is the heat flux, $k$ is the thermal conductivity of the SS wall, and $\frac{d T}{d x}$ is the change in temperature with respect to depth in the wall. To determine the heat flux in the equation, the heater power (heater voltage multiplied by current) is divided by the area available for heat transfer. Since the thermal conductivity of the SS wall varies with depth due to the change in temperature, an iterative procedure is used to obtain the average thermal conductivity in the wall. The heat transfer coefficient is found from

$$
q^{\prime \prime}=h\left(T_{\text {Wall }}-T_{\text {Bulk }}\right),
$$

where $h$ is the heat transfer coefficient, $T_{\text {Wall }}$ is the temperature at the mercury/SS interface, and $T_{B u l k}$ is the bulk mercury temperature. Furthermore, the Nusselt number is defined as:

$$
N u=\frac{h \cdot D}{k}
$$

where $N u$ is the Nusselt number, $D$ is the hydraulic diameter, and $k$ is the thermal conductivity of mercury. This procedure is performed for each thermocouple location on both sides of the test section.

\subsubsection{Heat Transfer CFD Analysis}

The above analysis only accounts for conduction in one-dimension (1-D) and does not consider the variation in heat flux from axial conduction and edge effects. The heat flux used in the analysis must also be adjusted for the as-fabricated interface of the copper heater block with the SS channel wall. The width of the copper plate is $36 \mathrm{~mm}$, but the mercury flow channel and thin-walled region of the SS is $40 \mathrm{~mm}$ wide. Although the original intent was to install insulation in the $2 \mathrm{~mm}$ gap on the sides of the copper block, the brazing process resulted in braze material filling this region to various degrees. To improve the estimate of the heat flux at the thermocouple locations affected by both axial conduction and edge effects, the test section was parametrically analyzed using the CFD code CFX. This is the same CFD code being used in the design of the SNS, so the comparison of model results with the experimental measurements also provides additional benchmarking of the code.

In analyzing the effect of the copper heater block interface, three scenarios were modeled to bound the conduction interface variation. Figure 35 shows one limiting scenario in which an adiabatic boundary condition is assumed at the edge of the copper plate. In Fig. 36, the $2 \mathrm{~mm}$ gap is assumed to be filled with copper, giving the copper plate the same width as the SS and mercury channel. In the third scenario, the test section is modeled so that the gap is only partially filled with copper, as shown in Fig. 37. This case is assumed to be the best estimate test section geometry. 


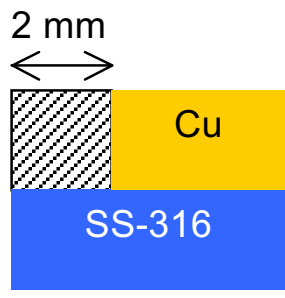

Fig. 35. Adiabatic boundary condition model.

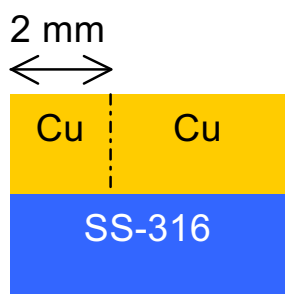

Fig. 36. Gap completely filled model.

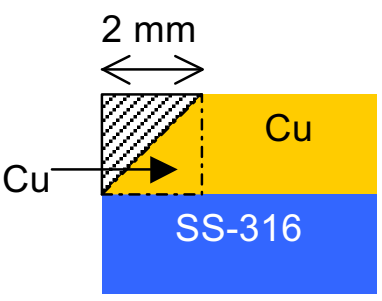

Fig. 37. Gap partially filled model.

Several cases were modeled using the CFD code covering a velocity range of 1 to $4 \mathrm{~m} / \mathrm{s}$. In these analyses, CFD input includes the velocity of the mercury, the inlet mercury temperature, and the power supplied to the heaters. A comparison of the experimental results and the CFD model results is shown in Figs. 38-40 for a test condition at $3.5 \mathrm{~m} / \mathrm{s}$, which is the current nominal SNS velocity at the minimum gap in the window cooling channel. These comparisons represent other velocity conditions examined. The three cases at this velocity correspond to the three heater interface cases presented earlier. Model results are presented as solid lines in the figure, whereas experimental results are plotted as point values at the axial thermocouple locations. The CFD model-predicted axial heat flux distribution along the span-wise centerline is shown in the bottom plot of each figure. The uncorrected heat flux for this test conditionassuming a $200 \mathrm{~mm}$ by $36 \mathrm{~mm}$ heater-is $840,000 \mathrm{~W} / \mathrm{m}^{2}$. For the three brazing scenarios assumed, the heat flux is nominally reduced by $3.5 \%$ (Fig. 35), 7\% (Fig. 36) and 6\% (Fig. 37), from the uncorrected values in the relatively flat portion of the axial heat flux profile (Table 8). The local heat flux is predicted to be higher than average at the entrance and lower than average at the exit of the heater region in the test section as shown in Fig. 38.

The upper plots in Figs. 38 through 40 show the CFD prediction for bulk fluid temperature, mercury/SS wall interface temperature, and the temperature at the SS/copper block interface (assumed thermocouple location) are shown as solid lines. The points labeled "Experiment - Wall" are calculated from the 1-D analysis with the heat flux adjusted based on the appropriate values from Table 8 for each case. The points labeled "Experiment - TC" are the temperatures given by the thermocouples, and the bulk temperatures calculated from the energy balance are labeled "Calculated - Bulk." These figures show that the CFD model reasonably predicts experimentally measured temperatures. 

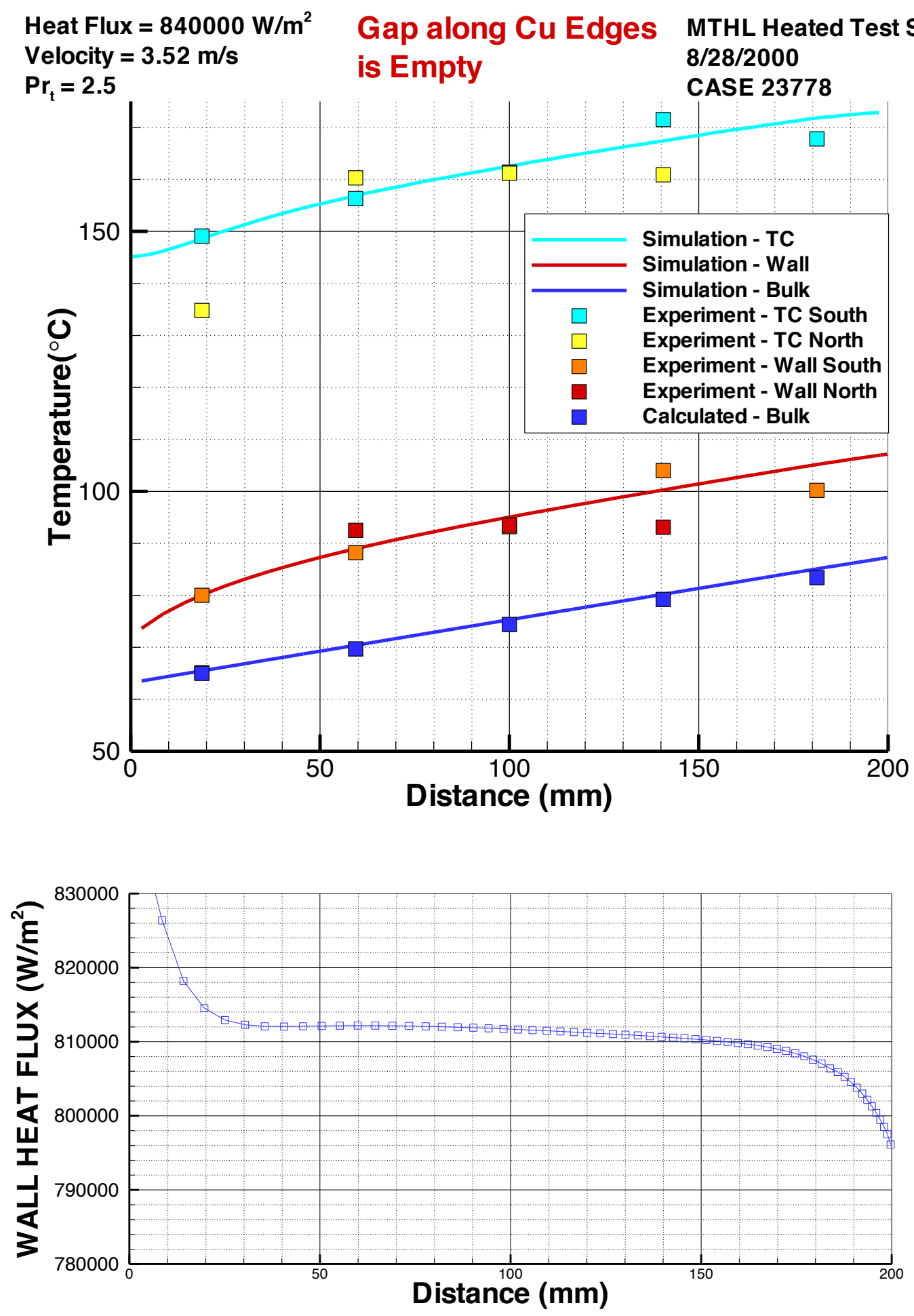

Fig. 38. CFD results from adiabatic boundary condition model. 

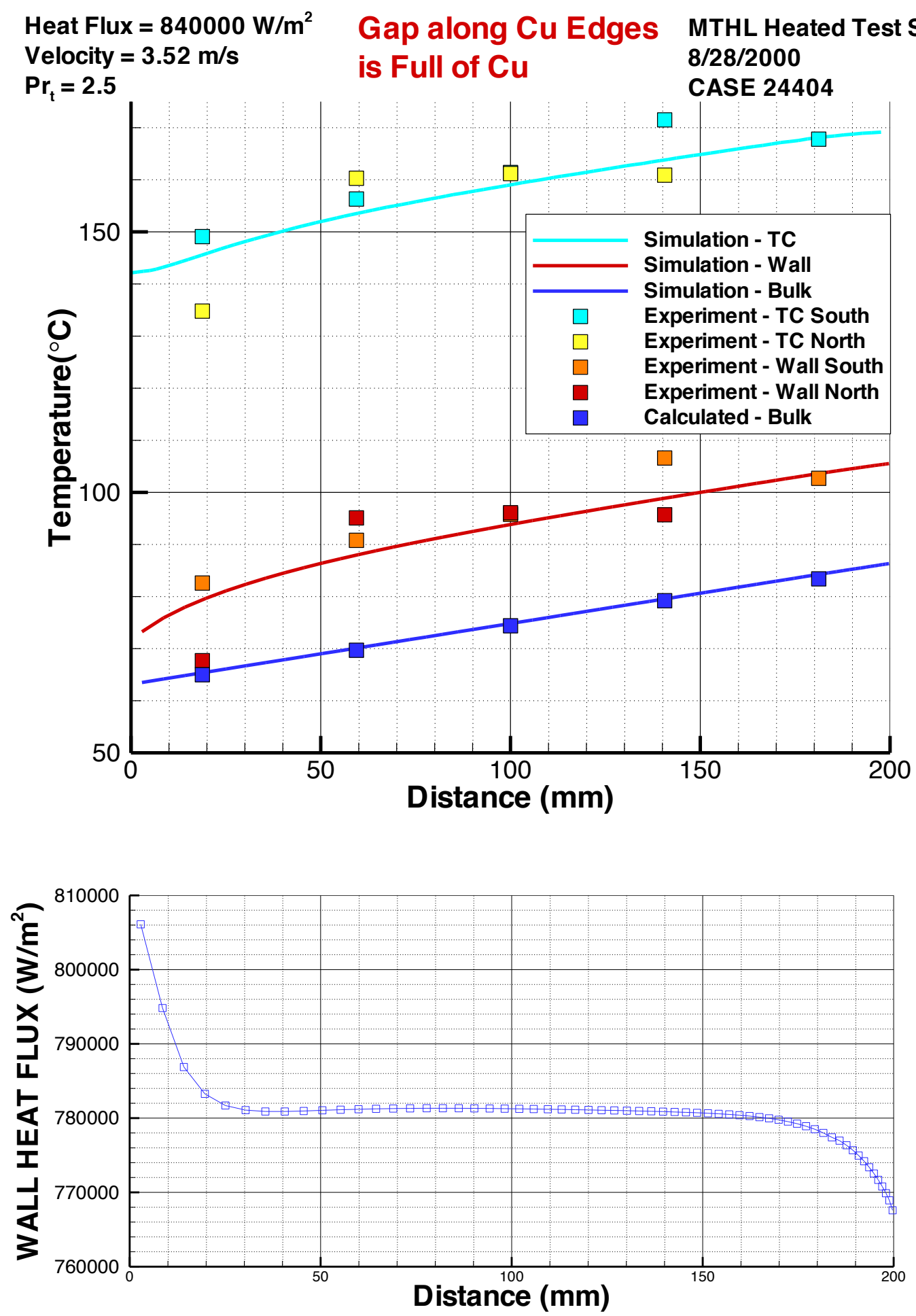

Fig. 39. CFD results with gap completely filled with $\mathrm{Cu}$ model. 

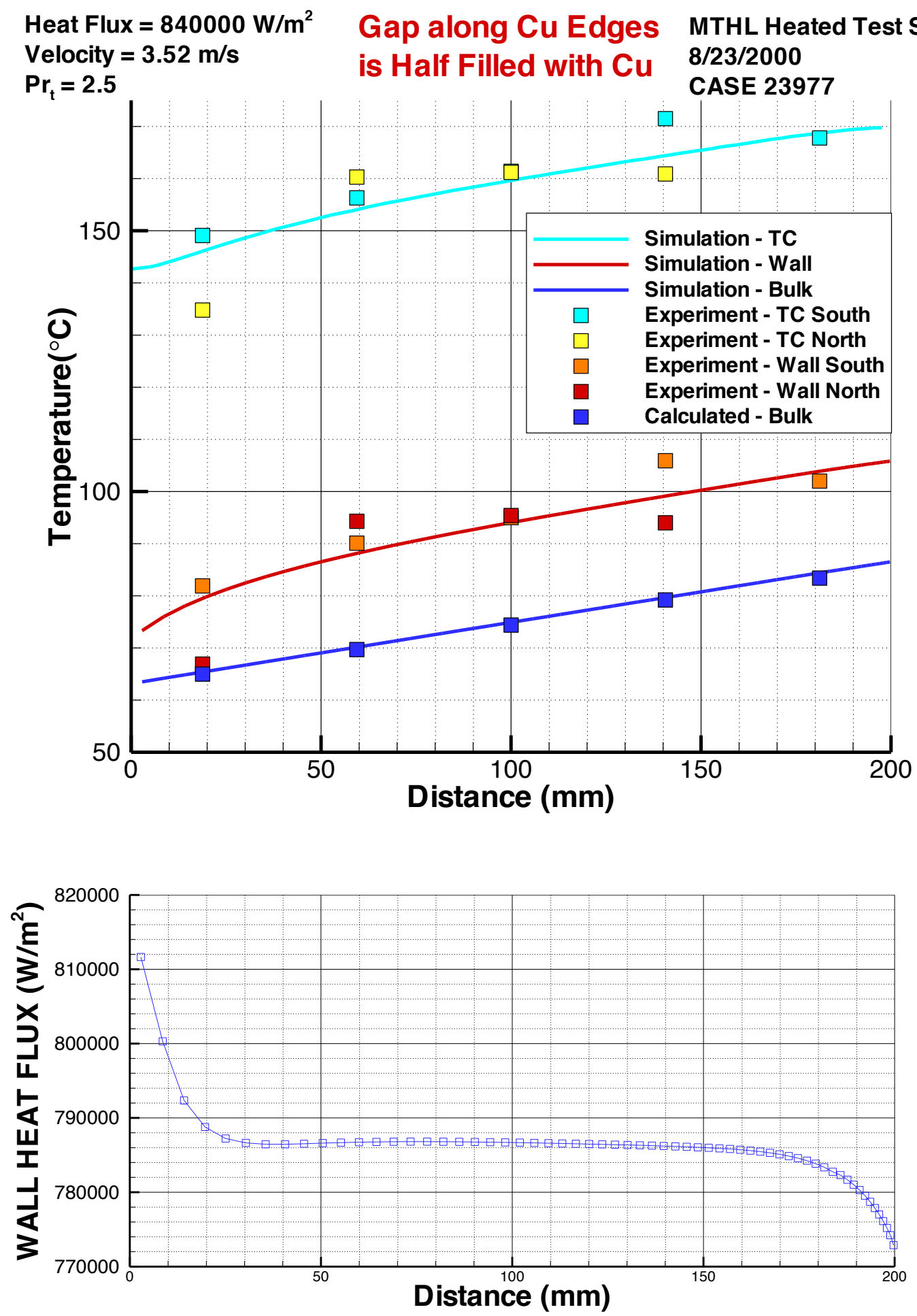

Fig. 40. CFD results with gap partially filled with $\mathrm{Cu}$ model. 
Table 8. Heat flux reductions for 1-D analysis

\begin{tabular}{lccc}
\hline & $\begin{array}{c}\text { Adiabatic Boundary } \\
\text { Condition }\end{array}$ & Gap filled with Cu & $\begin{array}{c}\text { Gap partially filled with } \\
\text { Cu }\end{array}$ \\
\hline Heat Flux Reduction & $3.5 \%$ & $7 \%$ & $6 \%$ \\
\hline
\end{tabular}

A comparison of CFD predictions and experimental data is also shown in Fig. 41. The data shown in this figure are for Location $\mathrm{C}$, the midpoint of the heated portion of the test section. The data have been corrected for a $6 \%$ reduction in heat flux, as indicated in Table 8 . The error bars on the data (only) represent the values obtained from the $3.5 \%$ and $7 \%$ reduction in local heat flux assumptions. While the CFD predictions at lower flows are higher than the experimental data, the CFD predictions are well within the error bars of the experimental data at higher flows, including the SNS nominal design flow.

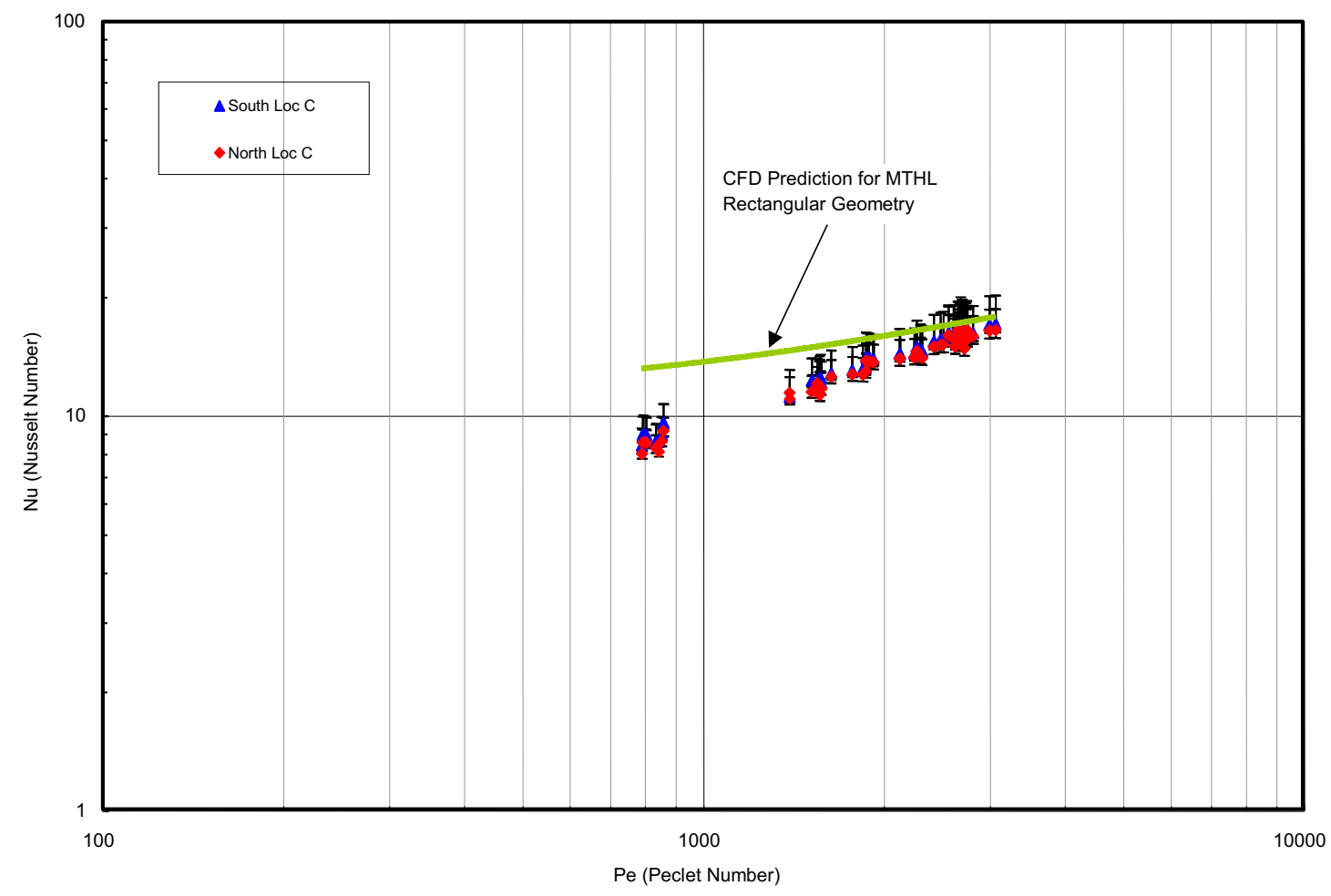

Fig. 41. Comparison of CFD predictions for a rectangular channel to experimental data.

\subsubsection{Heat Transfer Results}

To investigate the effects of mercury bulk temperature, pressure, and heat flux on the heat transfer coefficient, parametric experiments were conducted. Figure 42 shows the experimental heat transfer coefficient as a function of bulk temperature while holding other parameters constant. Similarly, the effect of pressure on the experimental heat transfer coefficient is shown in Fig. 43, and Fig. 44 demonstrates the effect of heat flux. From these figures, it is seen that the heat transfer coefficient is independent of all three parameters.

Finally, Fig. 45 shows a comparison of the experimental data obtained with the electrically heated test section of MTHL to world tube data for liquid metals. Data are only shown for the middle three thermocouple locations since the thermal boundary layer is not fully developed at the entrance of the test 
section and end effects occur at the exit location, as can be seen in Fig. 40. The data shown are an average of the thermocouple measurements on the north and south side of the test section at a given axial position. Again, the heat flux in this data has been reduced by $6 \%$, as indicated in Table 8 . The data show a fair amount of scatter, which appears to correlate with the thermocouple position. The large temperature gradients produced by the high heat flux levels and heat transfer rates translate into potentially significant uncertainties due to variations in location and/or contact resistances of the thermocouples. It is believed that sectioning the test section and evaluating the actual locations and braze interface would probably allow some reduction in the scatter.

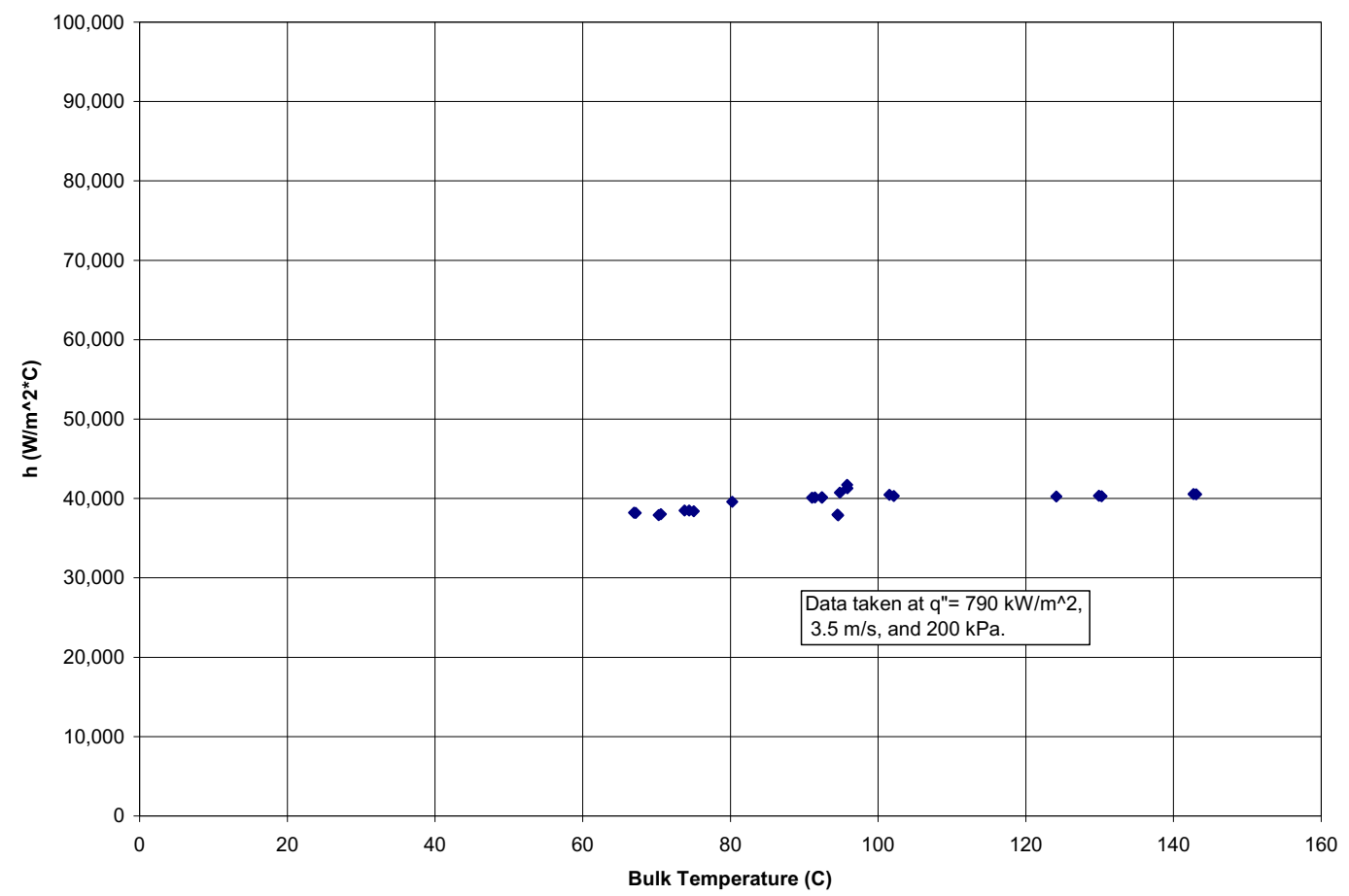

Fig. 42. Experimental heat transfer coefficient vs bulk temperature. 


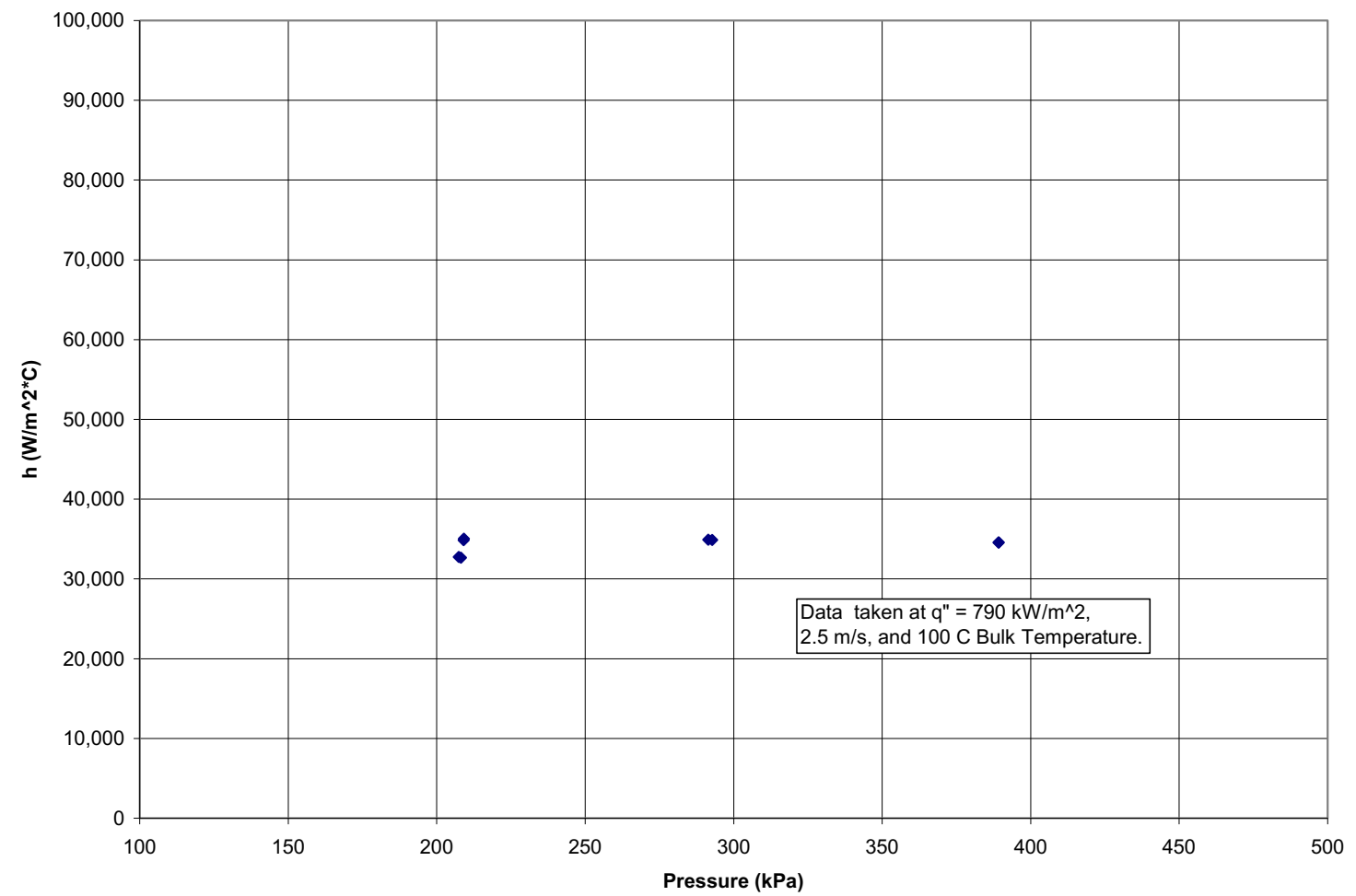

Fig. 43. Experimental heat transfer coefficient vs pressure.

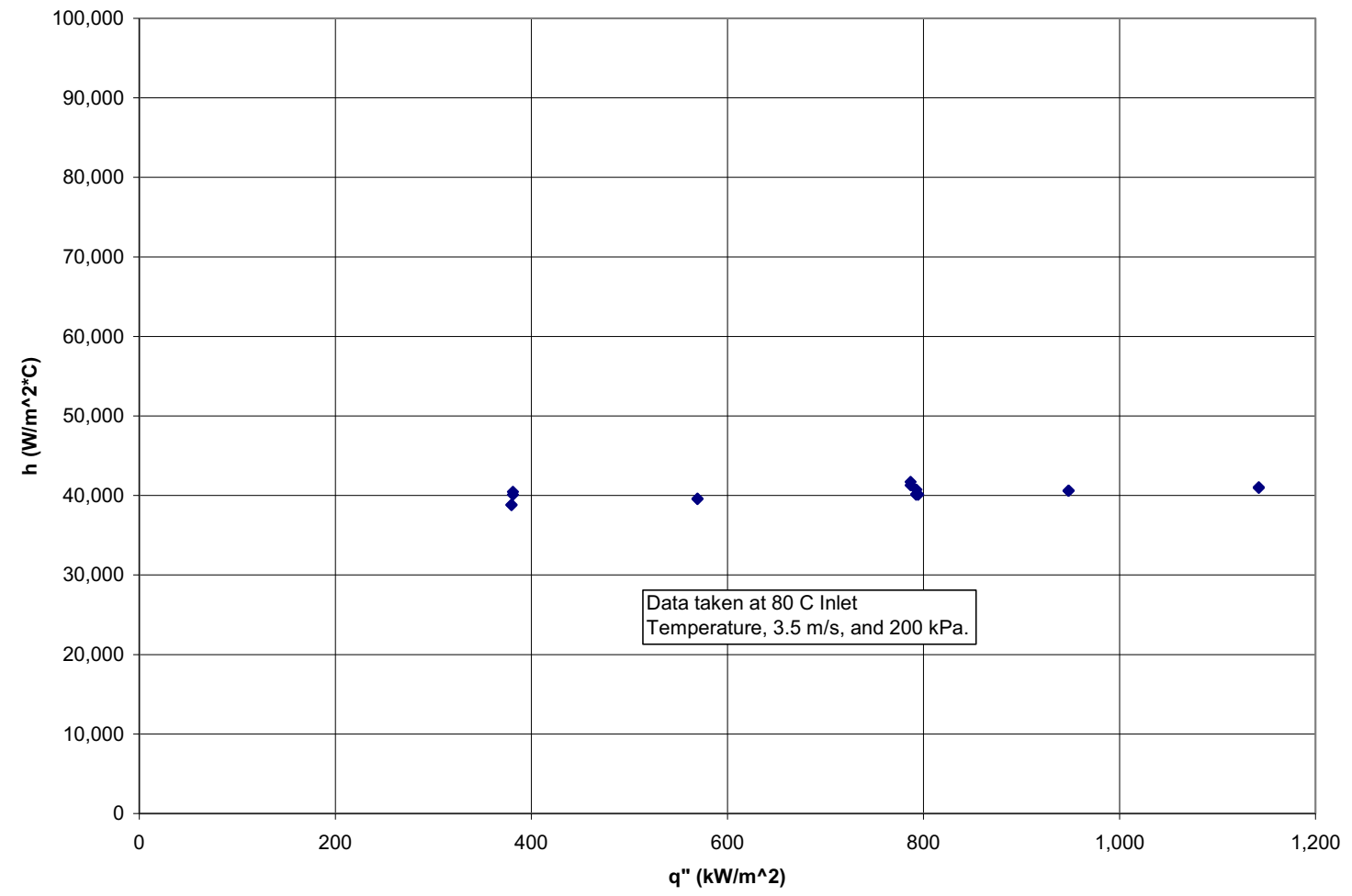

Fig. 44. Experimental heat transfer coefficient vs heat flux. 


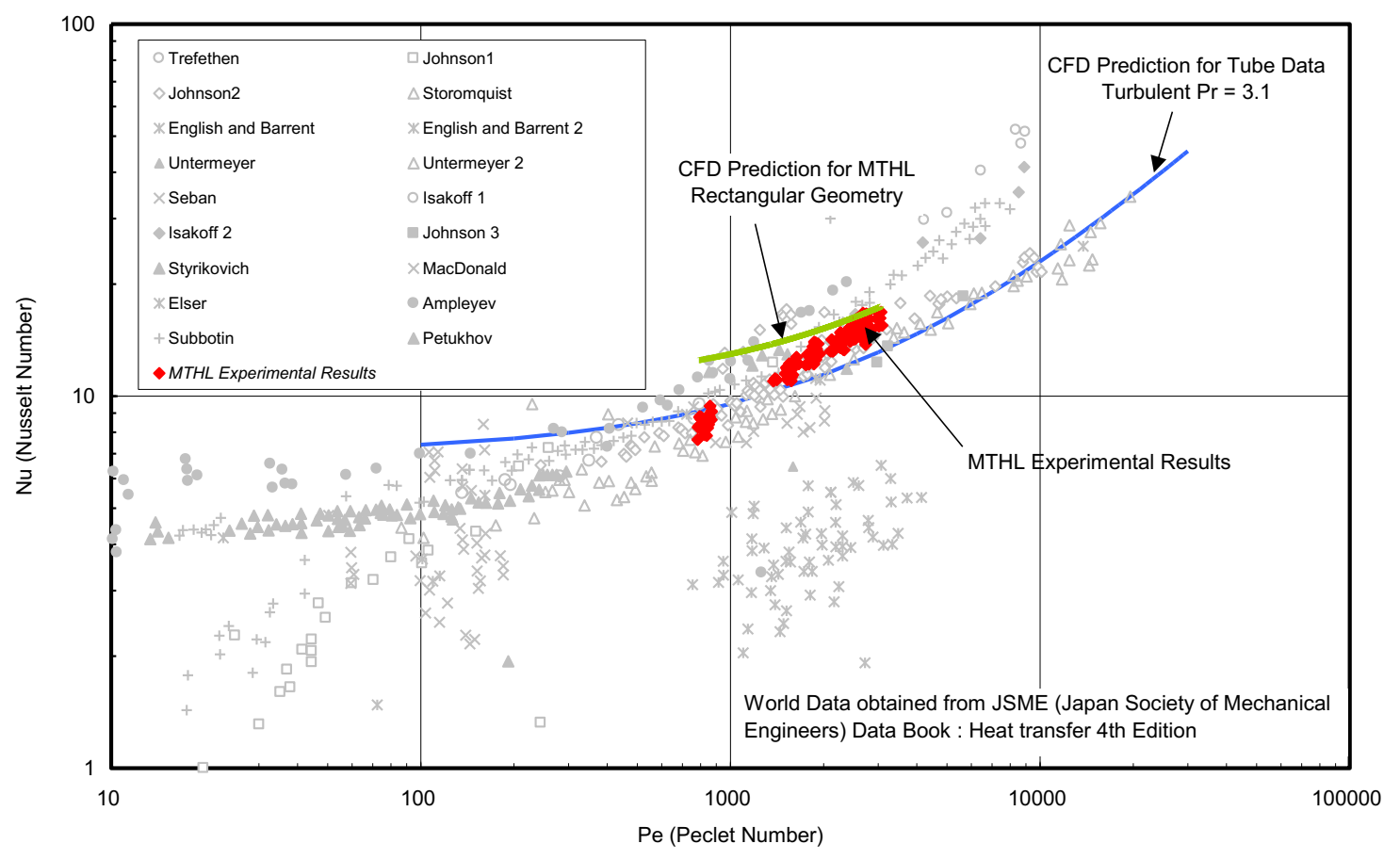

Fig. 45. Comparison of experimental data to world tube data ${ }^{11}$.

\subsubsection{Test Section Heat Transfer Performance Analysis}

A numerical investigation was conducted to determine how the thermocouples installed in the test section influence the temperature distribution and therefore the experimental temperature measurements. A 3-D schematic of the major test section components is presented in Fig. 46, along with a reference coordinate system. This diagram shows only one-quarter symmetry of the test section and is not to scale. As discussed in the test section description, miniature cable type heater elements were brazed into the heater pocket (or heater well in Fig. 46). The copper block is used to spread the heat generated in the heater elements, providing a uniform heat flux distribution at the cooling channel surface, and a smoothly increasing temperature distribution along the length of the cooling channel. Temperature changes in this direction ideally would only be influenced by the increase in coolant temperature as the mercury flows from the inlet to the outlet of the channel. Five sheathed thermocouples were installed on each side of the test section in grooves machined along the width of the copper block ( $Z$ direction). The copper block was then brazed to the SS wall of the test section. The thermocouples introduce a material nonhomogeneity in the copper, and they disturb both the temperature distribution and the heat flux within the copper block and SS wall, as well as at the SS/mercury interface. 


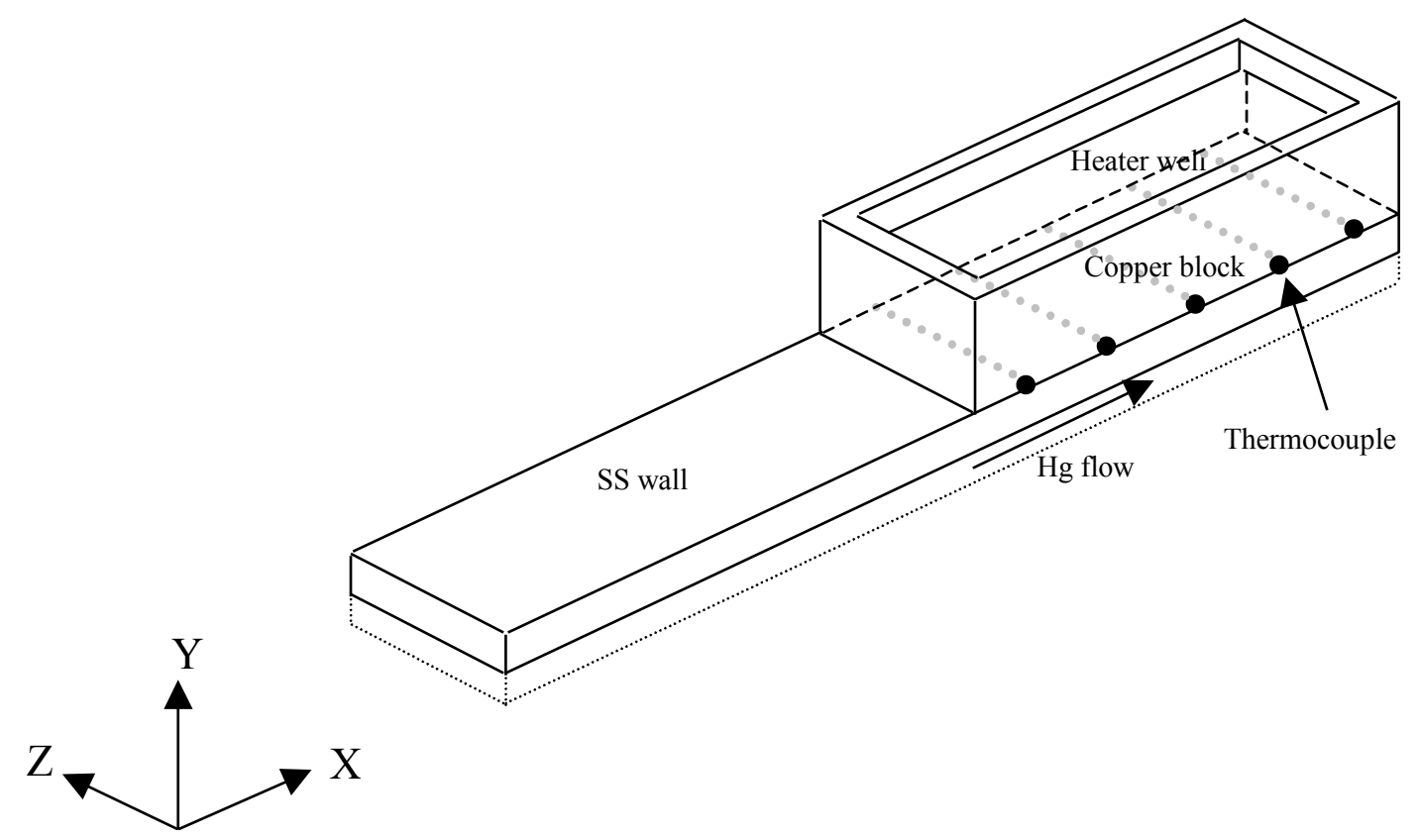

Fig. 46. Schematic of test section design.

The calculations were designed to determine the influence of these thermocouples on the temperature distribution and were performed using the HEATING 7 code. A two-dimensional (X-Y) model of the heater and test section wall was developed which included a single thermocouple. Figure 47 shows details of this model, which is symmetric about the thermocouple centerline and models the copper block, thermocouple, and SS wall. A single mercury temperature is assumed for the heat sink, and a single heat transfer coefficient is assumed at the mercury/SS interface. The Inconel thermocouple sheath (diameter $0.81 \mathrm{~mm}$, thickness $0.15 \mathrm{~mm}$ ) was modeled in Cartesian coordinates since HEATING does not have the capability of mixing two coordinate systems in a single problem. The $\mathrm{MgO}$ insulator and ChromelAlumel thermocouple bead were also included in the model. Since the copper block was brazed onto the SS test section wall, the conductivity of the gap between the thermocouple and the $0.89 \mathrm{~mm}$ thermocouple groove was examined parametrically. This gap was assumed to either be filled with braze material (assumed to have a conductivity $2 / 3$ that of copper) or remained unfilled (see Fig. 47). A uniform heat flux was applied to the top surface of the copper heater model. Two heat flux values and two heat transfer coefficients were also evaluated to determine the dependence of the thermocouple temperatures on these parameters.

The various cases studied are shown in Table 9. Fluid parameters used in Cases 1 and 2 are consistent with the experimental cases presented in Figs. 38 through 40. Temperature results are also presented in Table 9 for 4 positions in the model. The first is at the thermocouple bead centerline $\left(T_{b}\right)$ and indicates the measured temperature. The second is at the same $\mathrm{Y}$ position, but it is at the other end of the model where the temperatures are undisturbed $\left(\mathrm{T}_{\mathrm{b} \infty}\right)$. The third is at the thermocouple $\mathrm{X}$ position at the mercury/SS interface $\left(T_{w}\right)$, and the fourth is at the other end of the model, also at the mercury/SS interface $\left(\mathrm{T}_{\mathrm{w} \infty}\right)$. Figure 47 illustrates these locations. 


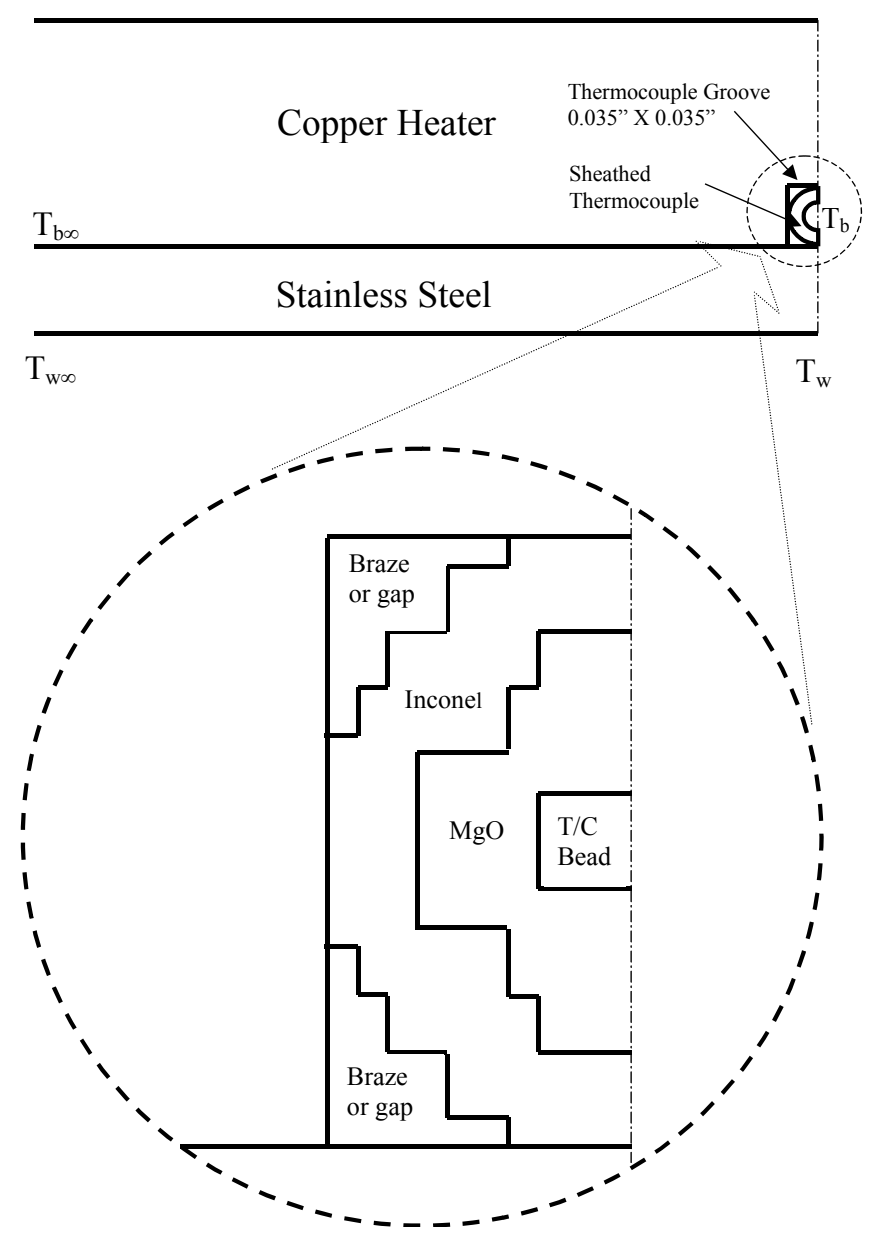

Fig. 47. HEATING 7.2 model.

Table 9. Conditions used in calculations and calculation results

\begin{tabular}{|c|c|c|c|c|c|c|c|c|c|}
\hline Case & Condition & $\begin{array}{c}\text { Velocity } \\
(\mathbf{m} / \mathbf{s})\end{array}$ & $\begin{array}{c}\mathrm{Hg} \\
\text { temp } \\
\text { (C) }\end{array}$ & $\begin{array}{c}\text { Heat flux } \\
\left(\mathbf{W} / \mathbf{m}^{2}\right)\end{array}$ & $\begin{array}{c}\text { Heat } \\
\text { transfer } \\
\text { coefficient } \\
\left(\mathbf{W} / \mathbf{m}^{2}{ }^{0} \mathbf{C}\right)\end{array}$ & $\begin{array}{c}T_{b} \\
\left({ }^{\circ} \mathbf{C}\right)\end{array}$ & $\begin{array}{l}\mathbf{T}_{\mathbf{b} \infty} \\
\left({ }^{\circ} \mathbf{C}\right)\end{array}$ & $\begin{array}{c}\mathbf{T}_{\mathrm{w}} \\
\left({ }^{\circ} \mathrm{C}\right)\end{array}$ & $\begin{array}{l}\mathbf{T}_{\mathbf{w} \infty} \\
\left({ }^{0} \mathrm{C}\right)\end{array}$ \\
\hline 1 & Braze in gap & 3.52 & 74.4 & 841,000 & 52,000 & 164.0 & 164.8 & 90.3 & 90.6 \\
\hline 2 & No braze in gap & $"$ & $"$ & $"$ & $"$ & 161.8 & 165.3 & 89.6 & 90.7 \\
\hline 3 & Braze in gap & $"$ & $"$ & $"$ & 39,000 & 169.3 & 170.2 & 95.6 & 96.0 \\
\hline 4 & No braze in gap & $"$ & $"$ & $"$ & $"$ & 167.6 & 171.3 & 95.3 & 96.7 \\
\hline 5 & Braze in gap & $"$ & $"$ & 420,500 & 52,000 & 119.2 & 119.6 & 82.4 & 82.5 \\
\hline 6 & No braze in gap & $"$ & $"$ & $"$ & $"$ & 118.0 & 119.9 & 82.0 & 82.6 \\
\hline
\end{tabular}

Results from the first two calculations shown in Table 9 are also shown in Fig. 48, which shows temperature profiles along the $\mathrm{X}$ direction for two different $\mathrm{Y}$ locations. The upper scale in this figure shows temperatures at the Y location of the thermocouple bead, while the lower scale shows temperatures at the SS/mercury interface. Two cases are shown at each Y position: one that has braze material in the gap, and the other without. This figure shows a temperature depression at the thermocouple location of approximately $0.8^{\circ} \mathrm{C}$ when the braze has penetrated the groove (no gap), and a $3.5^{\circ} \mathrm{C}$ depression if the 
braze has not penetrated the groove (gap). Surface temperature depression is only about $0.3{ }^{\circ} \mathrm{C}$ when the braze penetrates, and $1.1{ }^{\circ} \mathrm{C}$ when it has not. This implies that there would also be a modest variation in the local surface heat flux due to the presence of the thermocouple, approximately a $2 \%$ decrease with braze in the gap, and a 7\% decrease without the braze. There is also a slight increase in temperatures away from the thermocouple $\mathrm{X}$ position. The local heat flux must increase slightly at these positions because the local flux at the thermocouple $\mathrm{X}$ position is depressed, while total heat flow in the model must be conserved.

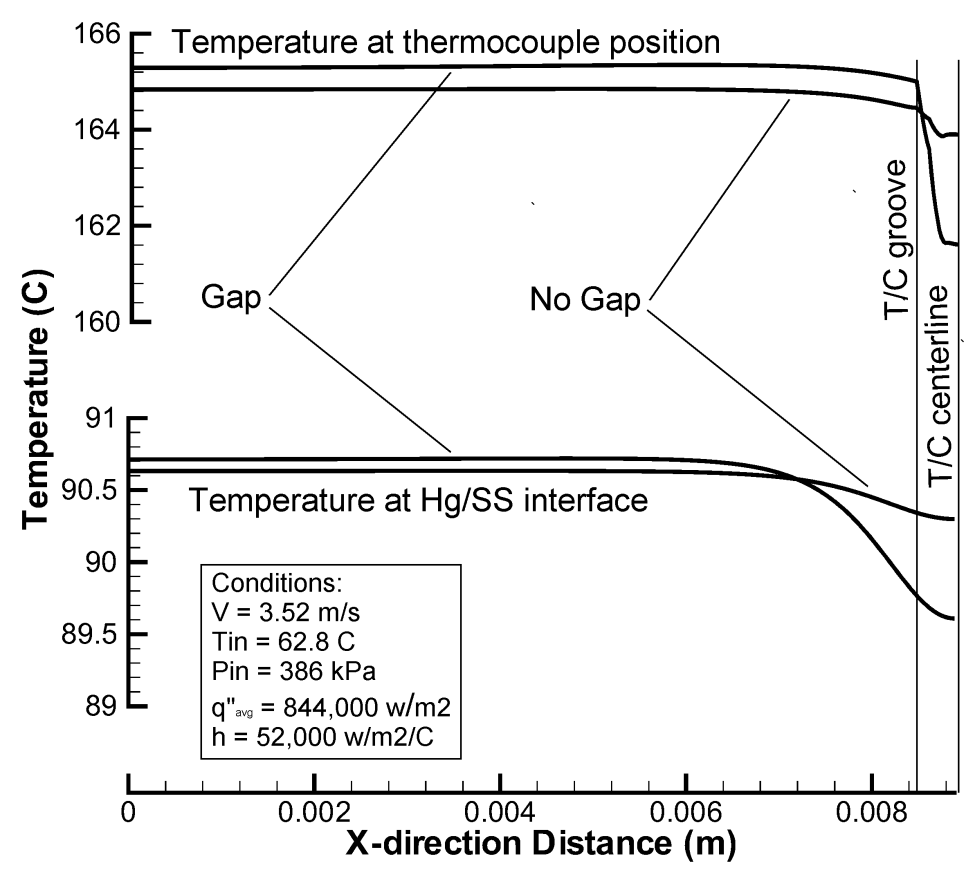

Fig. 48. Heating 7 results.

When evaluating the experimental data, heat transfer coefficients are determined by assuming a uniform heat flux through the test section and by assuming that the thermocouples do not disturb the temperature.

$$
\mathrm{h}_{\text {exp }}=\mathrm{q} \text { " }{ }_{\text {uniform }} /\left(\mathrm{T}_{\text {wcalc }}-\mathrm{T}_{\text {bulk }}\right) \text {, }
$$

where: $h_{\text {exp }}=$ the local heat transfer coefficient determined from experimental data,

$\mathrm{q}^{\prime \prime}$ uniform $=$ the assumed local heat flux based on power input and surface area,

$\mathrm{T}_{\mathrm{wcalc}}=$ the wall temperature calculated using the conduction equation below, and

$\mathrm{T}_{\text {bulk }}=$ the bulk coolant temperature based on power input or average heat flux.

The calculated wall temperature is determined from a conduction calculation through the test section wall (as discussed in section 3.1.1):

$$
\mathrm{T}_{\text {wcalc }}=\mathrm{T}_{\text {meas }}-\left(\mathrm{t}_{\mathrm{ss}} / \mathrm{k}_{\mathrm{ss}}\right) * \mathrm{q} \text { " uniform }-\left(\Delta \mathrm{t}_{\mathrm{c}} / \mathrm{k}_{\mathrm{c}}\right) * \mathrm{q} \text { " uniform, }
$$

where: $T_{\text {meas }}=$ the indicated thermocouple temperature,

$\mathrm{t}_{\mathrm{ss}}=$ the SS thickness,

$\mathrm{k}_{\mathrm{ss}}=$ the SS thermal conductivity,

$\Delta \mathrm{t}_{\mathrm{c}}=$ the thickness of the copper from the thermocouple bead to the steels, and

$\mathrm{k}_{\mathrm{c}}=$ the copper thermal conductivity. 
The heat transfer coefficient determination is therefore:

$$
h_{\text {exp }}=1 /\left(\left[T_{\text {meas }}-T_{\text {bulk }}\right] / \mathrm{q} " \text { uniform }-\left[t_{s s} / k_{s s}\right]-\left[\Delta t_{c} / k_{c}\right]\right) .
$$

This calculation is based on the assumption that there is no disturbance in the local temperature distribution: that $T_{\text {meas }}$ is equal to $T_{b \infty}$ using the nomenclature given in Fig. 47 above. However, $T_{\text {meas }}$ is lower than $\mathrm{T}_{\mathrm{b} \infty}$ because the thermocouple has actually distorted the temperature and heat flux field. The ratio of the actual heat transfer coefficient $h_{\text {act }}$ (used in the HEATING calculations) to the measured heat transfer coefficient (based on $\mathrm{T}_{\text {meas }}$ and calculated using the above equation) indicates the amount of error introduced by the presence of the thermocouple

For the conditions in the test cases examined, this ratio is approximately $95 \%$ for Case 1 in Table 9 (the case of a good braze between the thermocouple and the copper) and $81 \%$ for Case 2 in Table 9 (the case above where braze material has not filled all void in the groove).

In these calculations, a value for the conductivity of braze material is assumed to be $2 / 3$ that of copper (254 $\mathrm{W} / \mathrm{m}^{\circ} \mathrm{C}$ ). Subsequent to these calculations, the actual thermal conductivity of the braze material was determined to be $121 \mathrm{~W} / \mathrm{m}^{\circ} \mathrm{C}$. A decrease in the braze conductivity would decrease the heat transfer coefficient ratio noted above for the cases in Table 9 in which the braze was present. Although there were a limited number of grid studies performed on this model to ensure that the results were not grid dependent, there were no studies performed to examine the importance of the model geometry itself to the results (i.e., the step size used to model the round thermocouple shape). Therefore, the importance of this factor in the results is not known at this writing.

\subsection{FRICTION FACTOR}

Since the mercury flow geometry is the same for the electrically heated (straight) test section as the watercooled test section, the same friction factor analysis is used. Results are shown in Fig. 49, overlaid on the Moody Curve (tube flow). As with the water-cooled test section, the majority of the data at low Reynolds numbers lies slightly below the curve for a smooth pipe. However, data at Reynolds numbers 115,000 and 134,000, which correspond to velocities at 3.0 and $3.5 \mathrm{~m} / \mathrm{s}$, respectively, do indeed lie on the Moody Curve.

In addition to observing low friction factors at low flow rates as noted above, low heat transfer coefficients were also observed at low flows when compared to CFD predictions (see Fig. 41). Currently, there is no rationale to explain these results. However, Fig. 50 shows the ratio of the enthalpy rise in the mercury to the power input from the heaters as a function of velocity. The ratio is somewhat higher at $1 \mathrm{~m} / \mathrm{s}$ than at other velocities. This indicates that at low flow rates, the EM flowmeter may be reporting a velocity higher than that actually occurring in the loop. This would tend to shift the lower Reynolds number data in Fig. 41 slightly to the left towards the CFD prediction and the friction factor data upward and to the left. However, this error source does not appear to be significant enough to explain the magnitude of the low Reynolds number differences observed. 

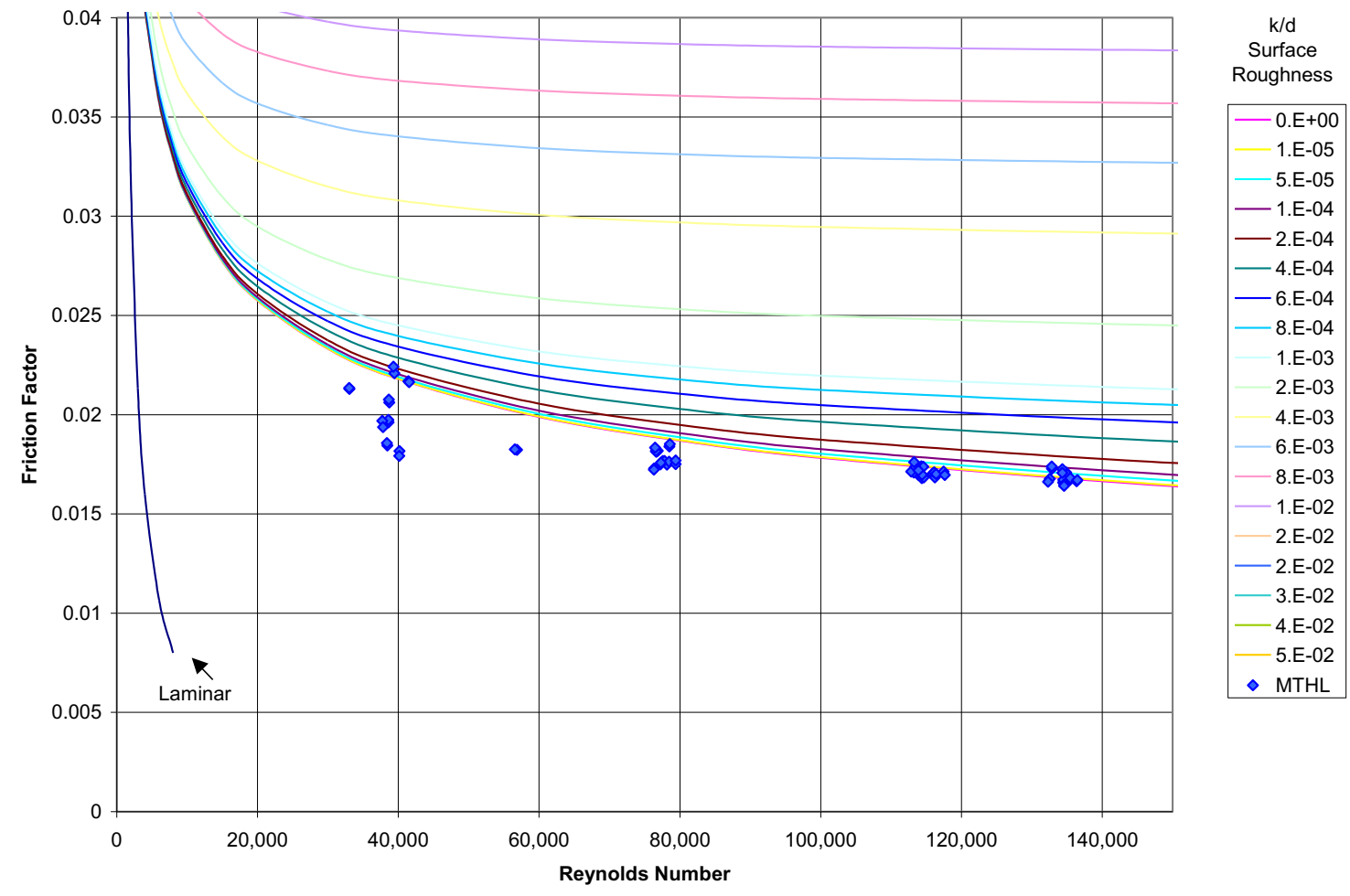

Fig. 49. Moody Curve with experimental data.

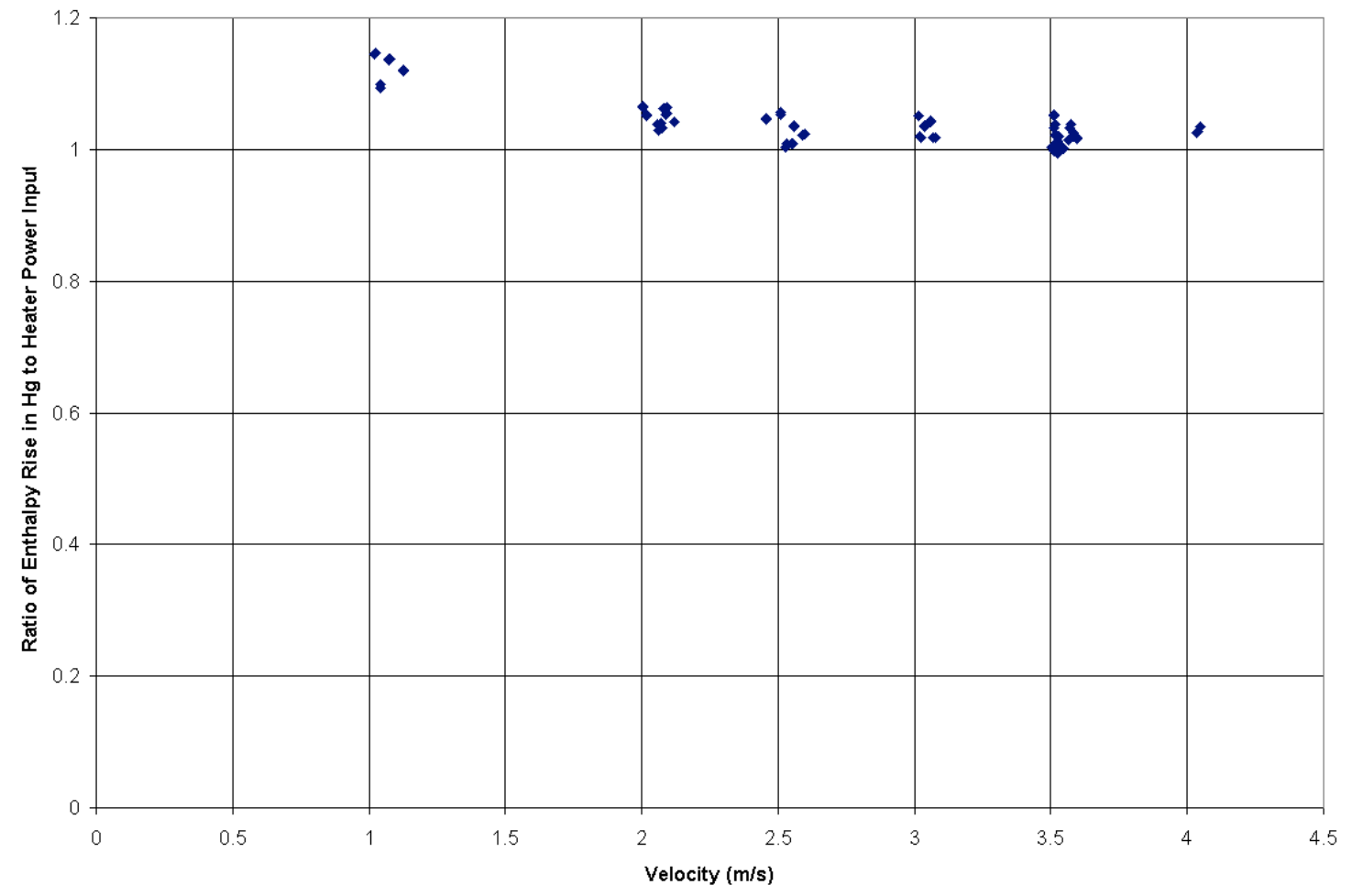

Fig. 50. Ratio of enthalpy rise in $\mathrm{Hg}$ to heater power input vs velocity. 


\section{CURVED ELECTRICALLY HEATED TEST SECTION}

The curved electrically heated test section is designed to simulate the actual window cooling flow channel geometry of the SNS target nose region. In this test section, as in the actual target, the flow gap changes from a nominal $6 \mathrm{~mm}$ at the bottom (flow entrance) to $2 \mathrm{~mm}$ at the front of the nose and back to $6 \mathrm{~mm}$ at the top (flow exit). The curvature of the window cooling channel produces centrifugal forces that may affect the flow and heat transfer coefficients. Additionally, the flow contraction and expansion may produce additional effects on the flow and heat transfer in the nose region. A schematic drawing of the test section is shown in Fig. 51. The axis for the inner and outer radii of the flow channel are offset to produce the converging/diverging geometry. The flow gap shown in Fig. 51 is fabricated to the full-scale SNS target dimensions. The width of the channel is reduced to $39 \mathrm{~mm}$, however, due to mercury volumetric flow and heater power supply limitations. The flow channel width is nominally the same as the rectangular test sections used in previous testing. A photograph of the test section base and one of the cover plates is shown in Fig. 52 prior to assembly. The flow channel geometry was machined into the base using electron-discharge machining (EDM). The cover plates are machined to provide a close-fitting channel-shaped insert which forms the sides of the channel. A high temperature o-ring visible on the flat surface of the cover plate in Fig. 52 is used to seal the interface.

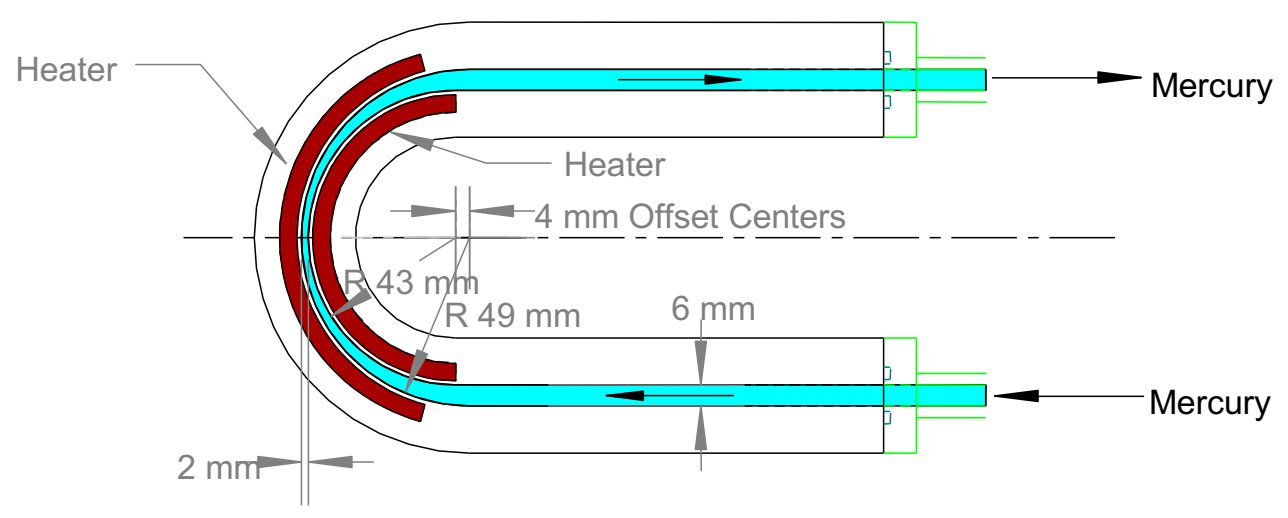

Fig. 51. Schematic drawing of the curved test section.

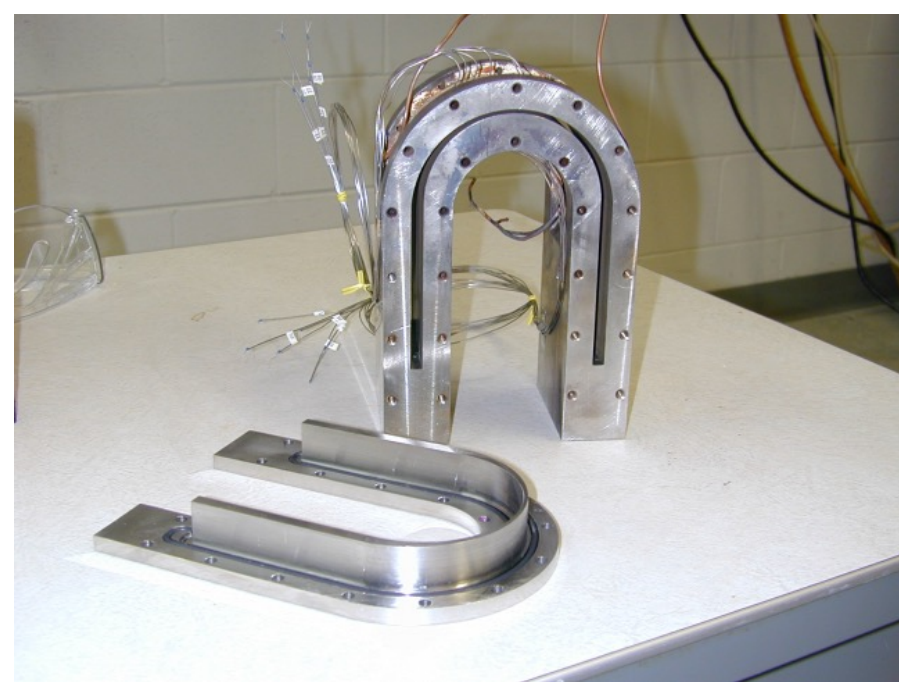

Fig. 52. Test section base and cover plate for MTHL curved test section. 
The test section walls in the nose region are electrically heated using miniature heater cables brazed to a copper plate. The copper plate is then brazed to the SS wall of the flow channel. The heaters are designed to provide a heat flux of up to $1.2 \mathrm{MW} / \mathrm{m}^{2}$. Thermocouples are installed in the bottom of the copper plates at seven positions along the channel at $-30,-10,0,10,20,30$, and 60 degrees, as shown in Fig. 53 for the outer heater plate. Thermocouples are installed in the inner plate at the same angular locations. The thermocouple junctions are located on the span-wise centerline of the heater plates.

A view of the inside heater brazed on the test channel base can be seen in Fig. 54, and a view of the outside heater is shown in Fig. 55.

The test section is shown installed in the MTHL in Fig. 56. The transition to the loop tubing is made using a tube flattened to a nominal $6 \mathrm{~mm}$ gap, which is in turn welded to a transition plate. The transition plate uses an o-ring seal at the interface with the test section.

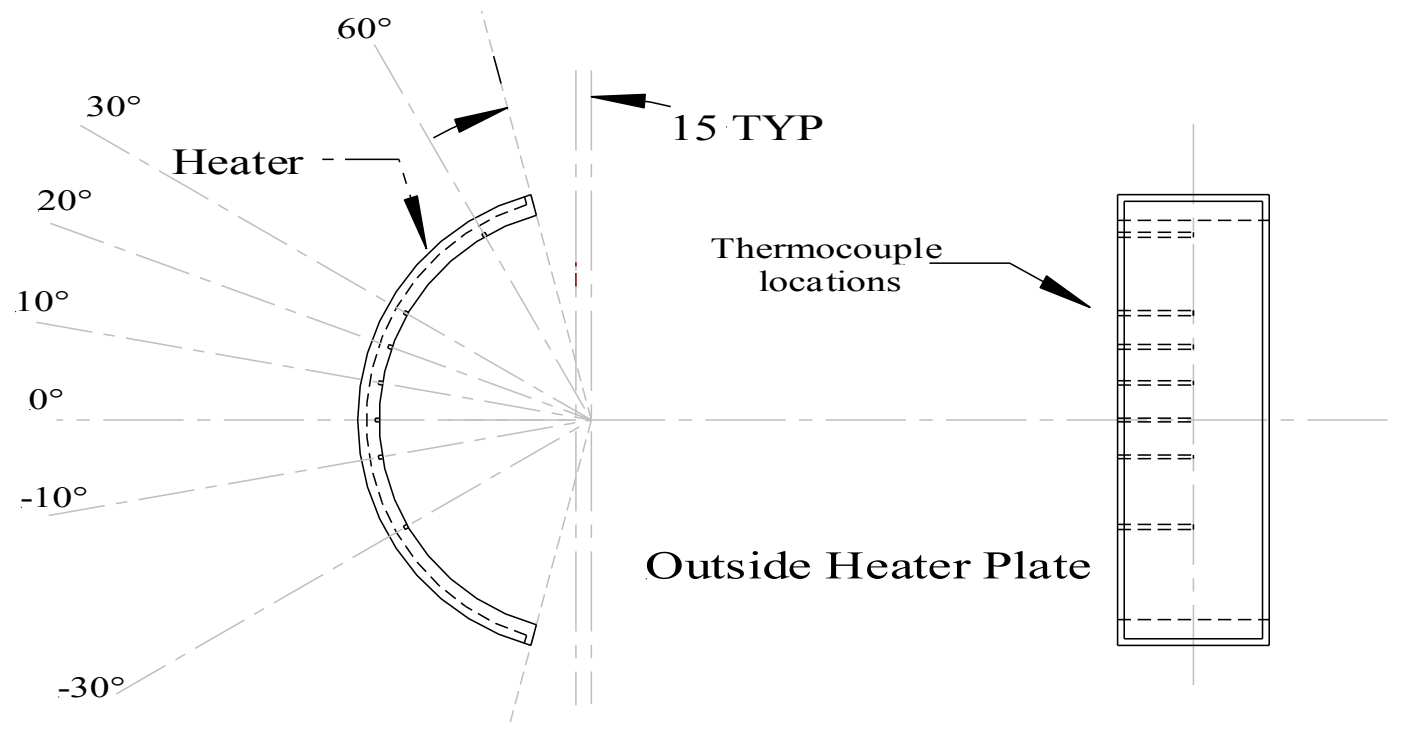

Fig. 53. Thermocouple locations for the outer heater plate. 


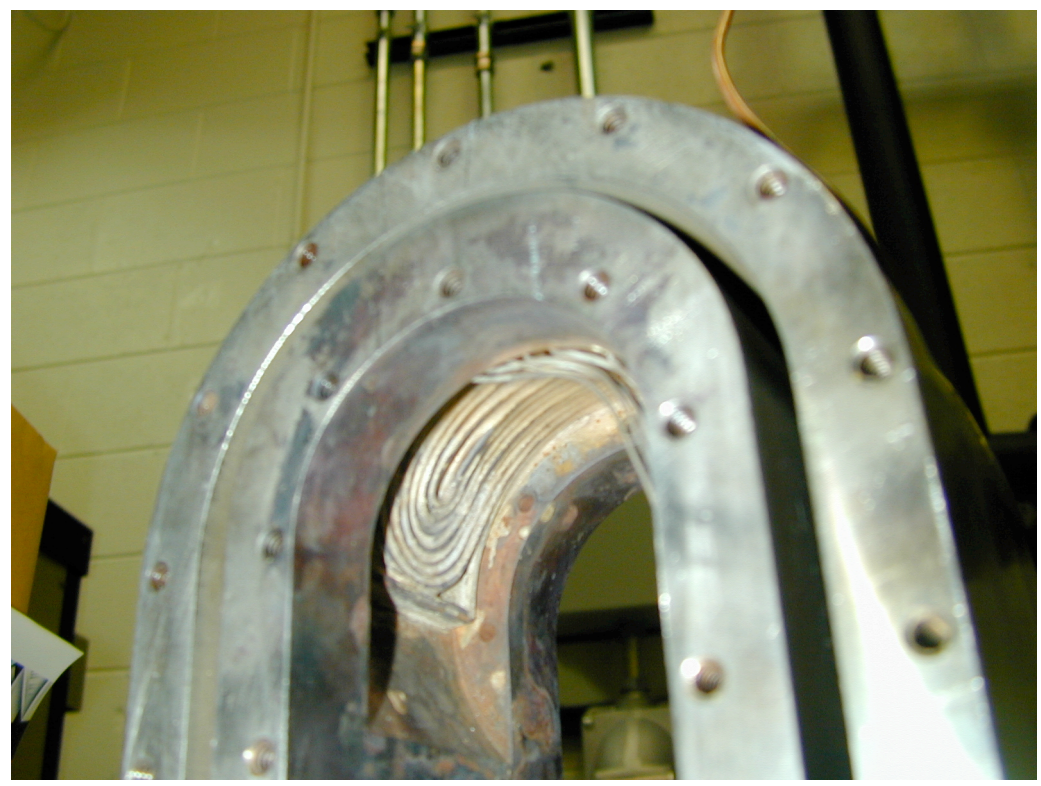

Fig. 54. Close-up view of the inside heater brazed on the test channel.

A close-up view of the installed test section is shown in Fig. 57. The heater leads and smaller diameter thermocouple wires are shown in the photograph for the outside heater. Following the connection of these leads, the entire assembly - from the inlet to the outlet fluid temperature measurement locations - was insulated, as shown in Fig. 58.

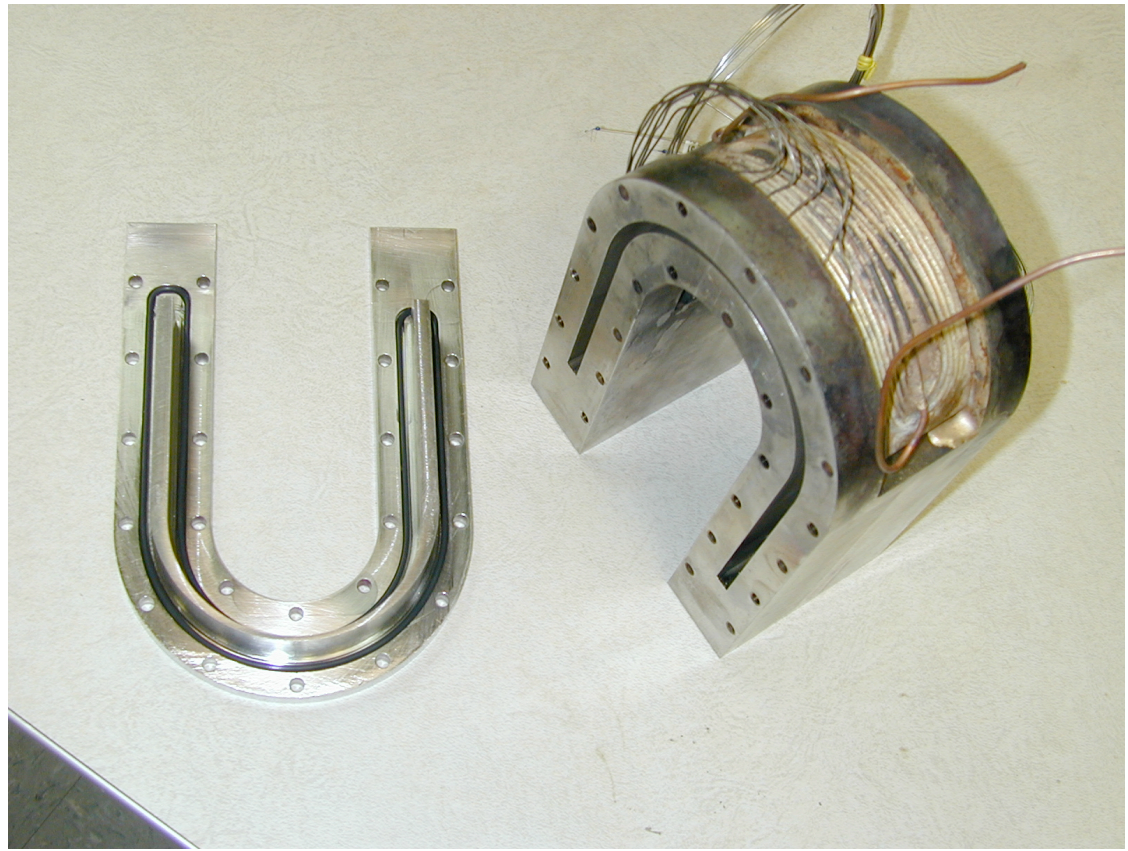

Fig. 55. Outside heater brazed on the test channel. 


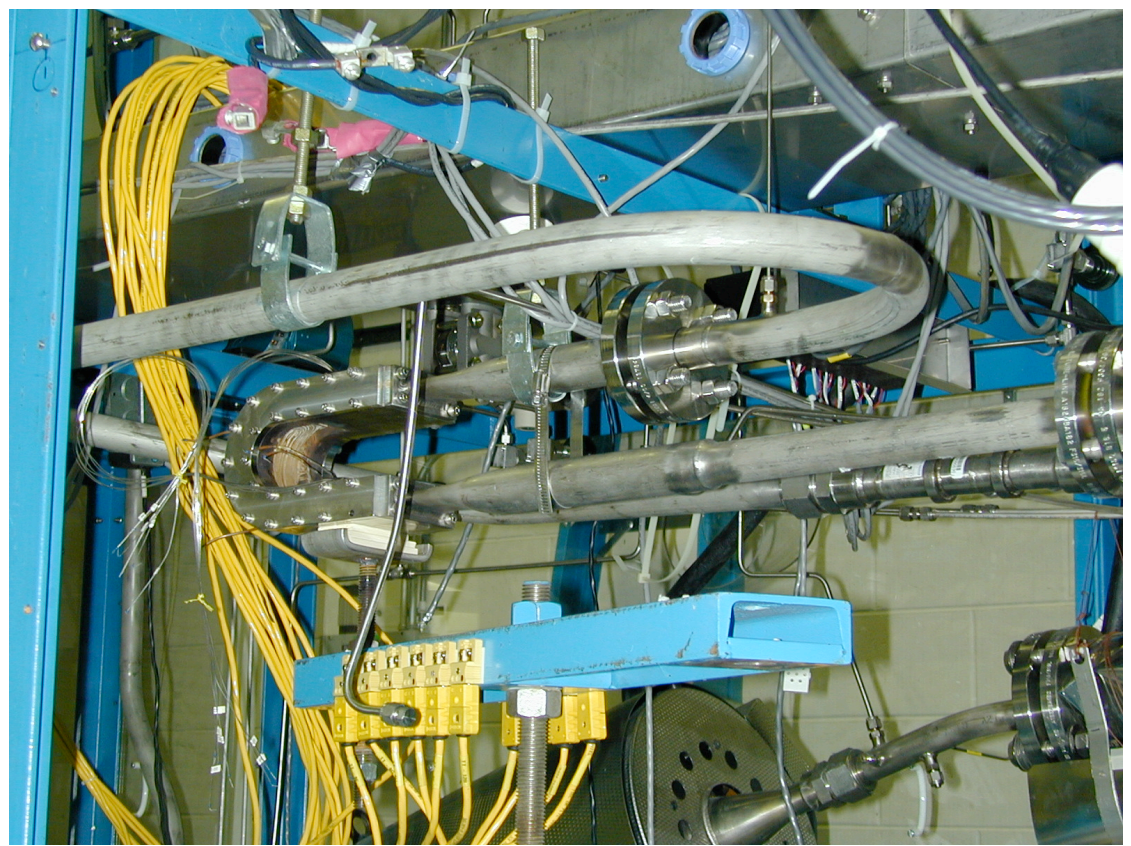

Fig. 56. Curved test section installed in the MTHL.

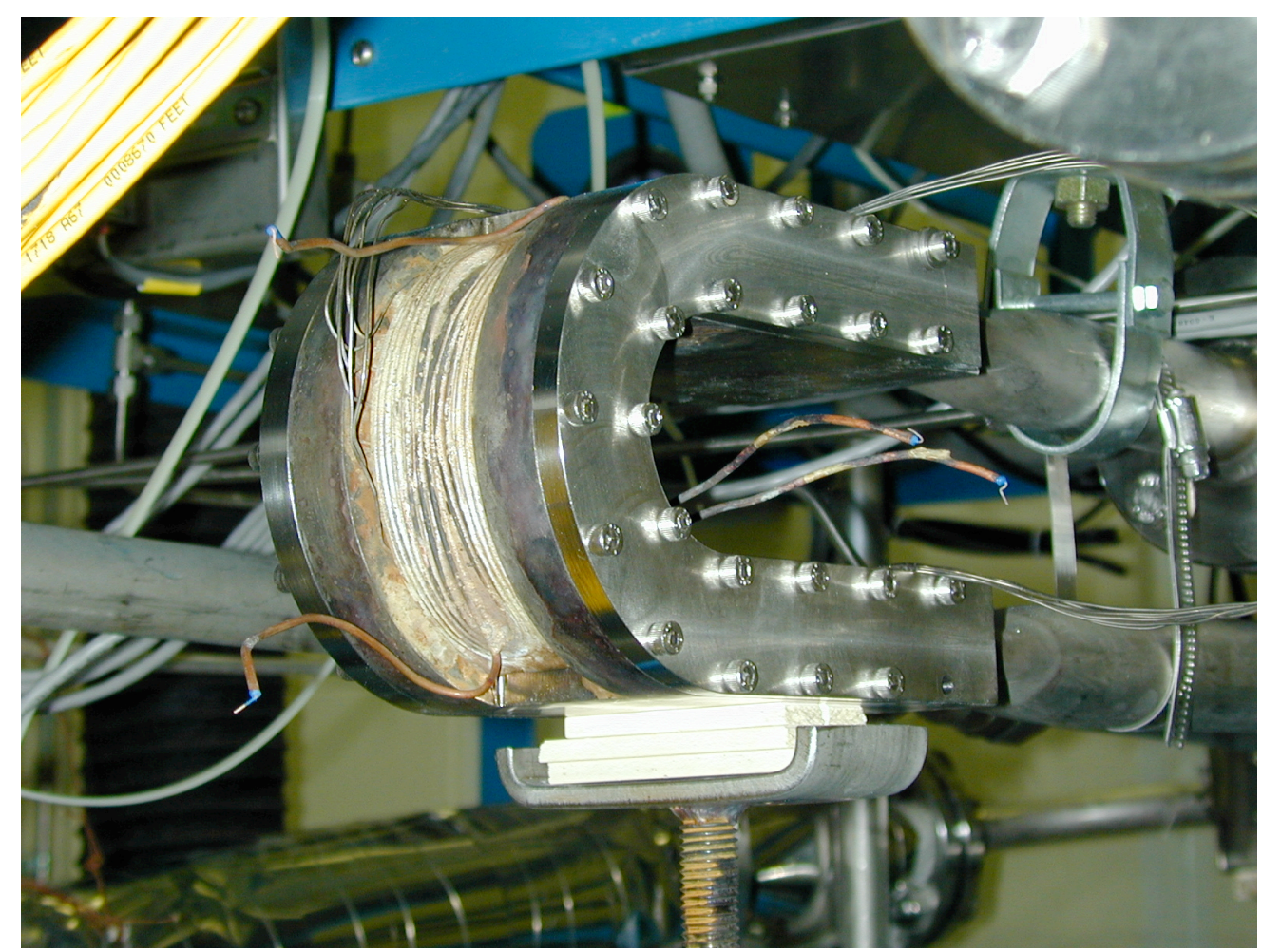

Fig. 57. Close-up view of the installed test section. 


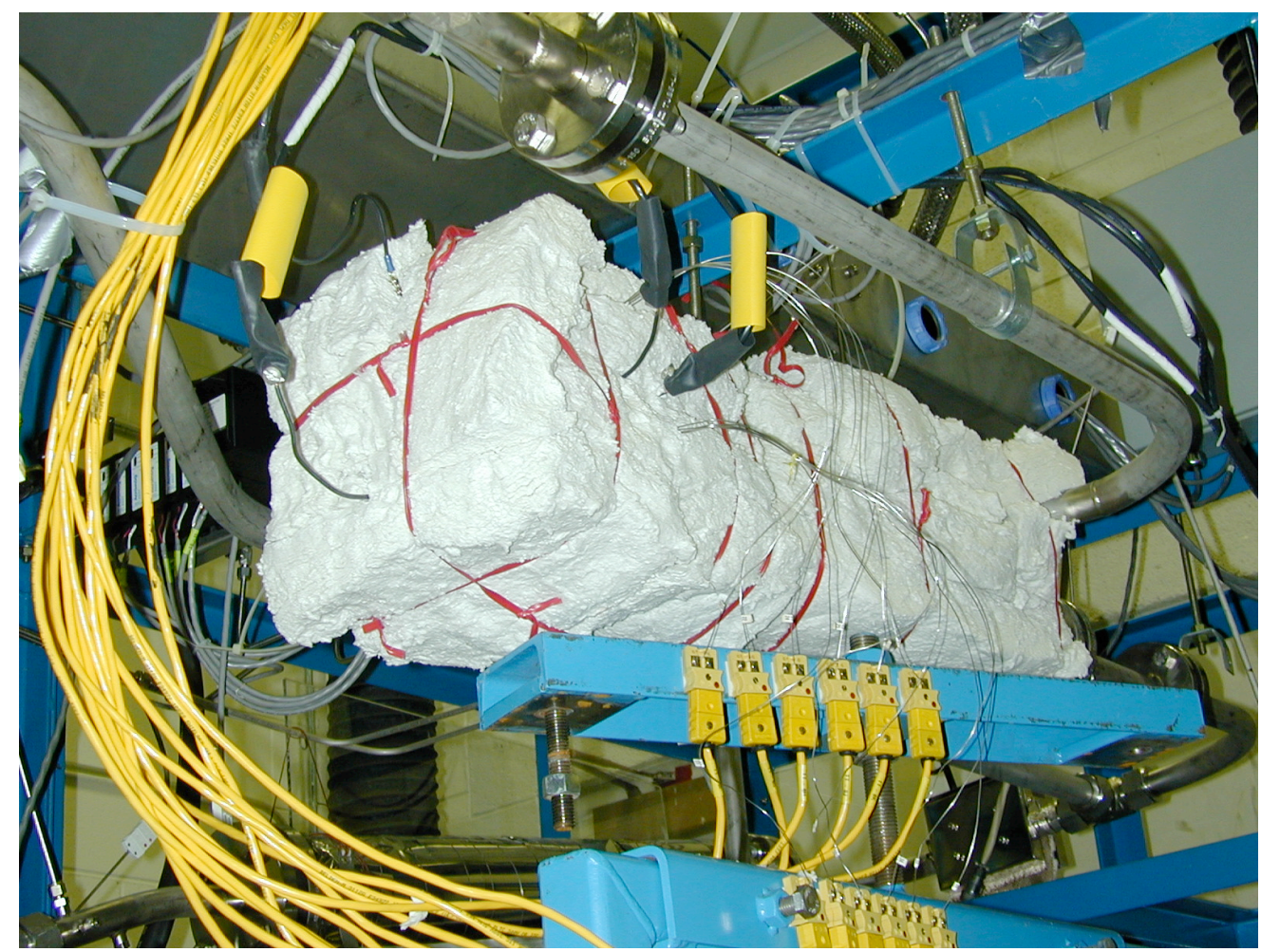

Fig. 58. Insulated curved test section installed in the MTHL.

\subsection{FABRICATION AND POST-TEST EVALUATION OF THE CURVED TEST SECTION}

A brief description of the fabrication sequence is provided for background for later discussion of the test results. The design called for a SS wall thickness of $1.27 \mathrm{~mm}$ in the region where the heaters are located. To prevent possible deformation of the relatively thin wall during the brazing process used to attach the heaters, the complete flow channel was not machined until after the brazing process. In order to limit conduction of heat from the inside heater to the outside heater during the brazing process, a narrower channel was machined in the flow channel region. This step was added after brazing problems were encountered on a test piece. Once the heaters were brazed on, the finished flow channel was machined into the test piece.

Following the test operations, the test channel was sectioned and polished to allow measurement of the actual geometry. The flow channel geometry itself was fairly consistent with the design specifications. The SS wall and braze thickness varied considerably from the design values, however. This can be seen in Fig. 59, which shows the flow channel and several thermocouple locations. The flow channel is the dark region in the center of the picture. The SS walls are located on either side. The thin, lighter region is the braze on the outside of the SS wall. The thermocouples are seen above this layer. Comparison of the thickness of the SS walls on the two sides shows a noticeable difference. In addition, it is apparent that the braze did not wet the region between the thermocouple and the SS wall. Close-up views of two thermocouple locations are shown in Figs. 60 and 61. The large divot to the left of the thermocouple in Fig. 61 was made when the edge of the slot was peened to hold the thermocouple in place during the assembly process. Thicknesses of the SS and braze layers were measured and accounted for in the analysis described below. An analysis of the effect of the lack of braze at the thermocouple locations is also discussed later in this report. 


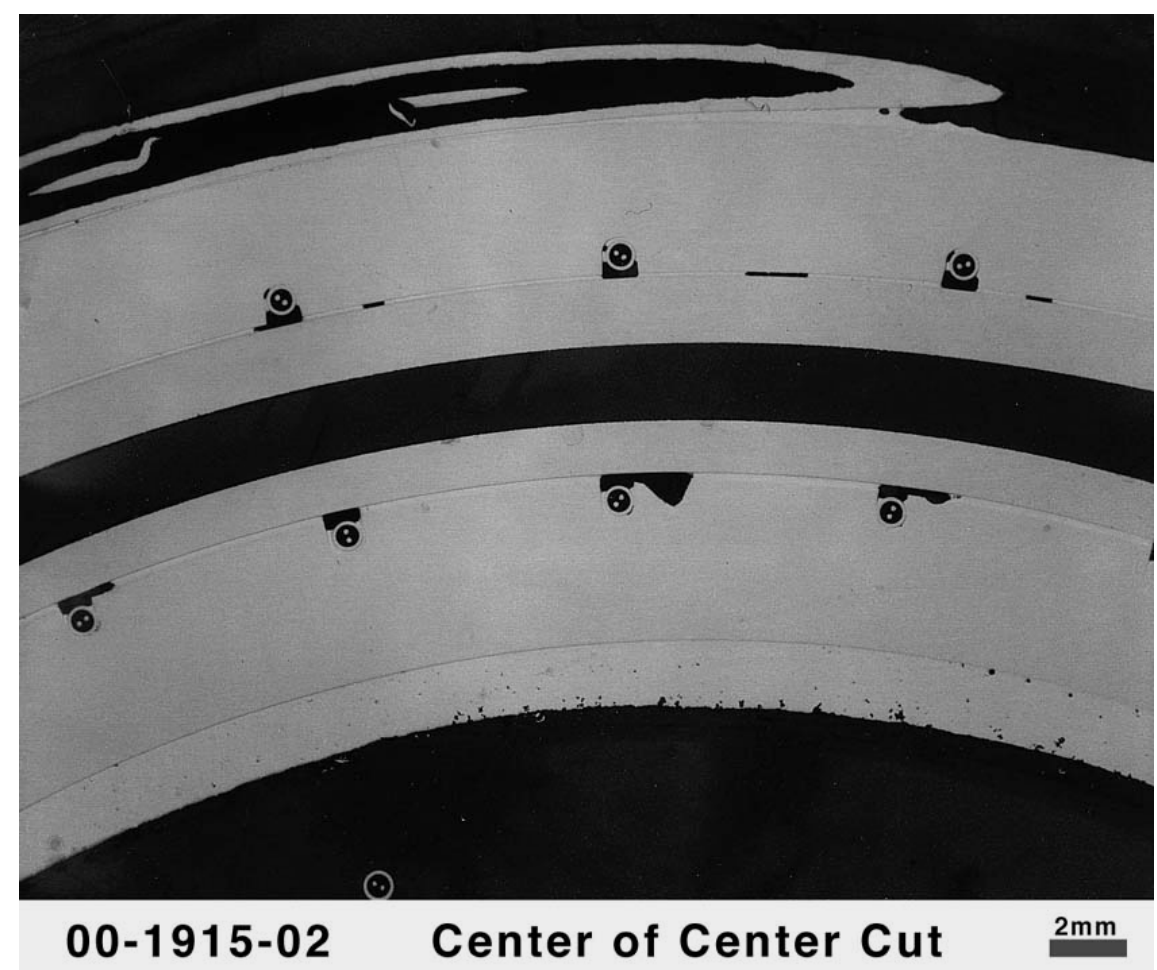

Fig. 59. Post-run section showing flow channel geometry and thermocouples at span-wise centerline.

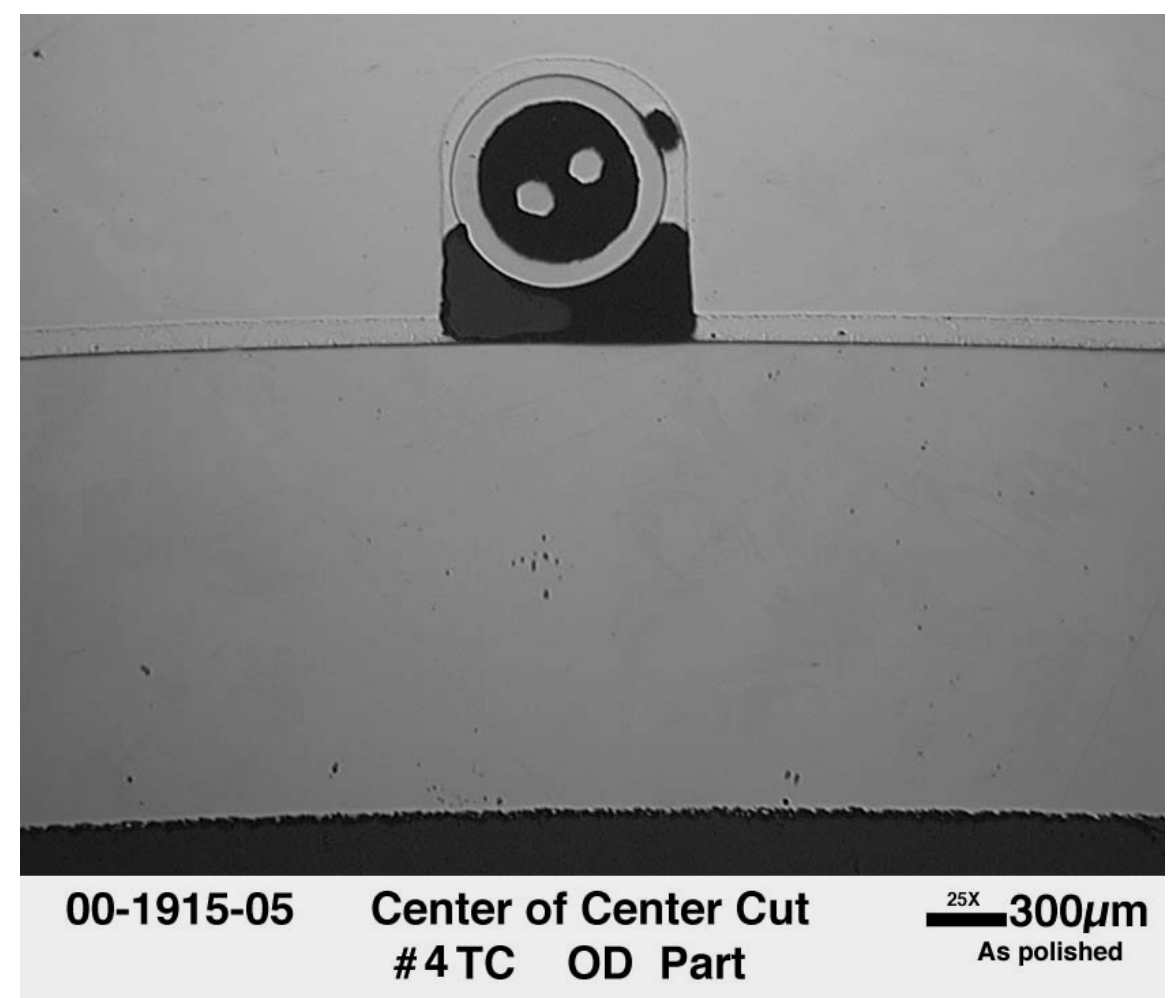

Fig. 60. Detail view of thermocouple and wall geometry $\left(+10^{\circ}\right.$ on outside wall). 


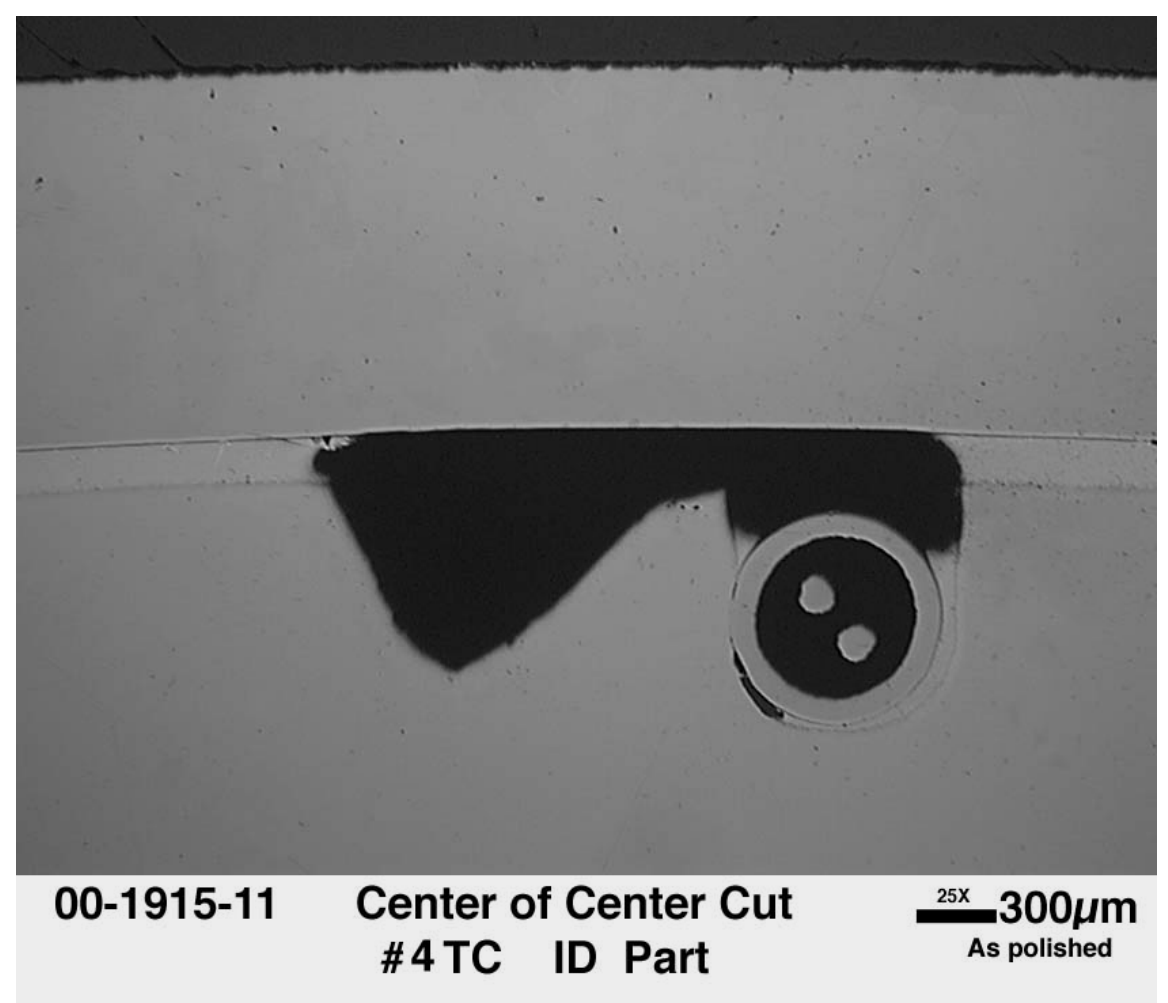

Fig. 61. Detail of thermocouple and wall geometry $\left(+10^{\circ}\right.$ inside wall $)$.

\subsection{DATA ANALYSIS METHODS AND RESULTS FOR THE CURVED TEST SECTION}

Tests were conducted on four separate days with the curved test section and covered a range of parameters, including mercury velocities (at the minimum gap) of $1-4 \mathrm{~m} / \mathrm{s}$, inlet mercury temperatures from $60-130{ }^{\circ} \mathrm{C}$, and heat flux levels from $200-840 \mathrm{~kW} / \mathrm{m}^{2}$. Additionally, test section exit pressure was varied for a few cases over a range of 200-400 kPa. Testing on each of the first three days of operation was terminated by the loss of one of the two heaters. Although the heaters were designed to reach a heat flux level of $1200 \mathrm{~kW} / \mathrm{m}^{2}$, a limitation was imposed by the sheathed copper lead wire that interfaces with the actual heater element portion of the miniature cables. As currently constructed, this copper lead wire is the same diameter as the heater element wire. Although the heater element showed no problem handling the high power levels (since that region was cooled by the mercury), the lead wires were not able to handle the resistance heating and eventually melted through. These wires were shortened and repaired following each of the failures, so it was possible to obtain data at the $840 \mathrm{~kW} / \mathrm{m}^{2}$ heat flux levels.

An analysis was performed on data for each thermocouple location in the test section. Distances such as the mercury flow channel gap, braze thickness, and SS thickness at each thermocouple location were obtained from photographs similar to those shown in Figs. 59-61. The bulk temperature was calculated for all locations in the test section by an energy balance. The resulting equation was

$$
T_{\text {Bulk }}=T_{I n}+\frac{q_{I}^{\prime} \cdot \delta_{I}+q_{O}^{\prime} \cdot \delta_{O}}{\dot{m} \cdot C_{p}},
$$

where $T_{B u l k}$ is the bulk temperature, $T_{I n}$ is the inlet test section temperature, $q^{\prime}$ is the power per total heated length, $\delta$ is the heated length to each location, $\dot{m}$ is the mass flow rate, and $C_{p}$ is the specific heat. Subscripts $I$ and $O$ refer to the inner and outer sides of the test section. Next, the temperature of the SS 
wall at the wall-mercury interface was calculated from the measured thermocouple temperature by using Fourier's Law of Heat Conduction in radial coordinates. With this information, heat transfer coefficients and $N u$ numbers were calculated from standard definitions outlined in previous sections. The velocity at each location was needed for $P e$ number calculation and was obtained by continuity of mass for the converging/diverging channel.

Significant variations in expected wall temperatures and calculated heat transfer coefficients were observed as testing progressed. These variations included measured wall temperature distributions along the flow path that did not appear reasonable for the assumed test section geometry. Additionally, variations in results under similar conditions were observed on different days as testing progressed. These indications led to the sectioning of the test section following completion of the testing sequence as described earlier. The differences in wall thickness measured from the sampled test section were included in the post-test analysis as mentioned previously. The nonwetting of the braze joint between the SS wall and the copper heater plate, especially at the thermocouple location, is an obvious source of error. A scoping analysis aimed at estimating the effect at the thermocouple locations is described later.

Another fabrication-related source of error is the uniformity of the miniature heater cable layout on the outside heater. As shown in Fig. 55, the cables were not spaced as tightly as on the inside heater. There are significant areas at either end of the copper plate where the heater cables are looped and do not provide uniform coverage, particularly along the centerline where the thermocouples are located. The significant variation from a uniform cable density, along with other conduction effects to the SS housing, would be expected to affect the actual heat flux at the wall measurement locations.

The 1-D analysis described previously in this section is limited since it does not account for these and other 3-D conduction effects. To obtain an improved estimate of the local heat flux at the measurement locations, the test section was modeled and analyzed using the CFD code, CFX. The results are shown in Fig. 62, where the $\mathrm{X}$-axis is the location along the flow path in degrees from centerline (as shown previously in Fig. 53). The model includes an estimation of the as-fabricated heater cable distribution for the outside heater. The upper plot shows the heat flux at the copper plate/SS wall (assumed thermocouple location) and the predicted heat flux at the SS wall/Hg interface for both the inside and outside heaters. The values shown are along the channel's span-wise centerline. The lower plot shows model-predicted temperature distributions along the flow path. The effect of the applied non-uniform heat flux on the outside heater wall temperature is apparent. Measured temperatures on the outside heater show this decrease in temperature on the downstream side of the 0 degree point, which appeared inconsistent with expected results when the tests were being conducted. 

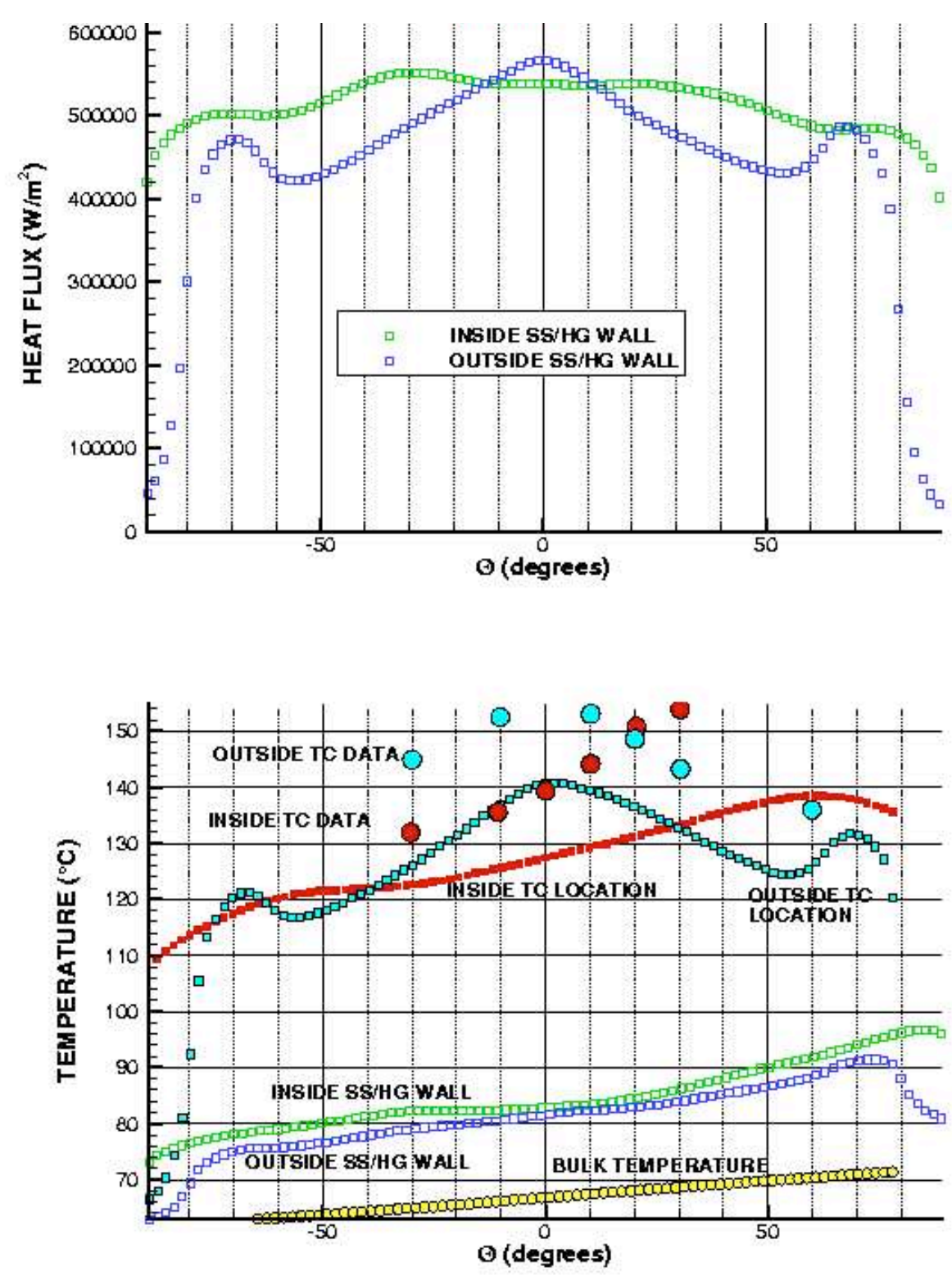

Fig. 62. Results of CFD analysis of curved test section (centerline velocity of $3.5 \mathrm{~m} / \mathrm{s}$, inlet temperature of $62^{\circ} \mathrm{C}$, inside heater power of $2860 \mathrm{~W}$, and outside heater power of $2910 \mathrm{~W}$ ).

The heat flux distribution from the CFD model is used to adjust the heat flux imposed in the 1-D analysis. These correction factors are applied to all of the data presented here in an attempt to account for the conduction effects and the as-built characteristics of the test section.

Tests were conducted on four separate days, as mentioned previously. The actual exposure time of the test section to flowing mercury was relatively short, with approximate run times of 5, 9, 4, and 4 hours. Each of the first three runs was terminated by failure of one of the heaters. As a standard practice, test cases under nominally the same conditions were repeated from day to day. Definite changes in measured temperatures and inferred heat transfer coefficients were observed as the testing sequence progressed. Figure 63 shows calculated $N u$ numbers as a function of the flow path position for the inside wall. A definite trend with position can be seen. In addition, the $N u$ number shows a consistent decrease over the three days represented here. The data taken at 14:47 $\mathrm{h}$ on September 25 are an exception to this trend. This data set was taken after a series of data points for which only one heater was powered at a time, so in 
effect, the heaters experienced another shutdown cycle. Figure 64 shows a similar comparison for the outside wall. With the exception of the location at 60 degrees on the downstream side, the dependence on position is noticeably less than that for the inside wall. The effect with time as the test sequence progressed is still evident, however, although the data at 14:47 h on September 25 do not show a distinct change following the shutdown cycle as they did for the inside heater. These changes over relatively short times seem to indicate that a physical change in the test section may be occurring, perhaps an interface at a braze opening up or flux being driven out of an incomplete braze joint as the heaters are operated and cycled. The data shown in these figures were taken at a centerline velocity of $3.5 \mathrm{~m} / \mathrm{s}$, an inlet temperature of 60 to $65^{\circ} \mathrm{C}$, an outside interface heat flux at $580 \mathrm{~W} / \mathrm{m}^{2}$, an inside interface heat flux of $550 \mathrm{~W} / \mathrm{m}^{2}$, and an exit test section pressure of $175 \mathrm{kPa}$.

A parametric variation in test section exit pressure was also conducted, and the results are shown in Figs. 65 and 66. The data in these figures were obtained under the same conditions as those described, with the exception of an exit pressure and a centerline velocity of $3 \mathrm{~m} / \mathrm{s}$. All of these data were obtained within 1 hour. Along with a dependence on position, a definite and repeatable effect with pressure is observed. Increasing static pressure in the channel results in increased heat transfer. This trend directly contradicts data obtained with the straight test section that showed no effect on pressure. In view of the effects with run time described above, it is likely that this dependence is also caused by a fabrication problem with the test section. If an interface were opening up, an increase in pressure would tend to close that interface and reduce the thermal resistance.

The post-test sectioning of the test channel did not reveal any large regions where the braze layer was not visually intact, although there are some smaller segments of nonwetting in addition to the regions near the thermocouple locations. The analysis in the following section looks at the potential errors that may result from the known problem regions near the thermocouples.

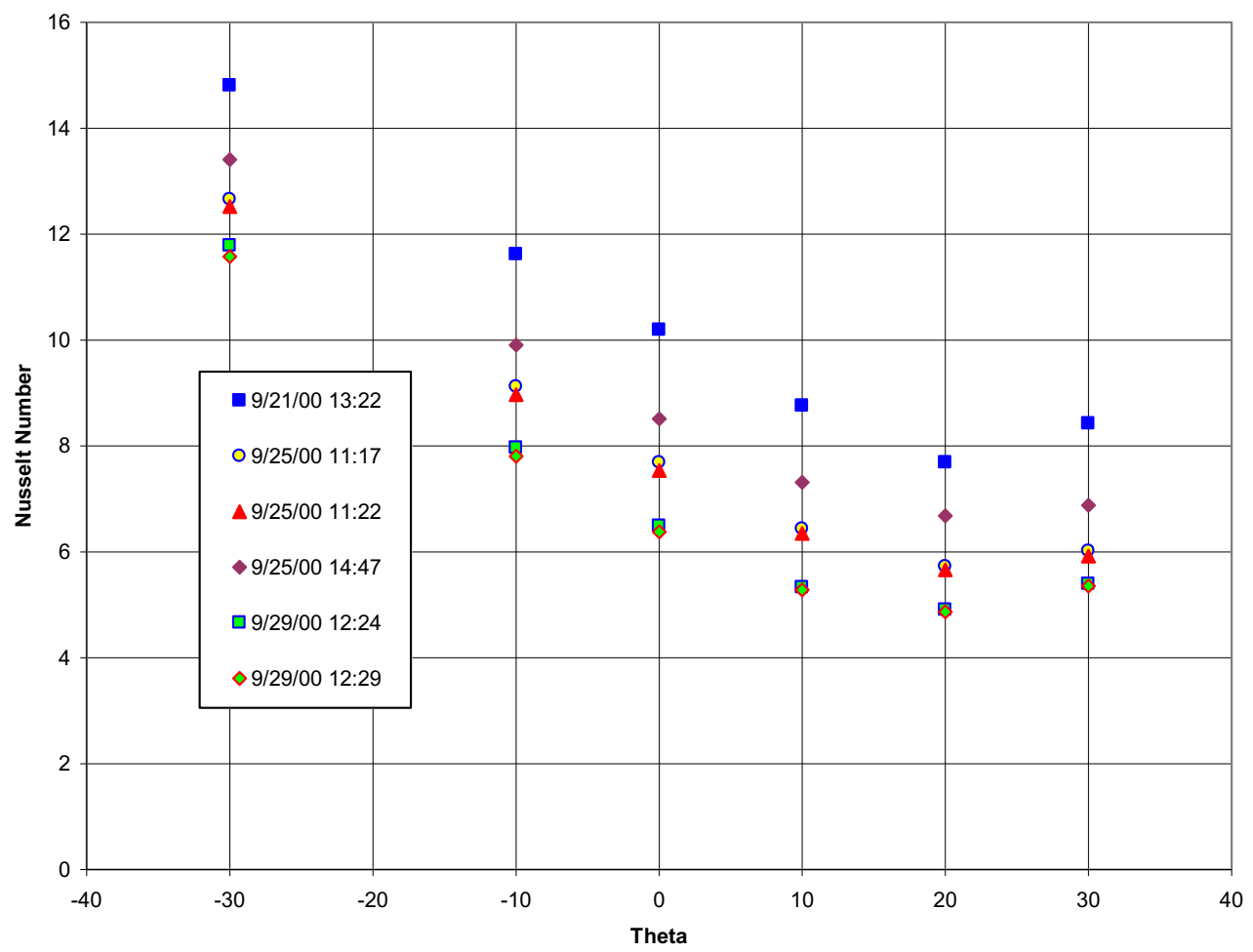

Fig. 63. Effect of time on heat transfer at inside thermocouple locations. 


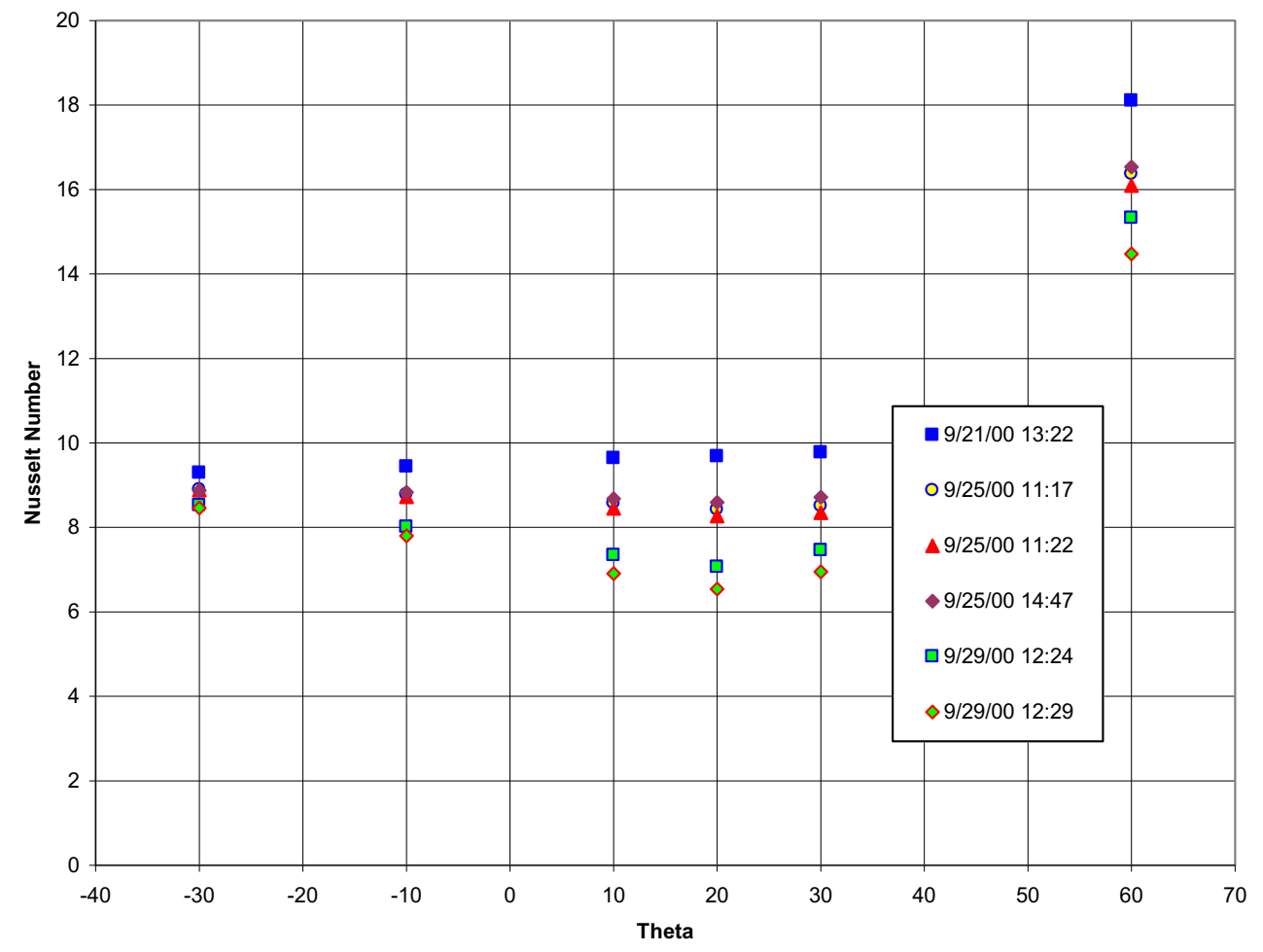

Fig. 64. Effect of time on heat transfer at outside thermocouple locations.

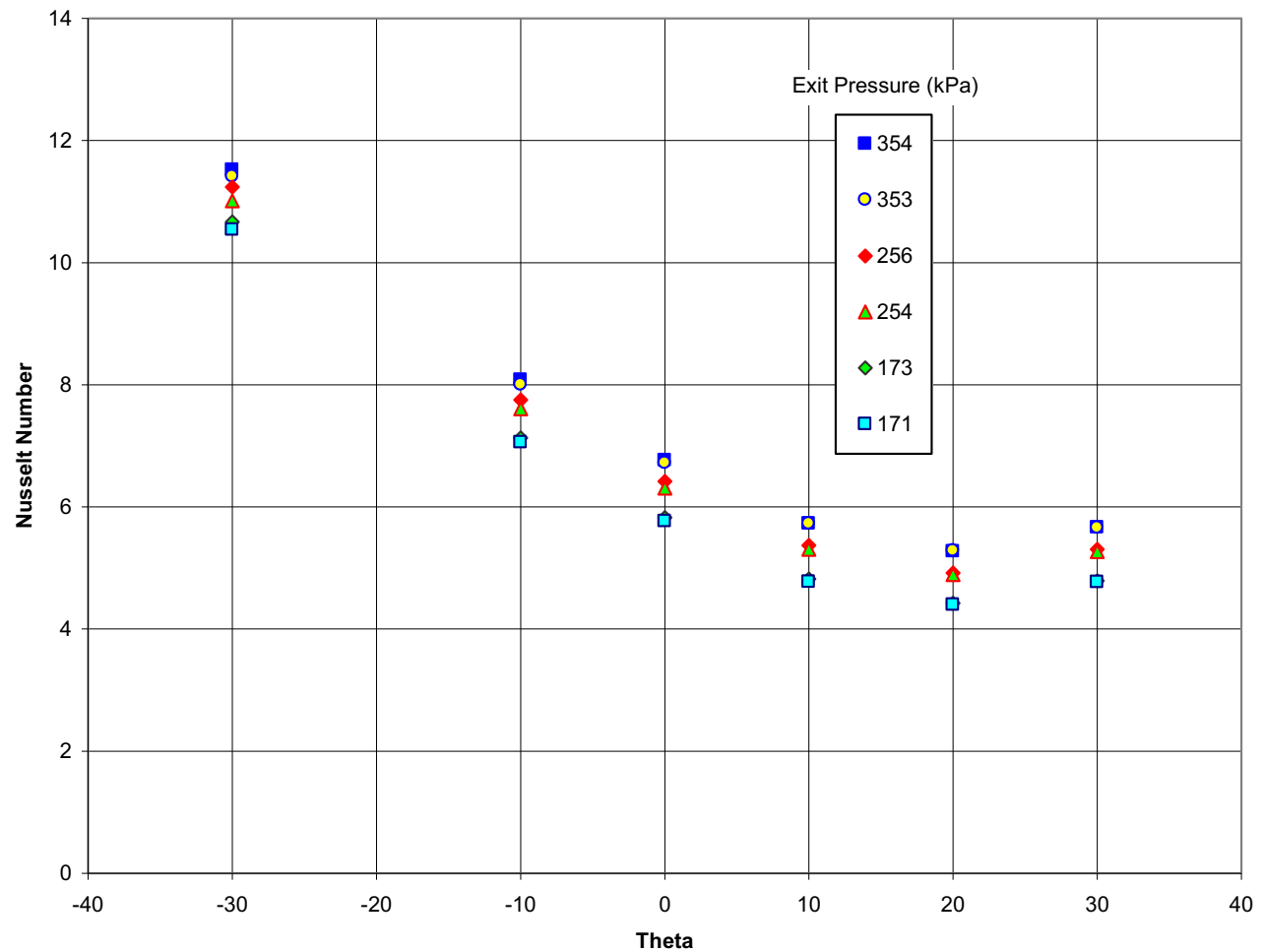

Fig. 65. Effect of exit pressure on inside thermocouple locations. 


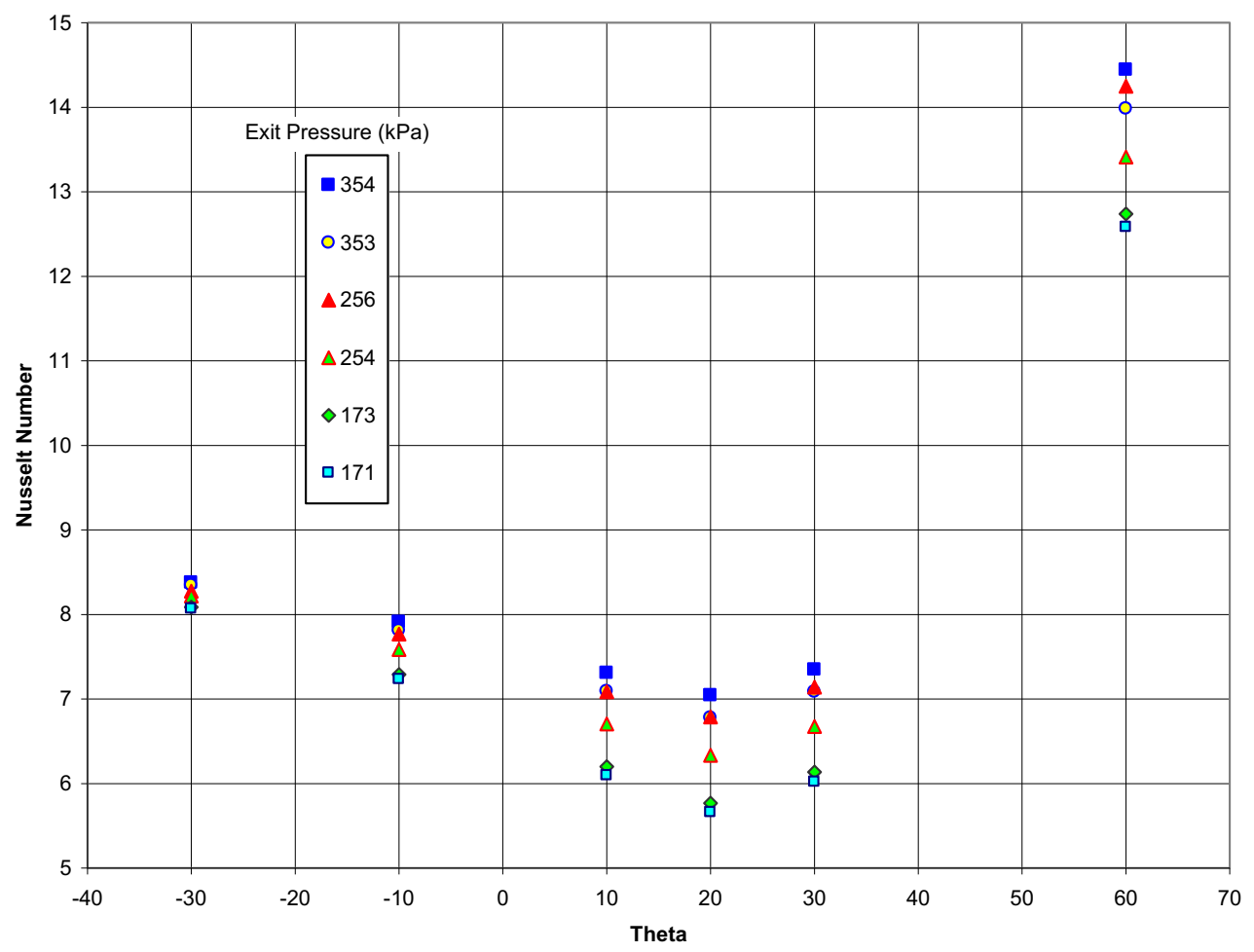

Fig. 66. Effect of exit pressure on outside thermocouple locations.

\subsubsection{Test Section Heat Transfer Performance Analysis}

Detailed conduction calculations were performed to determine the influence of the lack of braze at the thermocouple locations (e.g., see Figs. 59, 60 and 61) on the thermocouple readings. The specific objective of these calculations is to determine the measured temperature error in the thermocouple reading introduced by the defect in the brazing. The figure of merit used in these calculations is the difference in temperatures between the thermocouple reading and the temperature at the same radial location, but at a distance sufficiently far from the thermocouple so that it is undisturbed by the thermocouple. Several parametric calculations are performed to determine the sensitivity of the results on input parameters. These include heat flux (power to the heaters), mercury heat transfer coefficient, braze material thickness, conductivity of the braze material, and model grid size.

HEATING 7.3 models are developed for two thermocouple installation and braze conditions. The first model assumes that the braze material did not completely fill the gap between the thermocouple and the groove machined to locate the thermocouple. The thermocouple located beneath the outside heater at $+10^{\circ}$ from the centerline of the test section is the specific case modeled. A magnified view of the actual test section cross section at this location is shown in Fig. 60. A

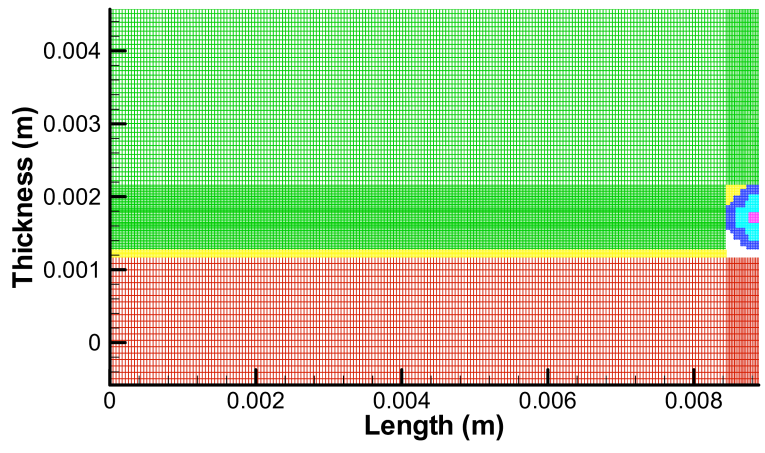

Fig. 67. HEATING 7.3 model of the thermocouple including a gap in the braze material. schematic of the model and the nomenclature used in this analysis is shown in Fig. 47. $T_{b}$ indicates the 
thermocouple bead temperature, while $T_{b \infty}$ is the temperature at the same radial location but at a distance far enough away from the thermocouple location so that it is undisturbed by the thermocouple. $T_{w}$ is the $\mathrm{SS} /$ mercury interface temperature directly beneath the thermocouple, while $T_{w \infty}$ is the SS/mercury interface temperature sufficiently distant from the thermocouple such that it is also undisturbed by the thermocouple. The HEATING model is shown in Fig. 67, where symmetry was assumed around the thermocouple centerline. For this analysis, a Cartesian coordinate system was used, and the curvature of the heater was ignored. Since the material thicknesses in this problem were of the order of $5 \mathrm{~mm}$ and the heater radius of curvature was on the order of $50 \mathrm{~mm}$, this assumption should not alter the conclusions reached from this analysis. This model included a layer of braze material between the copper heater block (green region in Fig. 67) and the SS test section (red region in Fig. 67). In this model, it was assumed that braze material had also filled the upper corners formed by the thermocouple groove and the thermocouple (yellow region in Fig. 67), as indicated in Fig. 60. However, a gap (conductivity assumed to be $1 \times 10^{-5}$ $\mathrm{W} / \mathrm{m}^{\circ} \mathrm{C}$ ) was assumed to exist between the bottom of the thermocouple and the SS test section (white region in Fig. 67). For cases in which the braze thickness between the copper block and the SS was varied parametrically, this gap increased with an increase in the braze material thickness.

Initial calculations are for the specific geometry shown in Fig. 60 and operating conditions that included a heat flux of $841,000 \mathrm{~W} / \mathrm{m}^{2}$, a bulk mercury temperature of $74.4^{\circ} \mathrm{C}$, and a mercury heat transfer coefficient of $52,000 \mathrm{~W} / \mathrm{m}^{2 \circ} \mathrm{C}$.

Calculated temperatures are presented in Fig. 68. The solid black lines indicate the location of the braze layer and the thermocouple groove. The gap region tends to increase the thermocouple bead temperature above that of the surrounding copper. In this case, the bead temperature is approximately $0.7^{\circ} \mathrm{C}$ higher than the copper temperature at the same radial location, but it is far removed from the thermocouple bead. Since the wall-tobulk coolant temperatures in these experiments were on the order of $20^{\circ} \mathrm{C}$, errors due to this type of flaw were expected to be small.

A series of parametric calculations for this geometry were performed to determine the sensitivity of the results to various parameters in the model. These results are presented in Table 10. This table shows that input parameters and braze geometry can be varied over a wide range without significantly affecting the error in temperature measurement. Braze conductivity was determined to be approximately $121 \mathrm{~W} / \mathrm{m}^{\circ} \mathrm{C}$ at room

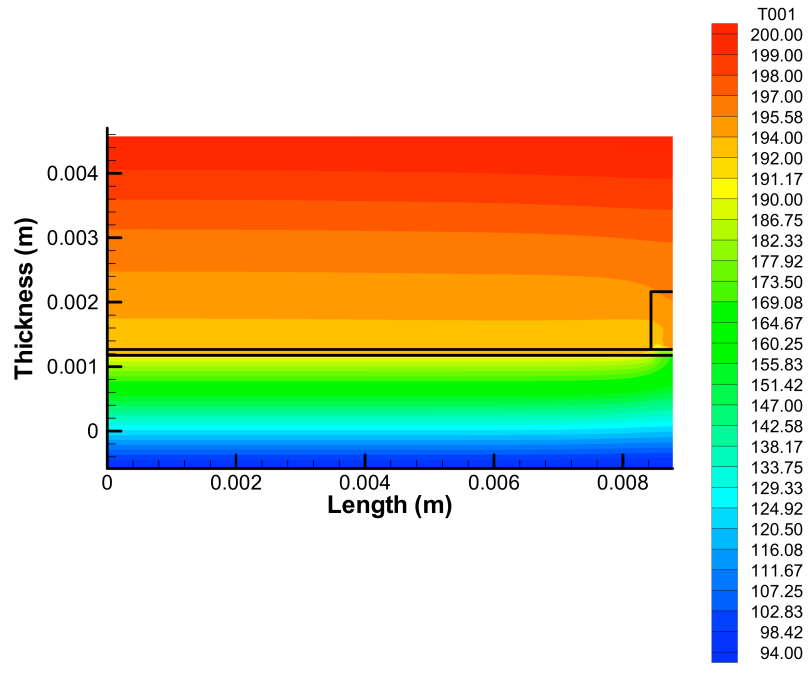

Fig. 68. Temperature profile for case with gap in braze material beneath thermocouple (Case 2 in Table 10; Temperatures in ${ }^{\circ} \mathrm{C}$ ). temperature by calculation using known values of electrical resistivity. The electrical resistivity of Bag 1 braze material was also measured at 150 ${ }^{\circ} \mathrm{C}$, with calculations indicating that the thermal conductivity at this temperature would be approximately $131 \mathrm{~W} / \mathrm{m}^{\circ} \mathrm{C}$. Braze thickness, SS thickness, and thermal conductivity have only a minor impact on the error in the temperature measurement. Similarly, variation in the heat transfer coefficient has little impact, while the temperature difference tends to decrease with decreasing heat flux, as might be expected. 
Table 10. Parametric calculations performed with gap geometry shown in Fig. 69

\begin{tabular}{|c|c|c|c|c|c|c|c|c|c|c|}
\hline $\begin{array}{c}\text { Case } \\
\#\end{array}$ & $\begin{array}{c}\text { Braze } \\
\text { cond. } \\
\left(\mathbf{W} / \mathbf{m}^{\circ} \mathbf{C}\right)\end{array}$ & $\begin{array}{c}\text { SS } \\
\text { thickness } \\
(\mathbf{m m})\end{array}$ & $\begin{array}{c}\text { Braze } \\
\text { thickness } \\
\text { (mm) }\end{array}$ & $\begin{array}{c}\text { Heat } \\
\text { flux } \\
\left(\mathbf{W} / \mathbf{m}^{2}\right)\end{array}$ & $\begin{array}{c}\text { Heat } \\
\text { transfer } \\
\text { coeff. } \\
\left(\mathrm{W} / \mathbf{m}^{2}{ }^{\circ} \mathrm{C}\right)\end{array}$ & $\mathbf{T}_{\mathbf{b}}\left({ }^{\circ} \mathbf{C}\right)$ & $\mathbf{T}_{\mathrm{b} \infty}\left({ }^{\circ} \mathrm{C}\right)$ & $\begin{array}{c}\mathbf{T}_{\mathbf{w}} \\
\left({ }^{\circ} \mathbf{C}\right)\end{array}$ & $\begin{array}{l}\mathbf{T}_{\mathbf{w} \infty} \\
\left({ }^{\circ} \mathbf{C}\right)\end{array}$ & $\begin{array}{c}\mathbf{T}_{\mathbf{b}}-\mathbf{T}_{\mathbf{b} \infty} \\
\left({ }^{\circ} \mathbf{C}\right)\end{array}$ \\
\hline 1 & 254.44 & 1.755 & 0.097 & 841,000 & 52,000 & 194.56 & 193.89 & 89.79 & 90.73 & 0.67 \\
\hline 2 & 121 & 1.755 & & & & 194.95 & 194.3 & 89.75 & 90.73 & 0.65 \\
\hline 3 & & 1.349 & & & & 171.6 & 170.9 & 89.25 & 90.76 & 0.7 \\
\hline 4 & & & .450 & & & 174.32 & 173.5 & 89.15 & 90.78 & 0.82 \\
\hline 5 & & & & 500,000 & & 133.82 & 133.33 & 83.18 & 84.15 & 0.49 \\
\hline 6 & & & & 300,000 & & 110.06 & 109.77 & 79.68 & 80.26 & 0.29 \\
\hline 7 & & & & 841,000 & 30,000 & 186.18 & 185.39 & 100.35 & 102.77 & 0.79 \\
\hline 8 & & & & & 20,000 & 200.19 & 199.43 & 113.88 & 116.89 & 0.76 \\
\hline
\end{tabular}

A second thermocouple/heater geometry was also noted in the post-test examination of the test section. This geometry is seen in Fig. 61. The thermocouples were installed in the grooves, and the groove was then peened to hold the thermocouple in place during the assembly and brazing process. In some cases, as shown in Fig. 61, the region that was peened was not wet by the braze material, so an additional gap was formed between the copper heater block and the SS test section wall. This region is sometimes significantly larger than the unbrazed region beneath the thermocouple. It was therefore decided to model this geometry as well to determine a limiting thermocouple error due to the braze not wetting some portions of the heater/SS interface. The geometry used in the model was taken directly from Fig. 61. Because this problem is nonsymmetric, a full model of the geometry is necessary, as shown in Fig. 69. To decrease the effect of the edges of the model, the lateral extent of the model is approximately 10 times the thermocouple diameter. Since temperature profiles near the lateral edges of the model are flat, it was determined that the length of the model is sufficient for this analysis. This is also a Cartesian model, and the curvature is ignored using the same logic as discussed above. Colors in this figure indicate the same material as those discussed above.

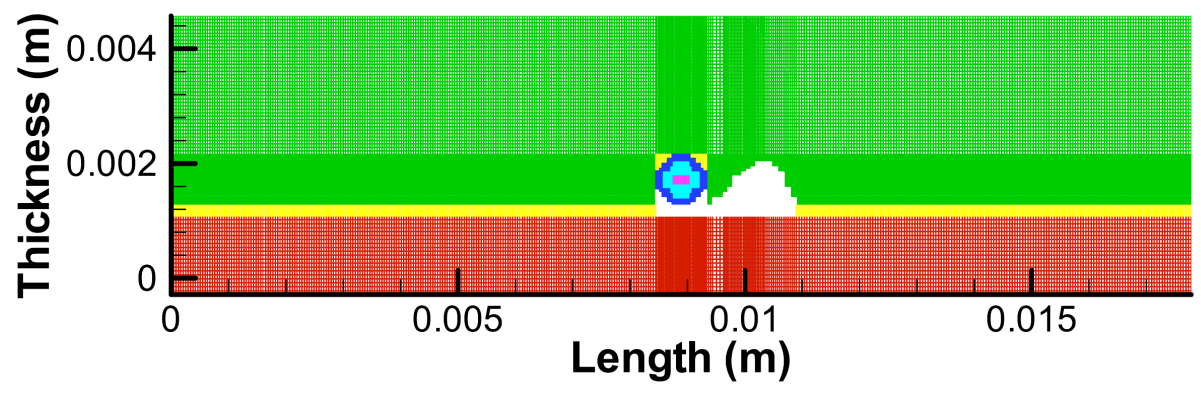

Fig. 69. HEATING 7.3 model of peened thermocouple groove.

Typical temperature contours are shown in Fig. 70. As expected, the affected area was significantly larger than that of the previous case. In this case, bead temperatures were approximately $3.5^{\circ} \mathrm{C}$ higher than temperatures at the same radial (or thickness) location but were far removed from the thermocouple. Thus, a significantly higher error in experimental heat transfer coefficient determination was introduced for thermocouples where this geometry existed. 


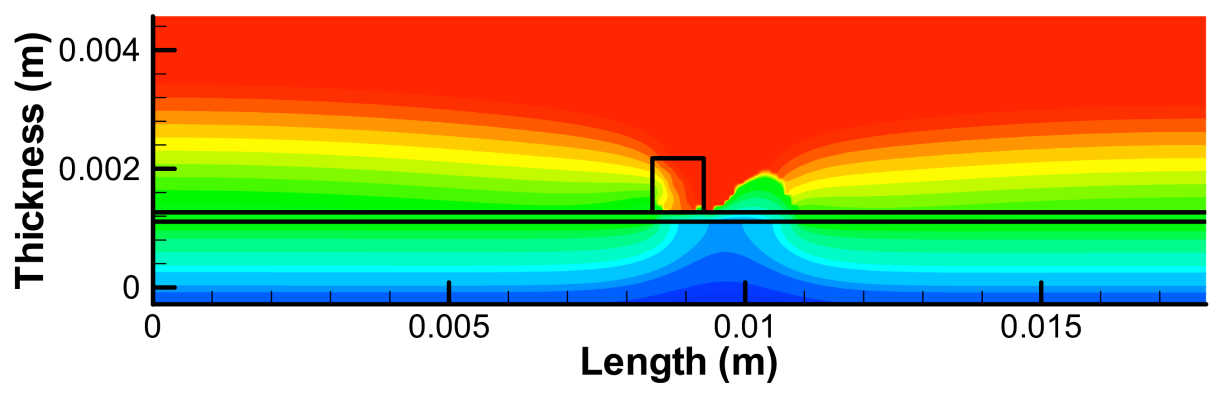

Fig. 70. Temperature profile for case with peened thermocouple groove (Case 1 in Table 2, temperatures in ${ }^{\circ} \mathrm{C}$ ).

Table 11 shows results of a series of parametric calculations conducted with this geometry. In general, geometric factors (SS and braze thickness) had only a secondary effect on the temperature difference, as did the heat transfer coefficient. Decreasing the heat flux tended to decrease the temperature difference. In Case 9, it was assumed that the peened region was filled with braze material. The conditions for this case were similar to those for Case 4 in Table 10, where the bead temperature difference was determined to be $0.82{ }^{\circ} \mathrm{C}$. In Case 9 of Table 11 , the temperature difference was determined to be $0.8{ }^{\circ} \mathrm{C}$, indicating that the peen itself did not have a significant influence on the measurement. It is only when the peened region did not wet that significant temperature measurement errors were introduced. A brief grid study was also performed, indicating that the grid used in the calculations should have been sufficient to characterize the thermocouple error.

Table 11. Parametric calculations performed with peened geometry shown in Fig. 71

\begin{tabular}{|c|c|c|c|c|c|c|c|c|c|c|}
\hline $\begin{array}{c}\text { Case } \\
\#\end{array}$ & $\begin{array}{c}\text { Braze } \\
\text { cond. } \\
\left(\mathbf{W} / \mathbf{m}^{\circ} \mathbf{C}\right)\end{array}$ & $\begin{array}{c}\text { SS } \\
\text { thickness } \\
(\mathrm{mm})\end{array}$ & $\begin{array}{c}\text { Braze } \\
\text { thickness } \\
(\mathrm{mm})\end{array}$ & $\begin{array}{c}\text { Heat } \\
\text { flux } \\
\left(\mathbf{W} / \mathbf{m}^{2}\right)\end{array}$ & $\begin{array}{c}\text { Heat } \\
\text { transfer } \\
\text { coeff } \\
\left(\mathrm{W} / \mathbf{m}^{2}\right. \\
\left.{ }^{\circ} \mathrm{C}\right)\end{array}$ & $\mathbf{T}_{\mathrm{b}}\left({ }^{\circ} \mathrm{C}\right)$ & $\begin{array}{l}\mathbf{T}_{\mathrm{b} \infty} \\
\left({ }^{\circ} \mathrm{C}\right)\end{array}$ & $\begin{array}{l}\mathbf{T}_{\mathrm{w}} \\
\left({ }^{\circ} \mathbf{C}\right)\end{array}$ & $\begin{array}{l}\mathbf{T}_{w_{\infty}} \\
\left({ }^{\circ} \mathbf{C}\right)\end{array}$ & $\begin{array}{l}\left(T_{b}-\right. \\
\left.T_{b \infty}\right) \\
\left({ }^{\circ} \mathbf{C}\right)\end{array}$ \\
\hline 1 & 121 & 1.372 & 0.183 & 841,000 & 20,000 & 207.8 & 204.64 & 106.5 & 118.86 & 3.16 \\
\hline 2 & & & & & 30,000 & 193.64 & 190.37 & 94.99 & 104.19 & 3.27 \\
\hline 3 & & & & & 52,000 & 181.63 & 178.25 & 85.78 & 91.68 & 3.38 \\
\hline 4 & & & & 500,000 & & 138.16 & 136.15 & 81.18 & 84.68 & 2.01 \\
\hline 5 & & & & 300,000 & & 112.67 & 111.46 & 78.48 & 80.58 & 1.21 \\
\hline 6 & & 1.755 & 0.097 & 841,000 & & 203.1 & 199.97 & 86.96 & 91.52 & 3.13 \\
\hline 7 & & 1.349 & & & & 179.52 & 176.17 & 85.74 & 91.67 & 3.35 \\
\hline 8 & & & 0.450 & & & 182.61 & 179.11 & 85.61 & 91.72 & 3.5 \\
\hline 9 & $\begin{array}{l}\text { Peen filled } \\
\text { with braze }\end{array}$ & & & & & 174.49 & 173.69 & 89.1 & 90.82 & 0.8 \\
\hline
\end{tabular}

In general, thermocouple reading errors should be relatively small for the geometry with a gap located beneath the thermocouple and between the thermocouple and SS wall; on the order of $0.8^{\circ} \mathrm{C}$ for heat flux levels of about $840,000 \mathrm{~W} / \mathrm{m}^{2}$. Errors were larger, on the order of $3.5^{\circ} \mathrm{C}$ for the geometry that included a depression due to peening the thermocouple in place. Both errors decreased as the applied power to the heaters decreased. 
With the somewhat extensive analytical estimations required to reduce the data, the results from the curved test section should be viewed only in a qualitative sense. The degrading heat transfer coefficients over relatively short operational times indicate a significant problem most likely related to fabrication. If the initial values are assumed to be the best case, then the $N u$ numbers for the curved test section are still lower than the straight test section results. Adjustment to account for the error due to lack of a complete braze joint from the above analysis is not included in these results, but it would increase the calculated $\mathrm{Nu}$ number. Most of these fabrication-related problems could likely be corrected with another iteration of the fabrication process. The uncertainties and variability of the data due to various problems with this test section prevent any clear separation of effects potentially caused by the curved flow geometry. 


\section{UNCERTAINTY ANALYSIS}

Uncertainty for MTHL experiments was obtained by using the definition of the total derivative. The friction factor and heat transfer coefficient can be expressed as functions of the primary variables obtained directly from the experiment. For example, instead of using power in the equation for the heat transfer coefficient, voltage was multiplied by current. The voltage and current were obtained directly from the instrumentation and were not calculated, so they were used independently. If the quantity $A$ was expressed as a function of the independent variables $C$ and $D$, then, $\sigma A$ could be expressed via the total derivative as

$$
\sigma A=\left(\frac{\partial A}{\partial C}\right) \sigma C+\left(\frac{\partial A}{\partial D}\right) \sigma D .
$$

The derivatives were found numerically. For calculating of and $\sigma h$, a small perturbation was inserted into each of the primary variables. The derivatives were then calculated by dividing the change in $f$ or $h$ resulting from the perturbation by the perturbation. The perturbation of $C$ is the uncertainty associated with $C$, so the term $\left(\frac{\partial A}{\partial C}\right) \sigma C$ is the change in $A$. The uncertainty associated with the friction factor or heat transfer coefficient is the sum of the changes in $f$ or $h$ when the value of each of the primary variables is perturbed by its uncertainty. Since the true value of the primary variable may be the recorded value from the experiment plus or minus its uncertainty, the signs of the perturbations were chosen so that all the contributions to the uncertainty in $h$ or $f$ were positive. This approach used existing software to evaluate the friction factor and heat transfer coefficient.

To establish the uncertainty in individual contributions to the calculation of the friction factor and heat transfer coefficient, several sources were used, including calibration data, geometric tolerances on test section design drawings, calculations to determine how the 1-D analysis was affected by the 3-D geometry, and a comparison of thermophysical data for mercury. Fig(s). 71 through 73 show the thermophysical data comparison. ${ }^{11-15}$

A total of fourteen variables affected the calculation of the friction factor, and representative values are shown in Table 12. A 20\% uncertainty was assumed for the form factors and friction factor correlation used in the entrance and exit regions due to a lack of information. As shown in Table 12, this assumption did not change the friction factor significantly. The prime contributors to friction factor uncertainty were the flow rate and the small channel gap dimension. This sensitivity analysis was performed for four cases, and the results are shown with all the data in Fig. 74. The uncertainty values used approximately two standard deviations. 


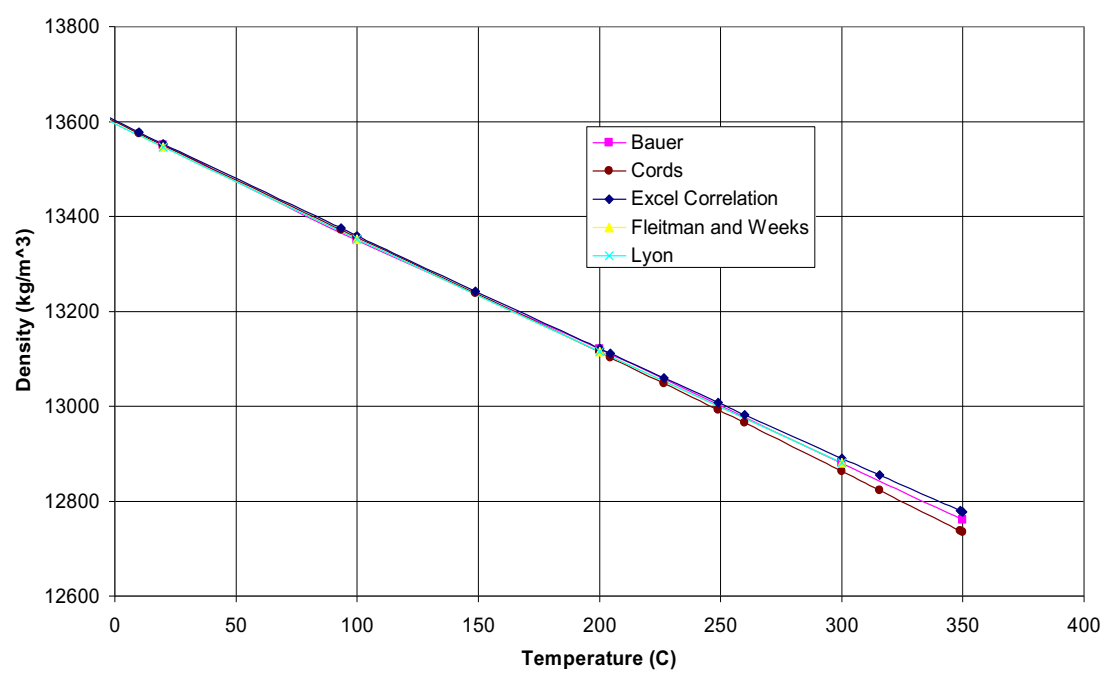

Fig. 71. Mercury density vs temperature.

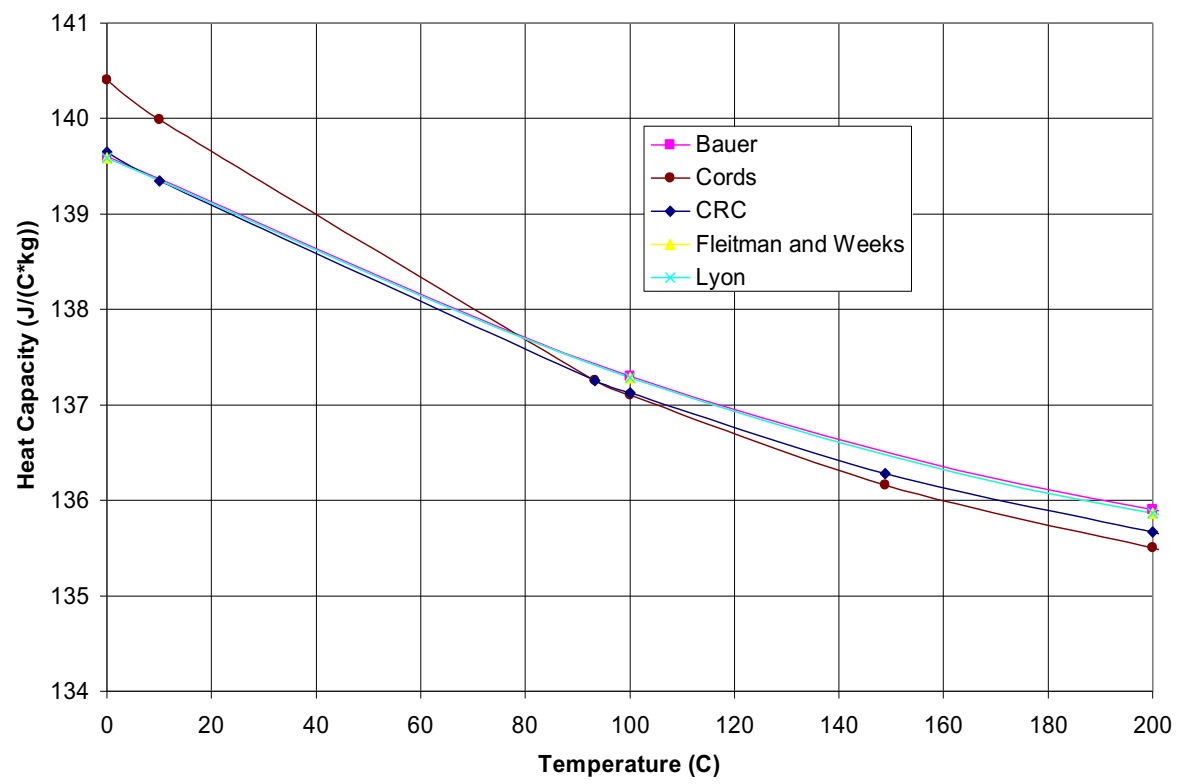

Fig. 72. Mercury heat capacity vs temperature. 


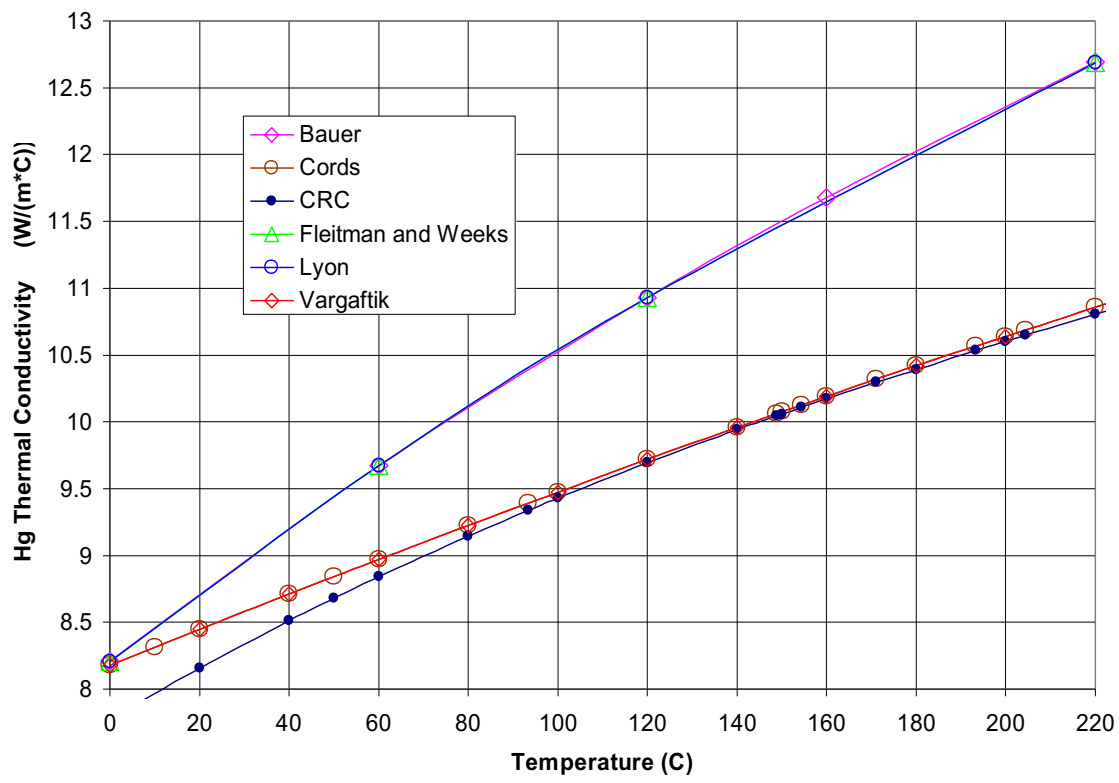

Fig. 73. Mercury thermal conductivity vs temperature.

Seventeen factors contributed to the uncertainty in the calculation of the heat transfer coefficient, and representative values are shown in Table 13. The terms labeled North Current and South Current refer to the current applied to the two sides of the test section. This representative case was for a heat transfer calculation on the south side. For this case, the south current affected the heat flux and bulk temperature, while the north current affected only the bulk temperature. This effect was seen in the uncertainty values in Table 13.

Table 12. Friction factor uncertainty

\begin{tabular}{lcccc}
\hline \multicolumn{1}{c}{ Friction variables } & Nominal value & Units & Uncertainty & $\begin{array}{c}\text { Change in } \\
\text { friction factor }\end{array}$ \\
\hline Mercury density & 13,435 & $\left(\mathrm{~kg} / \mathrm{m}^{\wedge} 3\right)$ & $0.11 \%$ & $0.12 \%$ \\
2mm gap flow length & 425.4 & $(\mathrm{~mm})$ & $0.06 \%$ & $0.06 \%$ \\
Differential pressure & 165.9 & $(\mathrm{kPa})$ & $0.60 \%$ & $0.67 \%$ \\
Length pressure tap to bend & 11.12 & $(\mathrm{~mm})$ & $9.00 \%$ & $0.01 \%$ \\
Length from bend to contraction & 32.33 & $(\mathrm{~mm})$ & $3.09 \%$ & $0.01 \%$ \\
Flow rate & 0.280 & $(\mathrm{~L} / \mathrm{s})$ & $2.50 \%$ & $5.35 \%$ \\
Small channel gap & 2.00 & $(\mathrm{~mm})$ & $1.27 \%$ & $4.09 \%$ \\
Large channel gap & 8.35 & $(\mathrm{~mm})$ & $1.52 \%$ & $0.00 \%$ \\
Channel width & 40.00 & $(\mathrm{~mm})$ & $0.32 \%$ & $0.72 \%$ \\
Cf contraction & 0.04513 & $(\#)$ & $20.00 \%$ & $0.50 \%$ \\
Cf expansion & 0.13551 & $(\#)$ & $20.00 \%$ & $1.50 \%$ \\
Cf bend & 8.00 & $(\#)$ & $20.00 \%$ & $0.18 \%$ \\
Correlation friction factor & 0.01739 & $(\#)$ & $20.00 \%$ & $0.25 \%$ \\
Mercury viscosity & 0.001333 & $(\mathrm{~kg} /[\mathrm{m}) \mathrm{s}])$ & $2.81 \%$ & $0.01 \%$ \\
\hline
\end{tabular}

The most significant contributors to the uncertainty in the calculation of the heat transfer coefficient, in order of importance, were the thermocouple measurement, heat flux reduction due to 3-D aspects, SS wall thickness, and SS thermal conductivity. Each of these changed the heat transfer coefficient by at least 3\% and also caused the same error contribution for all data presented herein. For this case study, the heat 
transfer coefficient is $38,483 \pm 17,604 \mathrm{~W} / \mathrm{m}^{2}{ }^{\circ} \mathrm{C}$. This analysis is also repeated for two other case studies, and three representative error bars are shown with all the data in Fig. 75. The uncertainty values used approximate two standard deviations.

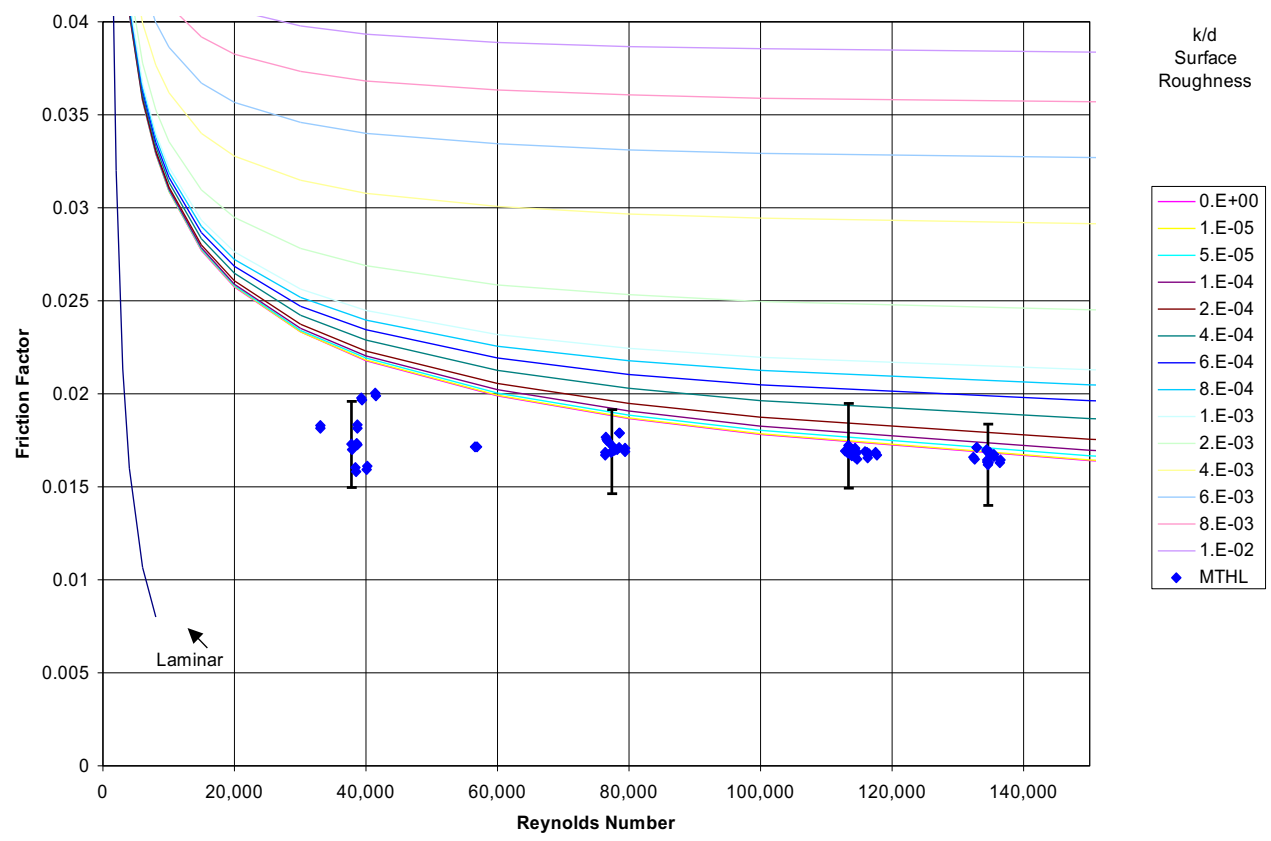

Fig. 74. Friction factor data with error bars.

Table 13. Heat transfer uncertainty

\begin{tabular}{lcccc}
\hline \multicolumn{1}{c}{ Heat transfer variables } & Nominal value & Units & Uncertainty & $\begin{array}{c}\text { Change in } \\
\text { heat transfer } \\
\text { coefficient }\end{array}$ \\
\hline Volts & 158.82 & $(\mathrm{Volts})$ & $0.10 \%$ & $0.49 \%$ \\
South current & 38.27 & $(\mathrm{Amps})$ & $0.20 \%$ & $0.93 \%$ \\
North current & 38.01 & $(\mathrm{Amps})$ & $0.10 \%$ & $0.03 \%$ \\
Inlet temperature & 62.78 & $\left({ }^{\circ} \mathrm{C}\right)$ & $0.40 \%$ & $1.24 \%$ \\
Flow rate & 0.28 & $(\mathrm{~L} / \mathrm{s})$ & $2.50 \%$ & $1.36 \%$ \\
Wall thickness & 0.00127 & $(\mathrm{~m})$ & $2.00 \%$ & $7.15 \%$ \\
Width of heat transfer & 36.00 & $(\mathrm{~mm})$ & $0.35 \%$ & $1.51 \%$ \\
Length of heat transfer & 200.00 & $(\mathrm{~mm})$ & $0.06 \%$ & $0.31 \%$ \\
Channel width & 40.00 & $(\mathrm{~mm})$ & $0.32 \%$ & $0.00 \%$ \\
Small gap & 2.00 & $(\mathrm{~mm})$ & $1.27 \%$ & $0.00 \%$ \\
Hg density & 13,420 & $\left(\mathrm{~kg} / \mathrm{m}^{\wedge} 3\right)$ & $0.11 \%$ & $0.06 \%$ \\
Hg Cp & 137.66 & $\left(\mathrm{j} / \mathrm{kg}^{\circ} \mathrm{C}\right)$ & $0.22 \%$ & $0.12 \%$ \\
Hg thermal conductivity & 9.07 & $\mathrm{~W} /\left(\mathrm{m}^{\circ} \mathrm{C}\right)$ & $17.10 \%$ & $0.00 \%$ \\
SS thermal conductivity & 15.20 & $\mathrm{~W} /\left(\mathrm{m}^{\circ} \mathrm{C}\right)$ & $1.04 \%$ & $3.19 \%$ \\
Distance to thermocouple & 100.00 & $(\mathrm{~mm})$ & $1.00 \%$ & $0.57 \%$ \\
Thermocouple & 161.36 & $\left({ }^{\circ} \mathrm{C}\right)$ & $2.29 \%$ & $16.14 \%$ \\
Heat flux multiple & 0.94 & $(\#)$ & $2.66 \%$ & $12.66 \%$ \\
\hline
\end{tabular}




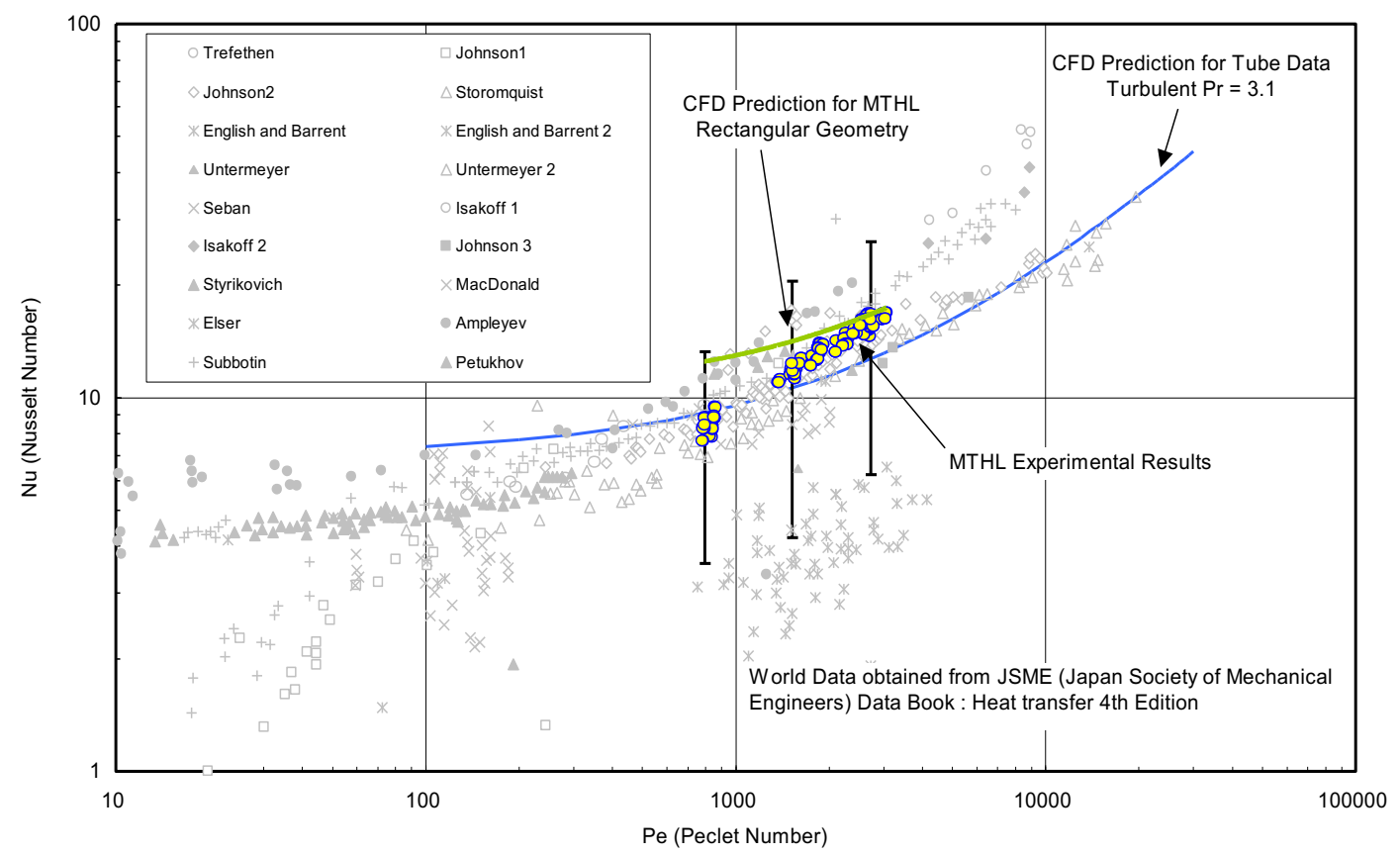

Fig. 75. $N u$ number vs $P e$ number showing all data with error bars. 



\section{CONCLUSIONS}

This report presents an analysis of pressure drop results from the water-cooled test section and electrically heated (straight) test section. Results for the friction factor show that at higher flow rates, including the SNS design velocity, good agreement is obtained between the experimental results and the Moody Curve. At the lower flows, the experimental results are lower than those predicted by the Moody Curve, with the greatest deviation occurring at the lowest flow rates. Results from later tests in the sequence show improved agreement with the Moody curve at the low flow rates, although the reasons for this improvement have not been identified. Pressure drop data were obtained with the test section surface continuously exposed to mercury from less than an hour to over 450 hours. No effect of time on friction factor values is discerned.

A large number of tests to observe the wettability of the SS surface were conducted using TLCs in the water-cooled test section. Despite the need to apply multiple layers of low conductivity material, the resolution of the crystals was sufficient to detect nonwettable regions on the order of $2.5 \mathrm{~mm}$ in diameter. Nonwettable regions were not observed in any of the tests. The test section geometry produced steep temperature gradients between the water and mercury channels that resulted in relatively large experimental uncertainties, especially where multiple coating layers were present. Although attempts were made, calculation of reliable heat transfer coefficients is difficult because of these uncertainties and is left primarily to tests conducted with the electrically heated test section design.

The electrically heated (straight) test section provided an improved design for calculation of heat transfer coefficients. Along with having heat flow in the same direction as the SNS window cooling channel, the test section provided simpler bounding conditions for analysis. Evaluation of test data was conducted using analytical methods, CFD modeling, and HEATING 7 models. The results expressed using appropriate nondimensional parameters are consistent with world tube data for liquid metals with good wetting. There is some scatter in the experimental data at different thermocouple locations, but all thermocouple locations show a similar slope on the plot. This scatter may have been due to deficiencies in the installation and brazing of the thermocouples. When CFD predictions of heat transfer in the same rectangular channel are compared to the data, the predictions are a bit higher, especially at low flow rates. However, data at the current SNS design velocity of $3.2 \mathrm{~m} / \mathrm{s}$ do agree well with the CFD predictions. Finally, a parametric study of the data showed that the heat transfer coefficient was independent of variations in bulk temperature, pressure, and heat flux.

An electrically heated curved test section was fabricated which simulated the semi-circular converging/diverging flow channel geometry of the SNS target window cooling channel. Tests were conducted to investigate the effects of this geometry on the heat transfer characteristics under prototypic SNS conditions. From a quantitative standpoint, results were largely inconclusive due to apparent fabrication-related problems with the test section. Calculated heat transfer coefficients taken early in the sequence show results lower than those measured with the electrically heated (straight) test section. A consistent degradation in measured heat transfer coefficients was observed over a relatively short time (hours) and appeared to be related to shutdown cycles, as well. A repeatable variation with static pressure was also measured. The design incorporated a copper heater plate brazed to the SS flow channel wall with thermocouples incorporated at this interface. Post-test sectioning indicated areas of nonwetting of the braze, particularly at thermocouple locations. The results showing a time and pressure dependence on heat transfer may have been an effect of deficiencies in the test section fabrication rather than a product of the curved flow geometry. The uncertainties and variability of the data due to these problems effectively prevent any clear separation of effects potentially caused by the curved flow geometry. 



\section{REFERENCES}

1. Jallouk, P. A., and Crye, J. M., MTHL Test Section \#1 Report, Spallation Neutron Source TSR-180, January 2000.

2. Jallouk, P. A., et al. MTHL Water-Cooled Test Section Report, Spallation Neutron Source TSR-196, June 2000.

3. Crye, J. M., et al. MTHL Electrically-Heated (Straight) Test Section Report, Spallation Neutron Source TSR-200, August 31, 2000.

4. Crabtree, J. Allen, "Use of Image Processing Techniques for Heat Transfer Measurements Using Thermochromic Liquid Crystals", HTD-Vol. 279, Optimal Design of Thermal Systems and Components, Book No. H00910-1994, pp. 27-33, 1994.

5. Allison, S. W., and Giles, G. T., "Remote Thermometry with Thermographic Phosphors: Instrumentation and Applications," Review of Scientific Instruments, Vol. 68(7) pp. 2615-2650, July 1997.

6. Crane Engineering Department, Flow of Fluids Through Valves, Fittings and Pipe: Technical Paper No. 410, King of Prussia: Crane Co., pp. 2-11, A-26, A-29, 1988.

7. Holman, J. P., Heat Transfer: Eighth Edition, New York: McGraw-Hill, Inc., p. 289, 1997.

8. Lide, D. and Kehiaian, Henry, CRC Handbook of Thermophysical and Thermochemical Data, Boca Raton: CRC Press, pp. 93, 94, 405, 409, 413, 417, 1994.

9. Siman-Tov, M., et al., "Thermal-Hydraulics of the Liquid Mercury Target for the Spallation Neutron Source (SNS)," Proc. $2^{\text {nd }}$ Int. Topical Meeting on Nuclear Applications of Accelerator Technology (AccApp' 98), Gatlinburg, Tennessee, September 20-23, 1998.

10. Lyon, R. N., "Forced Convection Heat Transfer Theory and Experiments with Liquid Metals," ORNL-361, August, 1949.

11. Japan Society of Mechanical Engineers Data Book. Heat Transfer $4^{\text {th }}$ Edition, 1986. 